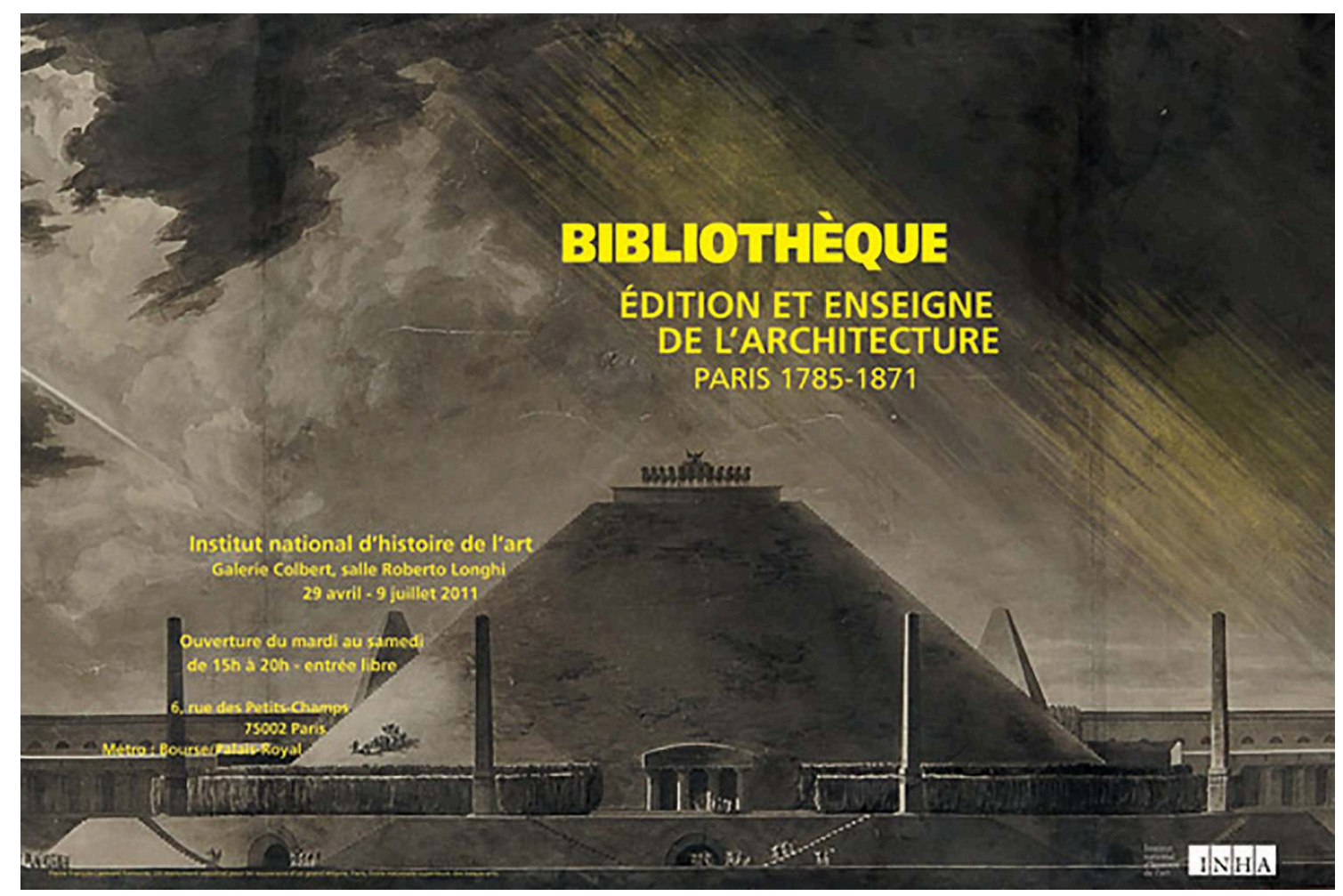




\section{Bibliothèques d'atelier}

Édition et enseignement de l'architecture, Paris 1785-1871

Jean-Philippe Garric (dir.)

DOI : 10.4000/books.inha. 3183

Éditeur : Publications de l'Institut national d'histoire de l'art

Lieu d'édition : Paris

Année d'édition : 2011

Date de mise en ligne : 5 décembre 2017

Collection : Catalogues d'exposition

ISBN électronique : 9782917902783

\section{Qboooks}

http://books.openedition.org

\section{Édition imprimée}

Date de publication : 28 avril 2011

ISBN : 9782917902097

Nombre de pages : 80

\section{Référence électronique}

GARRIC, Jean-Philippe (dir.). Bibliothèques d'atelier : Édition et enseignement de l'architecture, Paris 1785-1871. Nouvelle édition [en ligne]. Paris : Publications de l'Institut national d'histoire de l'art, 2011 (généré le 18 décembre 2020). Disponible sur Internet : <http://books.openedition.org/inha/3183> ISBN : 9782917902783. DOI : https://doi.org/10.4000/books.inha.3183.

Ce document a été généré automatiquement le 18 décembre 2020.

(C) Publications de l'Institut national d'histoire de l'art, 2011

Conditions d'utilisation :

http://www.openedition.org/6540 
À la fin du XVIII ${ }^{\mathrm{e}}$ et au début du XIX ${ }^{\mathrm{e}}$ siècle, si l'architecture était considérée comme un art d'imitation, sa vocation essentielle était de reproduire les édifices du passé, et notamment ceux de l'Antiquité gréco-romaine. Outre ce caractère autoréférentiel, elle était soumise à des difficultés matérielles d'exécution ou à des réalités financières qui faisaient que ses inventions les plus brillantes en restaient souvent au stade du projet. Ce qui explique l'intérêt et l'importance que cette discipline a toujours accordés aux livres. Libérés des contraintes économiques et des lois de la gravité, les ateliers où les élèves s'exerçaient en vue de prendre part aux concours académiques étaient les laboratoires de l'architecte de demain. Mais les modèles qu'on y étudiait attentivement, pour les reproduire dans des œuvres nouvelles, n'étaient pas des modèles vivants, plutôt des schémas reproduisant les travaux des aînés. Ces gravures formaient les recueils conservés dans les bibliothèques d'atelier. Parmi les pièces uniques appartenant aux collections de la bibliothèque Jacques Doucet, se trouvent deux exemplaires aquarellés du premier recueil des prix, qui reproduit les dessins des années 1780 ; ce recueil assura ainsi le relais entre les dernières années fécondes de l'Ancien Régime et les débuts de l'École des beaux-arts. Autour de ces volumes souvent remarquables, l'exposition réunit une série d'ouvrages qui ont tous joué un rôle majeur dans l'enseignement de l'architecture, et des dessins qui s'y rattachent, soit parce qu'ils y sont reproduits, soit parce qu'ils s'en inspirent. Associant un point de vue qui relève de l'histoire du livre d'architecture et des préoccupations qui touchent à l'histoire de son enseignement, cette exposition croise les programmes de recherche documentaire que l'INHA consacre à la bibliographie du livre d'architecture français et aux élèves architectes de l'École des beaux-arts; une première partie des résultats, mise en ligne sur AGORHA, est désormais accessible au public. Antoinette Le Normand-Romain, Directeur général de l'INHA. 
SOMMAIRE

\section{Bibliothèques d'atelier \\ Jean-Philippe Garric}

Durand ou Percier? Deux approches du projet d'architecture au début du XIXe siècle Jean-Philippe Garric

Deux approches aux origines communes

Composition artistique ou composition rationaliste?

Dessins d'école, bibliothèques d'ateliers : une affaire de copies

Marie-Laure Crosnier-Leconte

Créer ou reproduire un dessin d'élève à la fin du XVIII ${ }^{\mathrm{e}}$ siècle

Un tarissement éditorial de trente ans

Reprise sous le Second Empire

La photographie, copie fidèle

La bibliothèque d'atelier, réservoir à « tubards »

« Ne soyez donc pas seulement livresques»

Architecture et construction dans les cours de l'École centrale des arts et manufactures (1833-1864) et du Conservatoire national des arts et métiers (1854-1894)

Valérie Nègre

Composition / construction

Pratiques de l'enseignement pratique

En quête de la couleur : publication de dessins réalisés lors de voyages d'études en Grèce Stéphanie Guilmeau-Shala

De l'importance du dessin dans la formation à l'École des beaux-arts

La restitution de la polychromie grecque : entre archéologie et choix esthétique

Diffusion et fortune des dessins 


\title{
Bibliothèques d'atelier
}

\author{
Jean-Philippe Garric
}

1 À la fin des années 1960 et au début des années 1970, l'enseignement de l'architecture à l'École des beaux-arts de Paris volait en éclats, donnant naissance aux « Unités pédagogiques ", ancêtres des actuelles Écoles nationales supérieures d'architecture. Les étudiants contestataires et les jeunes enseignants, liquidateurs d'une institution officiellement créée cent cinquante ans auparavant, s'éloignaient du quai Malaquais, en emportant parfois avec eux quelques-uns des grands volumes malmenés par des générations de lecteurs peu précautionneux, qui provenaient des bibliothèques d'ateliers.

2 Certains de ces ouvrages étaient récents, mais beaucoup d'entre eux dataient du siècle précédent. Leur présence témoignait d'une relation aussi étroite qu'ancienne entre un apprentissage de l'architecture, dans lequel la dimension graphique était prépondérante, et des recueils de gravures, qui rassemblaient la culture de l'architecte, et parmi lesquels les annales des travaux académiques et l'œuvre des anciens élèves de l'École tenaient une grande place. Ce système autoréférentiel proposait une synthèse $\mathrm{du}$ sacro-saint modèle antique, de la grande tradition classique française et d'un italianisme fervent, étroitement lié à l'institution du Prix de Rome. Il s'organisait autour et au service d'une pratique de la « composition » élaborée et instaurée au seuil de la période contemporaine, dans les décennies qui précèdent et dans celles qui suivent la Révolution : une méthode de projet, qui a déterminé la pratique de la conception architecturale en France et dans les nombreux pays qui subirent son influence, pendant près de deux siècles ${ }^{1}$.

3 Les livres rassemblés dans l'exposition et les dessins qui leur sont confrontés témoignent d'une réalité disparue. Comme les fragments d'épaves rejetés sur le sable, ils sont les traces inertes, mais bien tangibles, d'un naufrage. Mais ils illustrent aussi, de la façon la plus concrète, les ambitions et les certitudes des professeurs d'architecture, les approches de la création architecturale qui fondaient ces enseignements et tout une profession. Cela ne signifie pourtant pas qu'ils relèvent d'une réalité monolithe. Au lendemain de la Révolution française, l'enseignement de l'architecture à Paris s'était organisé selon deux filières principales, reflétant une césure entre les héritiers de l'Académie royale d'architecture et la profession d'ingénieur, alors en plein essor, qui 
investissait désormais la dimension technique de l'architecture. Tandis que la formation des architectes gravitait autour de l'École des beaux-arts et de ses ateliers, celle des ingénieurs se mettait en place dans une institution nouvelle créée en 1794, l'École polytechnique, et se poursuivait à l'École des ponts et chaussées, transformée pour lui servir d'école d'application. À ces deux pôles principaux s'ajoutèrent, dans les décennies suivantes, les cours dispensés à l'École centrale des arts et manufactures, créée en 1829, et au Conservatoire national des arts et métiers.

Entre l'École des beaux-arts, qui privilégiait la dimension artistique de l'architecture, autour des concours et du prix de Rome, et les écoles d'ingénieurs, orientées vers des finalités pratiques, d'abord au service des équipements publics, puis des bâtiments industriels et de l'habitation, se dessine une opposition fondée sur des conceptions différentes du projet architectural. D'une part une approche accordant une importance majeure au goût, à l'ornement, portée par une maîtrise sophistiquée du dessin au lavis ou à l'aquarelle, de l'autre une doctrine rationaliste revendiquant la formation rapide et efficace de maîtres d'œuvre capables d'assumer des enjeux essentiellement constructifs et économiques.

5 Mais ces deux systèmes n'étaient pas entièrement étrangers l'un à l'autre. Mis en place au début du XIX ${ }^{\mathrm{e}}$ siècle par une génération d'architectes formée avant 1789, ils puisaient leurs racines communes dans les dernières décennies $d u x{ }^{e}{ }^{e}$ siècle et dans l'enseignement d'Étienne Louis Boullée ou d'Antoine François Peyre. Si ces deux approches reposaient sur des choix - voire sur des paradigmes - antagonistes de la conception architecturale elles se sont réciproquement influencées, donnant lieu à des hybridations.

6 Le rôle central de l'imprimé

7 À l'École des beaux-arts, comme dans les écoles d'ingénieurs, des livres et des documents imprimés, en lien étroit avec la pédagogie, jouaient un grand rôle dans la formation des élèves. Certes, de ce point de vue aussi, les deux pôles de l'enseignement de l'architecture se distinguaient par des pratiques différentes. Mais cependant, dans les deux cas, la dimension graphique de l'apprentissage du métier d'architecte demeurait prépondérante. Les ouvrages utilisés étaient pour la plupart des recueils de modèles, des répertoires de formes et de compositions, qui alimentaient une pratique du projet fondée sur le dessin, voire sur la copie. Les exemples étudiés étaient souvent des travaux des élèves des générations précédentes. Les annales des concours, les envois de Rome, puis d'Athènes, les édifices contemporains les plus emblématiques, formaient l'essentiel du corpus graphique des bibliothèques d'atelier.

Cette importance de l'image et de sa reproduction place le livre d'architecture au cœur et souvent à la pointe des évolutions techniques accomplies dans ce domaine tout du long $\mathrm{du} \mathrm{XIX}^{\mathrm{e}}$ siècle. Les documents présentés dans l'exposition ont été choisis pour rendre compte de cette dimension matérielle, offrant ainsi à la visite un second fil conducteur. Ils témoignent d'une multitude de méthodes, depuis la gravure sur cuivre, parfois aquarellée à la main pour restituer la couleur et mieux imiter les dessins originaux, jusqu'aux tirages photographiques montés sur des pages d'album ou reproduits en phototypie ou en héliogravure, qui permettaient une reproduction précise, mais toujours en noir et blanc. La quête conjointe de l'exactitude et de la simplicité d'exécution donna lieu au $\mathrm{XIX}^{\mathrm{e}}$ siècle à des procédés aux propriétés souvent contradictoires. Ainsi l'emploi de la lithographie, qui facilitait une reproduction rapide des figures et une fabrication économique en petit nombre était moins fine et 
contrastée que la gravure sur métal. Cette technique très utilisée par les Ponts et chaussées est ici illustrée par l'ouvrage précoce de Charles François Mandar imprimé en 1818 à 250 exemplaires sur les presses de l'école par le pionnier Raucourt de Charleville (fig. 1).

1. Détail du titre, au dos de la reliure d'un exemplaire du support de cours de Charles François Mandar à l'École des ponts et chaussées imprimé en lithographie en 1818 par Raucourt de Charleville.

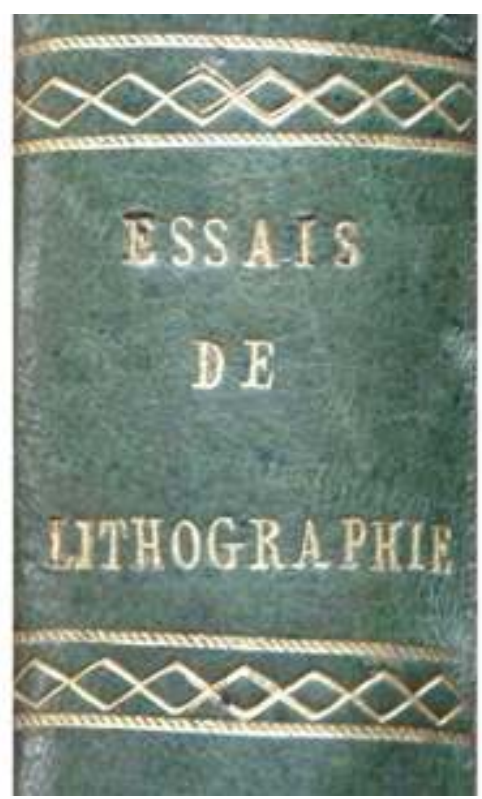

Titre et 102 planches lithographiées.

H. 45, L. 29

Paris, collection particulière.

Dans un autre domaine, le débat sur la polychromie, autour de l'architecture grecque, qui fut bridé dans les années 1820 par la difficulté de montrer la couleur dans une publication économiquement abordable, trouva un medium adapté quelques années plus tard dans la chromolithographie. Un rare exemplaire de l'ouvrage inachevé entrepris par Hittorff en 1826, qui conjuguait gravure au trait, gravure en couleur et rehauts manuels à l'aquarelle, témoigne de ces tâtonnements.

Étroitement liée aux programmes de recherche documentaire de l'INHA sur le livre d'architecture et sur les élèves architectes de l'École des beaux-arts, cette exposition centrée sur quelques exemples démonstratifs permet d'éclairer trois enjeux majeurs pour l'histoire du livre d'architecture : l'enseignement du dessin et du projet à partir d'un corpus d'images et d'une culture visuelle, la circulation et la généalogie des modèles, enfin la dimension physique et presque sensuelle de la théorie de l'architecture, qui lie étroitement les contenus au support de leur expression. 


\section{NOTES}

1. C'est dans ce substrat que s'enracinent la culture et la pratique de nombreux architectes et enseignants encore en activité aujourd'hui, comme en témoigne le récent ouvrage de Jacques Lucan, Composition. Non composition. Architecture et théories $\mathrm{XIX}^{e}-\mathrm{XX}{ }^{e}$, Lausanne, Presses polytechniques et universitaires romandes, 2009. 


\title{
Durand ou Percier? Deux approches du projet d'architecture au début du $\mathrm{XIX}^{\mathrm{e}}$ siècle
}

\author{
Jean-Philippe Garric
}

$1 \mathrm{Au}$ début du XIX ${ }^{e}$ siècle, deux filières principales s'organisent, en France, pour la formation des futurs architectes. La première, dont le concours du Prix de Rome est la clé de voûte, est l'héritière de l'Académie royale d'architecture. C'est elle qui donne naissance, à partir de 1819, à la section architecture de l'École des beaux-arts. La seconde commence dans une institution nouvelle, créée au cœur de la Révolution : l'École polytechnique, et elle se poursuit dans un établissement plus ancien, réformé pour lui servir d'école d'application : l'École des ponts et chaussées. Cette situation, étudiée notamment par Werner Szambien dans la monographie qu'il a consacrée à Jean Nicolas Louis Durand (1760-1834)1, peut aujourd'hui être abordée plus en détail, en tenant compte des travaux récents et en s'appuyant sur des sources nouvelles, principalement des travaux d'élèves.

2 Ces deux systèmes ne sont pas entièrement étrangers l'un à l'autre, mais ils sont séparés. Donnant accès à des carrières distinctes, ils reposaient sur des méthodes d'enseignement et des groupes de professeurs différents. Ils s'appuyaient sur deux visions antagonistes de ce qu'est le projet d'architecture et des compétences qu'il requiert. Dans les deux cas, cependant, dans un contexte général d'essor de l'imprimé, qui coïncide avec les premiers progrès de l'industrie, les publications jouaient un rôle déterminant dans la formulation et dans la transmission des savoirs et des pratiques, qui étaient le fondement de la formation des élèves. Les enseignants éditaient des ouvrages destinés, plus ou moins directement, à seconder leur pédagogie et à relayer leurs idées auprès d'un public qui constituait aussi une clientèle de lecteurs captifs.

Mais la fonction des livres n'était pas identique. La plupart de ceux-ci, destinés à alimenter des échanges de maitre à disciple faisant une large place à l'oralité, étaient des recueils de modèles presque dénués de commentaires, ou si l'on veut de mode d'emploi. À l'inverse, Jean Nicolas Louis Durand, le professeur d'architecture de Polytechnique, innovait, en 1802, en proposant un ouvrage dans lequel les principes et 
les règles sur lesquels reposait son enseignement étaient exposés de façon explicite. Ce Précis des leçons, mettant en évidence la cohérence de son point de vue et de la démarche qu'il proposait, lui permit d'apparaitre, a posteriori, comme un théoricien à la fois radical dans ses prises de position et consistant dans son argumentaire, par opposition aux patrons des ateliers, dont les publications étaient des suites de figures, des répertoires de formes. Pourtant, il serait hâtif de conclure trop mécaniquement et de façon définitive sur les modalités d'enseignement auxquelles ces publications correspondent, car, seuls des recoupements avec des travaux d'élèves permettent d'en évaluer la réalité.

\section{Deux approches aux origines communes}

4 Même s'il s'agit d'un basculement que l'on voit se dessiner par étapes dans les décennies qui précèdent la Révolution, c'est bien à l'extrême fin du xvIII ${ }^{\mathrm{e}}$ siècle ou au tout début $\mathrm{du}$ XIX ${ }^{\mathrm{e}}$ que l'on assiste à une césure. En effet, si l'on peut distinguer des tendances, voire des profils très différents, parmi les académiciens qui parrainaient les élèves pour leur permettre de participer au concours du Grand Prix, avant 1793, c'est bien aux mêmes épreuves que se confrontaient alors les principaux enseignants du début du siècle suivant, comme Charles Percier, lauréat du prix de Rome en 1786, sous la tutelle de Julien David Le Roy, et Jean Nicolas Louis Durand, Second Grand Prix en 1779 et 1780 , sous la houlette de Jean Rodolphe Perronet. À ces deux premiers noms, qui se relient ainsi, pour l'un, à l'architecte archéologue « inventeur » de l'architecture grecque, pour l'autre, au fondateur et premier directeur de l'École des ponts et chaussées, s'ajoutent leurs deux plus proches amis et confrères, Pierre Fontaine (1762-1853), lui-même Second Grand Prix en 1785 présenté par Jean François Heurtier (1739-1822) et plus tard professeur de perspective dans l'école de Percier², et Jean Thomas Thibault (1757-1826), premier alter ego du jeune Fontaine ${ }^{3}$, plus tard associé à Durand $^{4}$, puis professeur de perspective à l'École des beaux-arts ${ }^{5}$.

Durand, élève d'un ingénieur, et Percier élève d'un architecte archéologue, seraient ainsi déterminés dès leur jeunesse à emprunter des chemins divergents. Mais cette première opposition, en la personne de leurs parrains académiques, qui, d'une certaine façon, s'est confirmée dans la suite de leurs parcours, doit cependant être considérée avec circonspection, puisque les académiciens qui présentaient les jeunes architectes au Grand Prix leur apportaient un soutien formel. Ces derniers subissaient plutôt l'influence de leurs maitres d'atelier, qui étaient bien les véritables responsables de leur préparation au concours. Dans le cas de Percier et de Fontaine, il s'agit d'Antoine François Peyre (1839-1823), qu'ils ont d'ailleurs considéré avec révérence pendant toute leur vie ${ }^{6}$. Dans celui de Durand, ce fut Julien David Le Roy (1724-1803). Comme l'a écrit Werner Szambien, «l'influence de Leroy sur l'œuvre ultérieure de Durand est plus déterminante que celle de Perronet $^{7}$ ». Sans doute leurs penchants étaient-ils très dissemblables, mais les formations reçues par le futur maître de l'École des beaux-arts et par le futur professeur de l'École polytechnique n'ont pas été si différentes l'une de l'autre.

6 Pour mieux comprendre l'état de l'enseignement de l'architecture à Paris dans les toutes dernières années $d u x$ IIII $^{e}$ siècle, avant que ne s'instaurent les voies parallèles que nous évoquons, nous disposons d'un document précieux, au cœur du système d'acteurs qui nous intéresse : le cahier d'étude de François Léonard Séheult (1768-1840), 
élève présumé de Peyre le jeune en $1796^{8}$. Le Nantais Séheult, qui a publié un recueil d'Italie en 1821, le Recueil d'architecture dessiné et mesuré en Italie dans les années 1791, 92 et $93^{9}$, semble avoir été simultanément, dans les années qui précèdent le tournant du siècle, le confrère de Durand au sein de l'atelier d'Étienne Louis Boullée ${ }^{10}$ et l'élève du maitre de Percier, voire de Percier lui-même, si l'on en croit le secrétaire perpétuel de la classe des beaux-arts, Joachim Lebreton (1760-1819), qui le rangeait parmi les élèves de ce dernier lors d'une allocution prononcée le 25 octobre 1815, peu avant sa destitution ${ }^{11}$. Le cahier en question, réapparu en 2003 à l'occasion de la vente aux enchères d'un fonds encore conservé par les descendants, se compose de 46 feuillets au format oblong de $26 \mathrm{~cm}$ par $37 \mathrm{~cm}$, soit 92 pages dont 18 sont restées vierges et 74 présentent des dessins à la mine de plomb ou à l'encre, diversement élaborés. Il n'est pas signé, ses dessins ne sont pas légendés et il ne contient, pour toute indication d'appartenance, que l'étiquette du papetier parisien Niodot « Au chant de l'alouette », où il fut acheté, avec, juste en dessous, la mention manuscrite au crayon du « 22 fructidor an $4 »$, le 8 septembre 1796, jour de la bataille de Bassano (fig. 1).

1. François Léonard Séheult (Nantes 1768 -1840), Façades et plans d'édifices publics, [Cahier d'études réalisé dans l'atelier de Peyre le jeune], daté du 22 Fructidor an IV [8 septembre 1796].

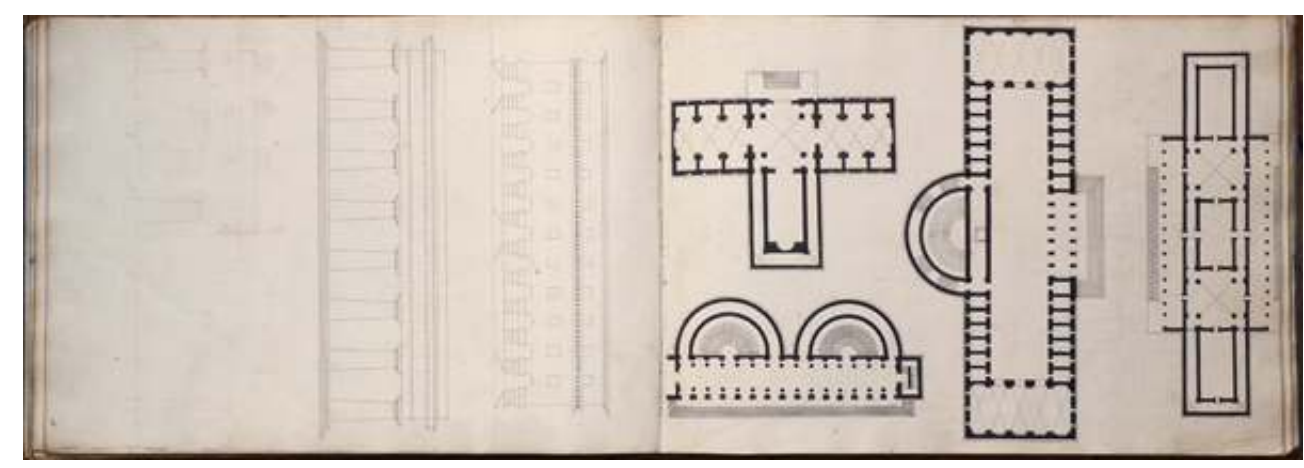

Album de 46 feuillets, mine de plomb, encre et lavis d'encre de Chine, fol. $19 \mathrm{~V}^{\circ}$ et fol. $20 \mathrm{R}$.

H. 26, L. 37.

Provenance : Succession Séheult - Garreau - Hillereau, vente du 14 juin 2003 par l'étude Beugnard à Neuville-de-Poitou.

Paris, collection particulière.

7 Lorsqu'on se penche sur son contenu, tout corrobore la date de 1796 et l'hypothèse d'une exécution rapide. Les projets qu'il contient relèvent exclusivement d'une pratique académique et ne sont pas étudiés jusqu'à résoudre dans le détail les problèmes de distribution. Il s'agit plutôt de la mise en place de partis architecturaux, sous la forme d'esquisses demandant encore à être approfondies. L'ensemble comprend beaucoup de dessins terminés, des plans et, dans une moindre mesure, des façades et des coupes. Mais on y trouve aussi des figures ébauchées à des degrés divers, illustrant toutes les étapes du processus de conception et de son élaboration graphique, depuis de tout petits croquis pour la recherche d'un parti, jusqu'à des esquisses complètes. Certains documents sont seulement griffonnés, comme la façade pour une prison, d'autres sont commencés aux instruments et inachevés, comme son plan. C'est donc, en premier lieu, la méthode de travail elle-même qui est ainsi documentée : l'emploi d'un cahier sur les pages duquel on jette directement, à main levée, les premières intentions $\mathrm{du}$ projet, avant de construire les figures au crayon et aux instruments, puis de les passer à l'encre au tire-ligne et, enfin, de pocher les plans à l'encre de Chine. Les projets de petites dimensions sont représentés en plan, coupe, élévation, coordonnés sur une 
seule page, parfois à deux par page. Mais, lorsqu'il s'agit de programmes plus vastes, les plans seuls occupent parfois toute la feuille jusqu'au bord du papier (fig. 2).

2. François Léonard Séheult (Nantes 1768 -1840), Esquisse pour une chapelle et pour un prytanée, [Cahier d'études réalisé dans l'atelier de Peyre le jeune], daté du 22 Fructidor an IV [8 septembre 1796].

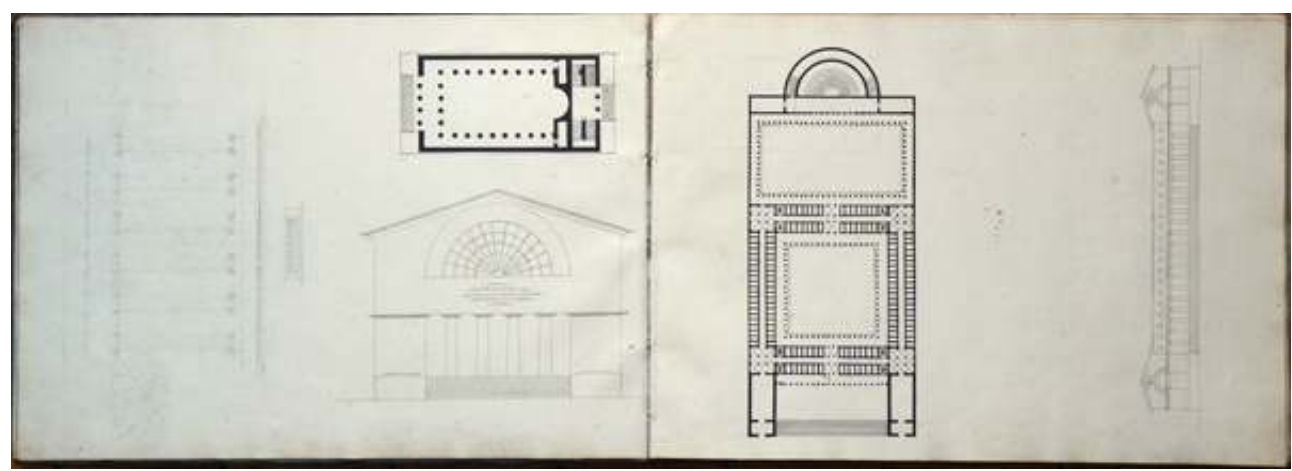

Album de 46 feuillets, mine de plomb, encre et lavis d'encre de Chine, fol. $5 \mathrm{~V}^{\circ}$ et fol ${ }^{\circ} 6 \mathrm{R}^{\circ}$.

H. 26, L. 37.

Provenance : Succession Séheult - Garreau - Hillereau, vente du 14 juin 2003 par l'étude Beugnard à Neuville-de-Poitou.

Paris, collection particulière.

8 L'expression des façades est conforme au goût dominant à l'époque. Ce palladianisme d'un extrême dépouillement, qui évoque l'œuvre d'un Ledoux sans en avoir jamais l'emphase, s'accompagne d'une utilisation très mesurée du décor et d'un goût pour le " nu du mur ", suivant la formule jadis développée par André Chastel à propos du palladianisme ${ }^{12}$. L'emploi des ordres y est très libre et les rares éléments de sculpture ornementale sont rapportés superficiellement sur la maçonnerie, comme en témoigne la façade pour une salle de spectacle animée par des figures en relief étroitement inspirées des danseuses Borghèse, au sommet de laquelle les couronnes de la frise semblant servir de cadres à une galerie des grands hommes, font ressortir l'abstraction des surfaces de mur lisses plutôt qu'elles ne l'atténuent (fig. 3). 
3. François Léonard Séheult (Nantes 1768 -1840), Projet pour un théâtre, façade principale, [Cahier d'études réalisé dans l'atelier de Peyre le jeune], daté du 22 Fructidor an IV [8 septembre 1796].

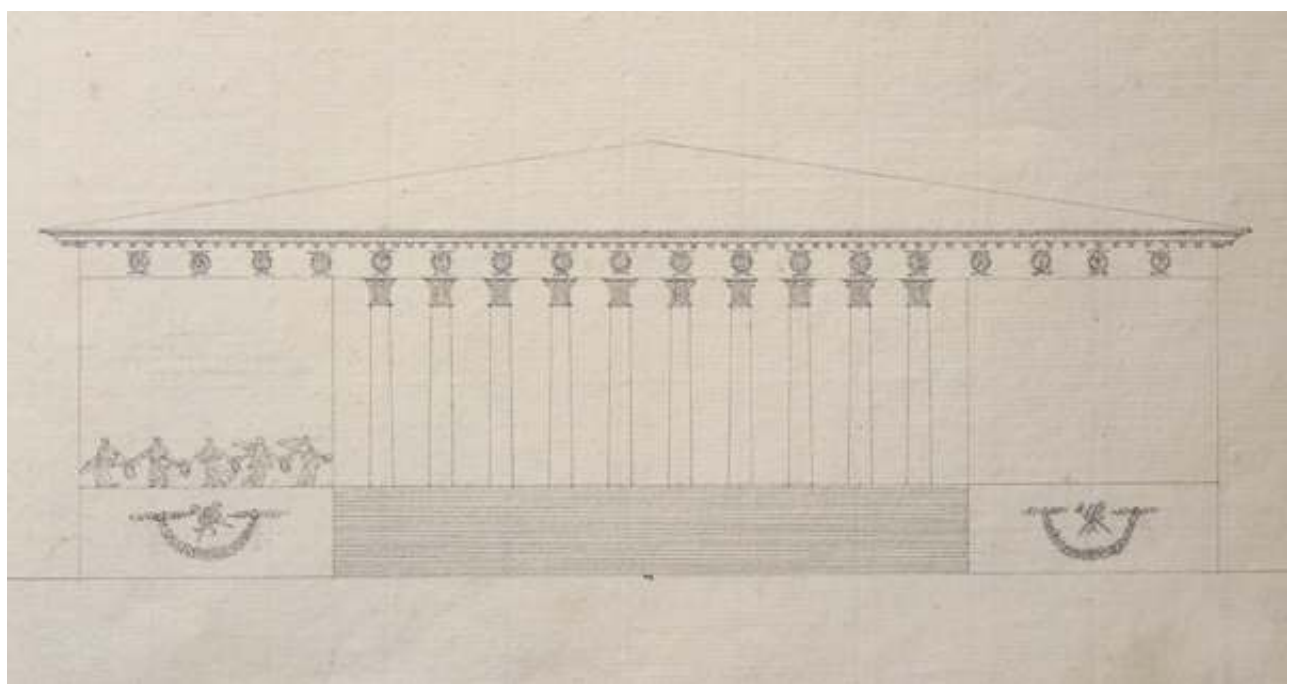

Album de 46 feuillets, mine de plomb, encre et lavis d'encre de Chine, fol. $9 \mathrm{R}^{\circ}$

H. 26, L. 37.

Provenance : Succession Séheult - Garreau - Hillereau, vente du 14 juin 2003 par l'étude Beugnard à Neuville-de-Poitou.

Paris, collection particulière.

9 Mais la dimension la plus développée et la plus frappante de l'ensemble concerne le travail en plan et la variation programmatique et géométrique qu'il recèle. En l'absence de légendes, les programmes traités sont parfois incertains, mais beaucoup peuvent être identifiés en analysant la distribution des plans. Ils comprennent des corps de gardes, des temples décadaires, des laiteries, des tribunaux, des bains publics, un prytanée, un hôpital, etc.

10 Édifices cultuels, édifices culturels ou administratifs, marchés, bourses ou cimetières, la collection imparfaitement ordonnée illustre toutefois une nouvelle ambition architecturale, qui inscrit tous les programmes - de la laiterie au prytanée - dans une suite logique, dans une typologie, s'appuyant pour se faire sur une méthode de conception basée sur l'assemblage d'éléments primaires ; une approche du projet que Durand allait codifier dans les années suivantes et porter à ses ultimes conclusions en 1821, dans la Partie graphique du cours d'architecture ${ }^{13}$. Elle témoigne d'une recherche qui est moins une somme de réponses spécifiques à une série de programmes préalablement édictés, qu'un processus de conception architecturale rationnel en partie autonome, héritier des concours académiques du siècle qui s'achève. Plus largement, cette rationalité et cette approche systématique semblent émerger en parallèle du processus d'organisation juridique et administrative du pays, alors en gestation. Les dessins de l'album Séheult illustrent la construction d'une nouvelle approche de l'art de concevoir les édifices, héritière des Lumières dans son rationalisme géométrique universaliste, comme le sont les programmes politiques et juridiques de son temps. Ils reflètent la méthode émergente, très largement graphique, d'une discipline en mutation, qui se prépare sans le savoir vraiment à bâtir les projets nouveaux d'une civilisation en germe.

11 Ce document permet aussi de replacer la théorie de Durand dans une généalogie qui trouve son origine dans les projets académiques des deux décennies précédant la 
Révolution. Car le jeune architecte, qui, selon toute vraisemblance, se servit de ce cahier pour préparer le concours du prix de Rome, utilisait simultanément, comme référence, le recueil gravé des prix publié par Prieur et Van Cléemputte, qui rassemble les annales des concours académiques de la fin de l'Ancien Régime ${ }^{14}$. C'est ce que montrent le rapprochement de la planche gravée présentant l'un des pavillons du projet de Grand Prix de Jean Nicolas Sobre ${ }^{15}$ et le dessin d'un pavillon figurant dans le cahier de Séheult ${ }^{16}$ (fig. 4 et 5), ou la similitude entre le plan du projet de bourse de Jean Jacques Tardieu et les plans d'édifices publics contenus dans les dernières pages du manuscrit ${ }^{17}$.

4. François Léonard Séheult (Nantes 1768 -1840), Projet pour un pavillon, plan et façade, et plan d'un édifice d'enseignement, [Cahier d'études réalisé dans l'atelier de Peyre le jeune], daté du 22 Fructidor an IV [8 septembre 1796].

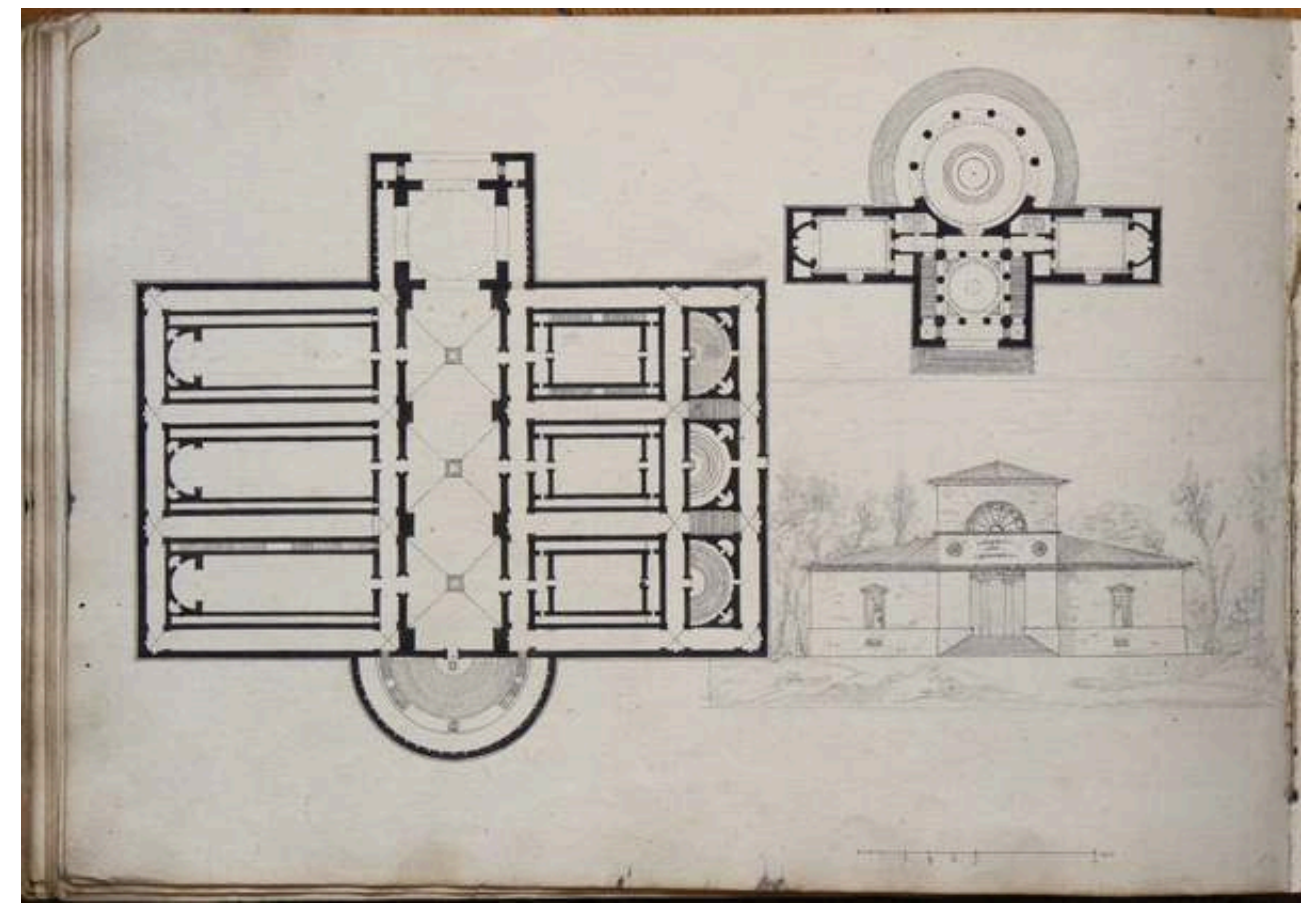

Album de 46 feuillets, mine de plomb, encre et lavis d'encre de Chine, fol. $25 \mathrm{R}^{\circ}$.

H. 26, L. 37.

Provenance : Succession Séheult - Garreau - Hillereau, vente du 14 juin 2003 par l'étude Beugnard à Neuville-de-Poitou.

Paris, collection particulière. 
5. Jean Nicolas Sobre, Projet pour un pavillon, dans Armand Parfait Prieur ( ? - ?) et Pierre Louis Van Cléemputte (1792 - 1834), [Collection des prix que la ci-devant Académie d'architecture proposait et couronnait tous les ans]. Paris, Basan, Joubert et Van Cléemputte, [1787-1796], cahier XIV, pl. 4.

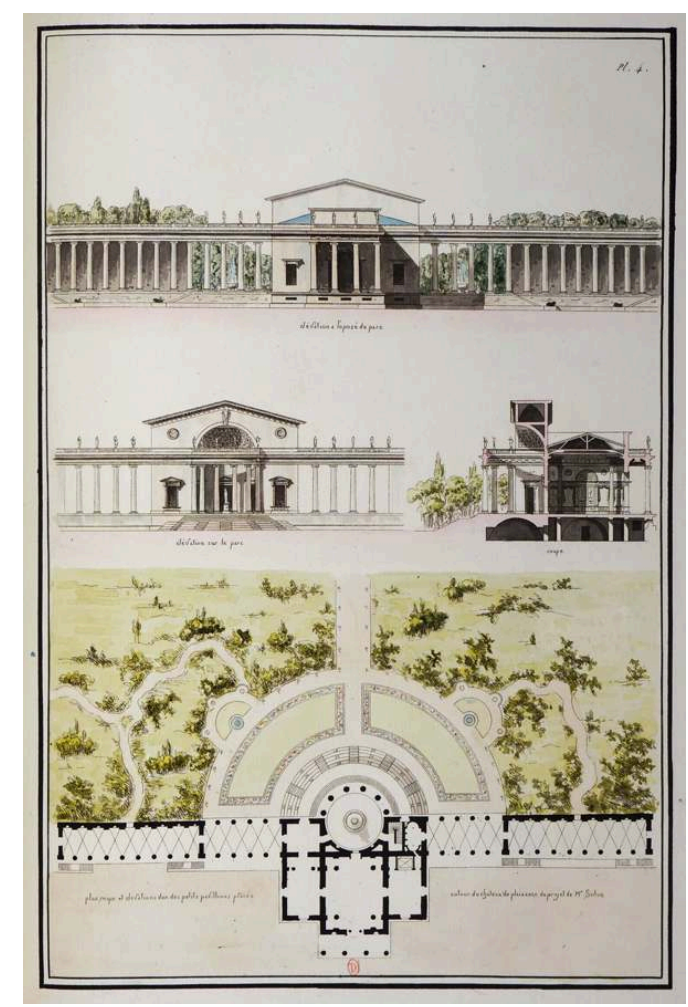

Recueil unique des planches du recueil de Prieur et Cléemputte réunies sous un titre factice, rédigé à la plume et encre noire, et lavis gris : "Recueil des prix proposés et couronnés par l'Académie d'Architecture: enrichi des plans, coupes et vues des plus Jolies Maisons de Paris, A Paris, Chez Joubert Graveur, Ruë des Mathurins, aux deux Piliers d'Or ».

745 planches gravées sur cuivre imprimées sur papier de Hollande, lavées, aquarellées et rehaussées au pastel pour les plans des «maisons ».

Exemplaire exceptionnel qui comprend une très rare addition de 30 pl. consacrée aux «maisons de Paris ». C'est l'un des deux exemplaires entièrement rehaussés à l'aquarelle et au lavis qui se trouvent à la Bibliothèque de I'INHA, collections Jacques Doucet.

Paris, Bibliothèque de I'INHA-Collections Jacques Doucet.

12 En sens inverse, on peut également mettre en évidence les liens que ces études entretiennent avec les travaux académiques des décennies suivantes, en soulignant la proximité entre le projet de bains étudié par l'architecte nantais et celui qui fut publié trente ans plus tard par Charles Normand, dans Le Vignole des architectes ${ }^{18}$. Même disposition générale fondée sur la répétition de trois parties alternant avec des cours, même principe d'élévation laissant apparaitre ces trois salles principales en pignon audessus de la corniche principale, même type de petites arcades en rez-de-chaussée à l'entrée de l'édifice : la version de l'ancien partenaire de Durand, au service de Boullée, et celle de son collaborateur, comme graveur du Précis des leçons et du Recueil et parallèle, semblent sorties d'une même matrice (fig. 6 et 7). 
6. François Léonard Séheult (Nantes 1768 -1840), Projet de bains publics, plan, coupe et façade, [Cahier d'études réalisé dans l'atelier de Peyre le jeune], daté du 22 Fructidor an IV [8 septembre 1796].

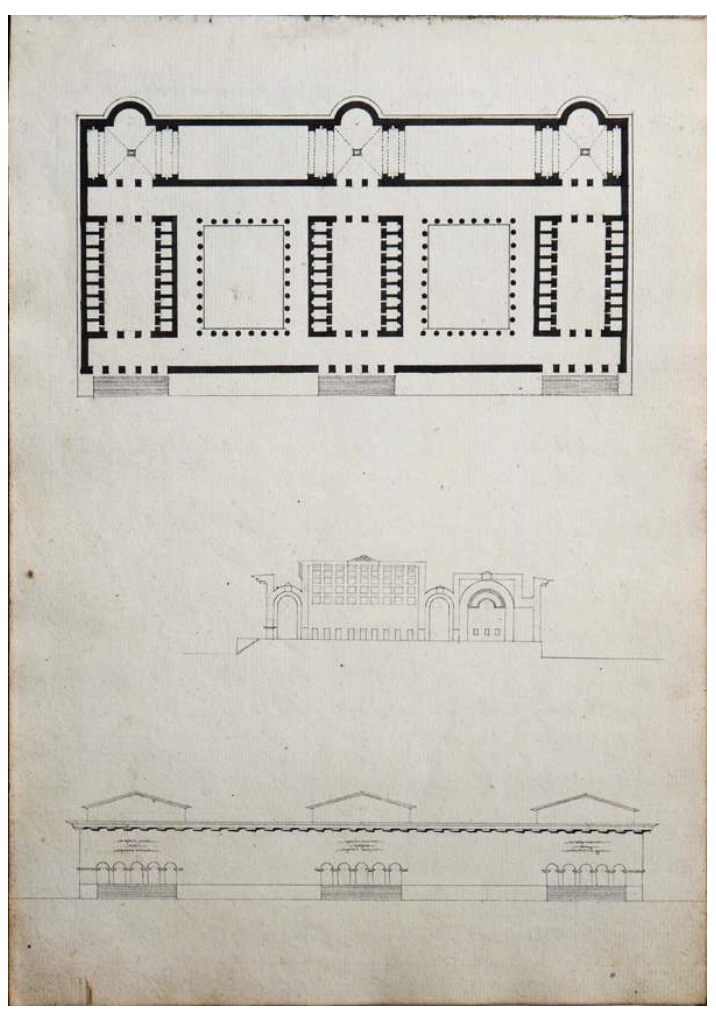

Album de 46 feuillets, mine de plomb, encre et lavis d'encre de Chine, fol. $17 \mathrm{~V}^{\circ}$

H. 26, L. 37.

Provenance : Succession Séheult - Garreau - Hillereau, vente du 14 juin 2003 par l'étude Beugnard à Neuville-de-Poitou.

Paris, collection particulière. 
7. Charles Normand, Projet de bains publics, plan et façade, Le Vignole des architectes et des élèves en architecture. Seconde partie, Paris, l'auteur, 1828, pl. 33.

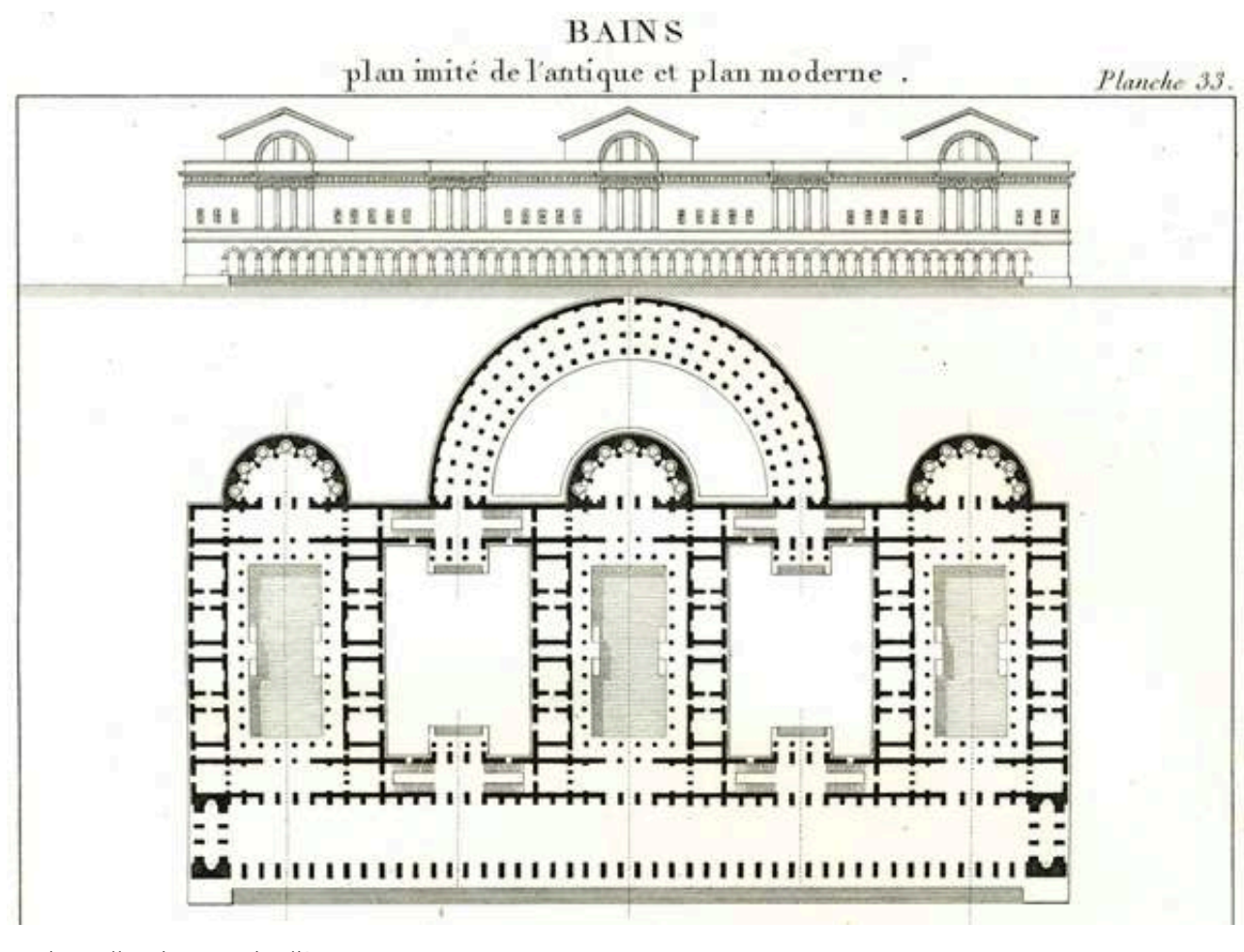

Paris, collection particulière

\section{Composition artistique ou composition rationaliste?}

Depuis ces origines communes, issues des travaux académiques des années qui précèdent la Révolution et des recherches conduites dans les entourages féconds de Peyre et de Boullée, avant la mort de ce dernier en 1799, les orientations poursuivies par Charles Percier et par Jean Nicolas Louis Durand, à partir de 1800, affirment des priorités distinctes. S'ils partagent un même souci de la régularité géométrique des plans et bien que le projet de prix de Rome du premier fasse partie des poncifs que le second proposait à ses élèves ${ }^{19}$, l'ancien pensionnaire de l'Académie de France à Rome revendique haut et fort son statut d'artiste, quand le professeur de l'École polytechnique refuse de faire de la beauté un enjeu du projet.

Art ou raison ? La question s'était déjà posée de façon frappante à l'occasion des participations au Grand Prix de Pierre Fontaine et de Charles Percier, respectivement en 1785 et en 1786. Le rendu dramatique et grandiloquent du premier poussait si loin la recherche de l'effet et le désir d'émouvoir le spectateur, qu'il lui aurait coûté la première place. Le sujet traité était celui d'une sépulture pour les souverains d'un grand empire. Au milieu de la composition se dressait une "pyramide circulaire sur laquelle on voyait au centre d'un cercle de coursiers lancés au galop du destin qui portait sur le monde, la faux à la main, la mort en tout sens ${ }^{20}$ ». Déchirant un ciel noir d'orage, un éclair illuminait le sommet de l'édifice. L'allégorie était emphatique, sa représentation se complaisait à des effets faciles et prenait trop d'importance. Elle faisait assaut de sentiment et de pathos dans un esprit annonciateur du Romantisme. La correspondance des directeurs de l'Académie de France à Rome semble montrer que 
l'Académie, d'abord décidée à lui accorder le Premier Grand Prix, trouva ensuite son projet "si supérieurement dessiné » qu'elle voulut faire un exemple « contre ceux qui, en faisant alors du dessin, donnent à cette partie seule une attention qui peut nuire à l'objet essentiel de son étude ${ }^{21} »$. Si bien qu'en 1786, manifestement échaudés par l'épisode de l'année précédente et par le tumulte suscité par la soumission de Fontaine, les rédacteurs du sujet choisirent un thème qui était moins sujet à des débordements : un palais des académies, et qu'ils décidèrent, surtout, d'interdire "les ciels, les paysages, les perspectives et en général tout ce qui n'est pas du ressort d'un dessin purement géométral ${ }^{22}$ ». Percier, élève modèle, s'en tint à une démonstration des plus rigoureuses destinée à des experts et susceptible en rien de séduire le grand public et c'est ainsi qu'il l'emporta. Le plus artiste des deux n'était pourtant pas celui-là.

Comme nous l'avons montré ailleurs, l'exemple le plus emblématique de l'engagement de ce dernier dans une définition artistique du métier d'architecte est le soin qu'il consacra à concevoir les frontispices du recueil sur les palais de Rome ${ }^{23}$, qui ne sont, d'ailleurs, qu'un aspect de son importante contribution au domaine de l'art du livre (fig. 8).

8. Charles Percier et Sophie Dupuis (1777 - Paris 1845), Frontispice du IVe cahier du recueil de Percier et Fontaine, Palais, maisons et autres édifices modernes dessinés à Rome [1798].

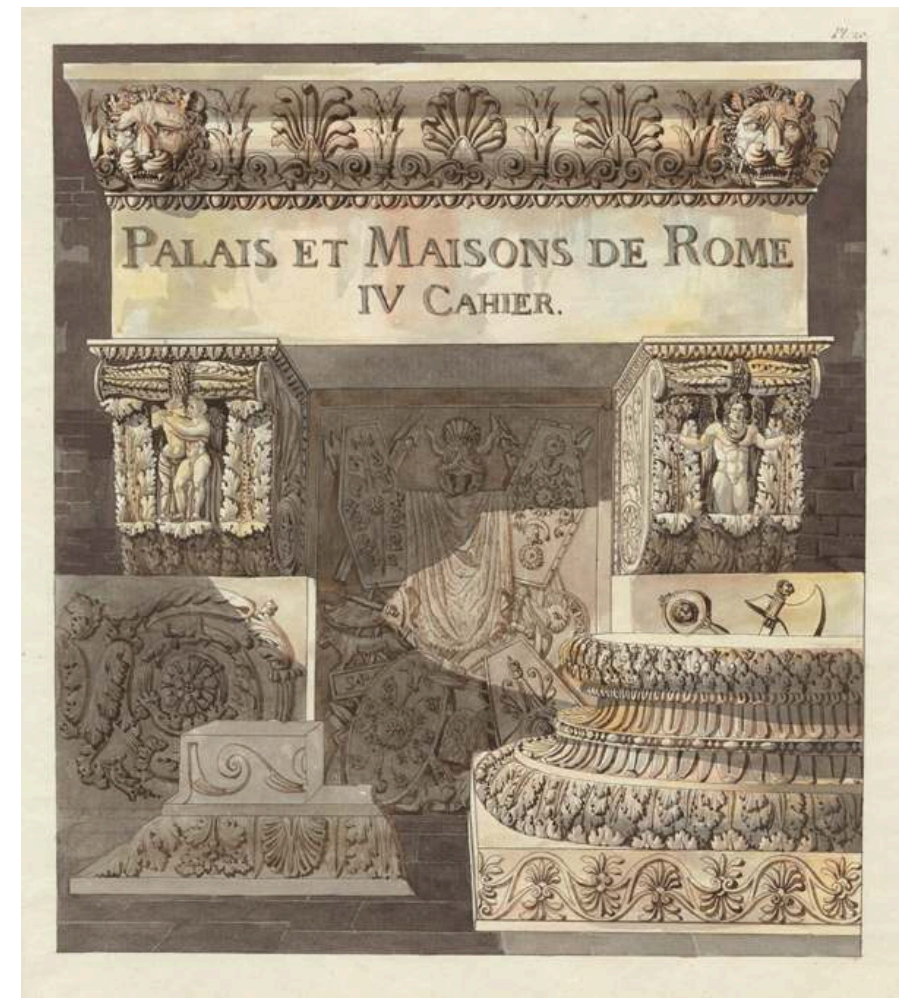

Gravure sur cuivre imprimée sur papier de Hollande et rehaussée à l'aquarelle.

H. 42, L. 32

Pour leur premier livre, Percier et Fontaine, qui ne disposaient pas encore de la reconnaissance et surtout des moyens financiers qu'ils obtinrent par la suite, décidèrent d'utiliser la technique de gravure au trait rehaussée à l'aquarelle pour les exemplaires de prestige, déjà mise en oeuvre par Prieur et Van Cléemputte, et que Fontaine avait admirée à Rome dans l'atelier d'Abraham Louis Joseph Ducros. Fontaine, qui avait fait la rencontre de Sophie Dupuis, orpheline de l'architecte Charles Dupuis (1733-1792) et qui l'avait formée au dessin, à l'aquarelle et à la gravure, lui confia, avec l'accord de son ami Percier, la mise en couleur des ouvrages.

Paris, Collection particulière. 
On se bornera ici à rappeler la longévité au sein de l'École des beaux-arts de la tradition qu'il avait ainsi instaurée, qui se manifeste notamment par la présence, en 1906, d'une composition à la Percier en ouverture de la nouvelle revue de la Société des architectes diplômés par le gouvernement, L'Architecte. Le commentaire qui accompagne ce travail d'un architecte né en 1871 montre bien les valeurs attachées à ce type d'exercice : «Nous ouvrons la série de nos planches par la reproduction du si joli dessin de M. Hulot, pensionnaire de l'Académie de France à Rome, où il a su réunir dans un ensemble fort harmonieux divers fragments d'architecture romaine. Le charme de la composition et de l'arrangement ajoute encore au plaisir que ressentiront tous les artistes à constater l'impeccabilité [sic], la souplesse du dessin et l'habileté du rendu ${ }^{24} »$. Mais le penchant du créateur du style Empire pour «l'architecture au pinceau», pour la sculpture et pour le décor, peut-être acquis dès son apprentissage, comme élève de l'École gratuite de dessin, marque tout son parcours, depuis son envoi de Rome consacré à la colonne Trajane, jusqu'aux travaux graphiques qu'il consacra dans ses dernières années au palais de Fontainebleau et au palais du Té à Mantoue ${ }^{25}$.

En comparaison, les préoccupations de Jean Nicolas Louis Durand se veulent étroitement pragmatiques. Il est inutile de revenir ici sur ses positions rationalistes, qui sont connues et que symbolise bien la planche du Précis des leçons dénonçant le plan de Saint-Pierre de Rome, dont l'exemple aurait causé « aux trois-quarts de l'Europe des siècles de calamités ». En revanche, il n'est pas inutile d'étudier plus en détail les travaux effectivement réalisés par ses élèves, dans la première décennie du XIX siècle. Ils nous renseignent sur la réalité de son enseignement, connu par ailleurs par ses publications et par les programmes imprimés de l'École polytechnique, permettant, par exemple, de constater que l'enseignement du lavis n'était pas entièrement absent de sa pratique, puisque l'on connaît des exercices de ce type réalisés sous sa férule et contresignés de sa main. En dépit de ses réticences sur le sujet, ils montrent que les élèves ingénieurs étaient capables d'exécuter des rendus d'une certaine qualité, ce à quoi les préparaient d'ailleurs d'autres enseignements, comme les cours de dessin topographique et les cours de dessin de la figure et du paysage (fig. 9). 
9. Henri Nicolas Raimond Jeannest-Lanoue, Exercice de dessin de la carte topographique, dessin à la mine de plomb et à l'aquarelle, 1806-1807.

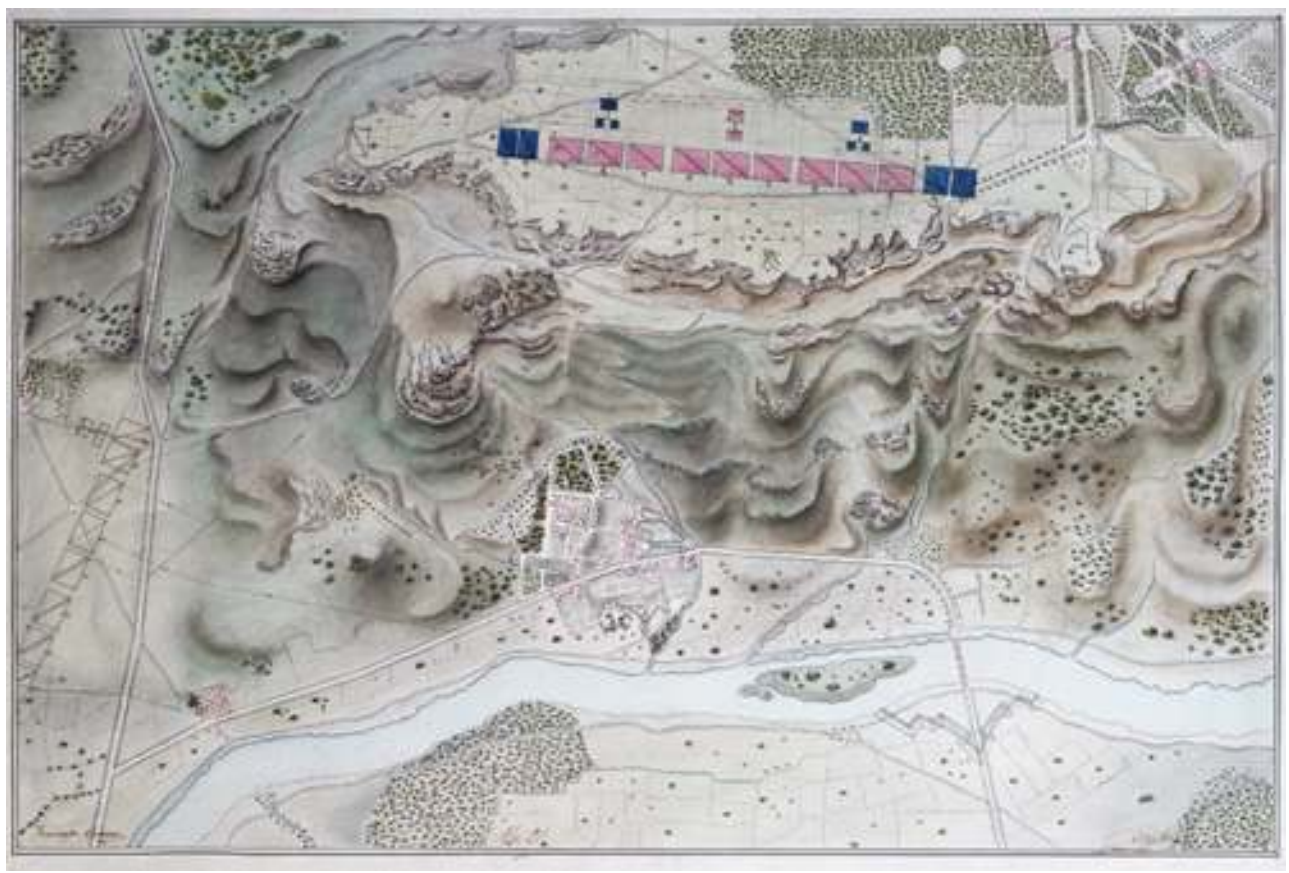

Paris, collection particulière.

18 L'album des travaux de Louis Léger Vallée (1784-1864), conservé à Paris dans une collection particulière, a le mérite de provenir de l'un des principaux élèves de Durand, figure importante $\mathrm{du}$ corps des Ponts et Chaussées, grâce notamment à ses publications ${ }^{26}$. Mais son intérêt tient surtout à sa date précoce, puisqu'il correspond à l'année 1801-1802, une période à laquelle le Précis des leçons n'était pas encore imprimé, les modèles qu'il contient n'étant donc pas encore fixés de façon intangible. Ses dessins, cependant, présentent déjà une très grande similitude avec les gravures, qu'il s'agisse des planches sur les ordres d'architecture, ou de celle qui représente plusieurs façons de bâtir une maison ${ }^{27}$ (fig. 10). 
10. Louis Léger Vallée (1784-1864), Projet d'une maison, [Travaux d'élèves à l'École polytechnique, Fortification, Architecture, Ponts et chaussées], 1801-1802.

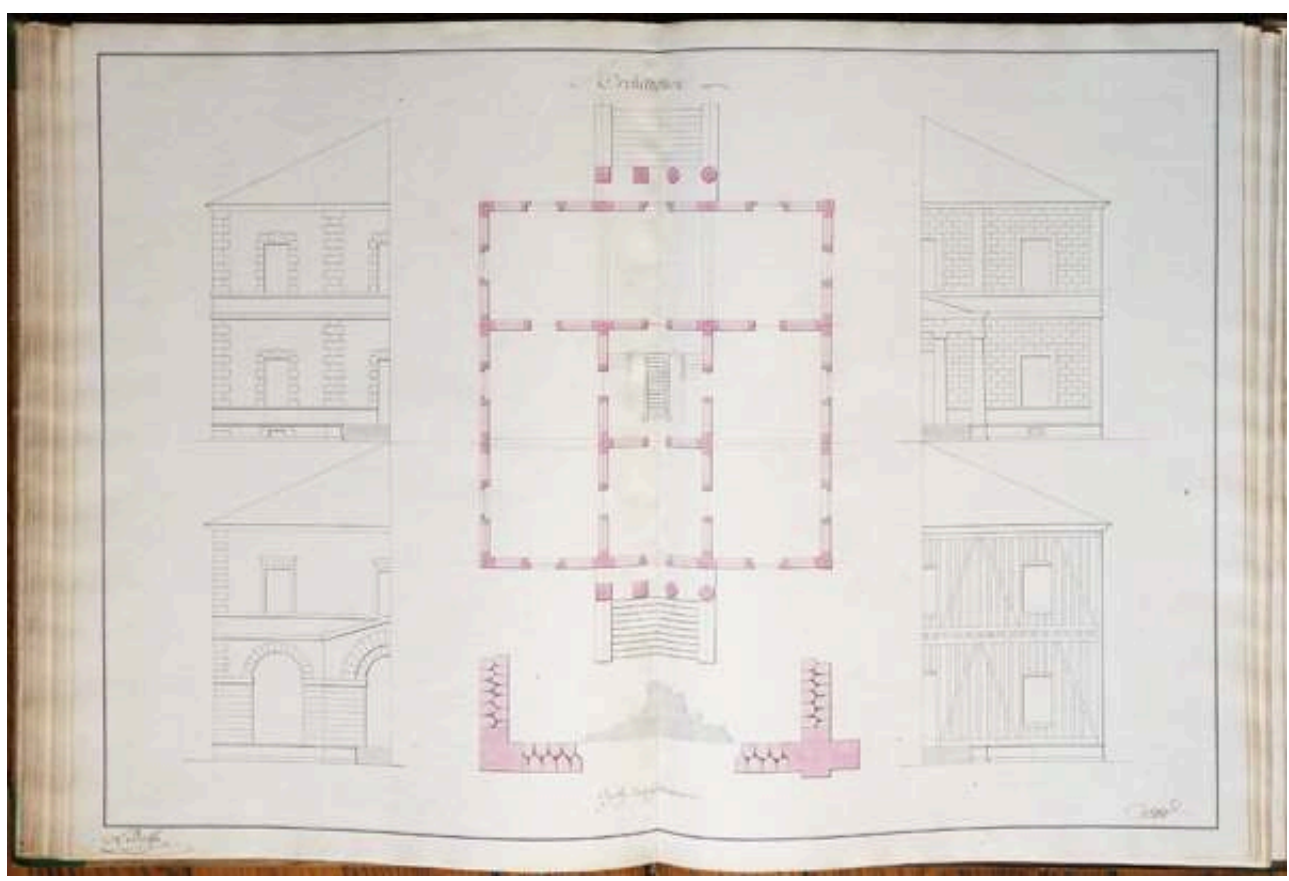

Atlas relié comprenant 31 grands dessins à la mine de plomb, à l'encre et à l'aquarelle, dont 17 doubles et 1 exécuté sur un feuille quadrillée imprimée d'après une plaque de cuivre ; 4 feuilles de modèles gravées sur cuivre et imprimées sur papier bleu.

H. 52,5, L. 38

Les élèves de l'École polytechnique faisaient souvent relier leurs travaux afin de les conserver. L'atlas ainsi réalisé par Louis Léger Vallée, particulièrement précoce, illustre les premières années de l'enseignement de Jean Nicolas Louis Durand, au moment où son Précis des leçons n'était pas encore publié. Dans la partie " architecture ", il comprend notamment une planche d'esquisse réalisée sur une feuille quadrillée obtenue à partir d'une gravure sur cuivre imprimée à l'encre bistre.

Paris, collection particulière.

La dix-huitième planche du recueil manuscrit est un témoignage de la fameuse méthode "des petits carreaux » de Durand moquée bien plus tard par César Daly ${ }^{28}$. Il s'agit en effet d'une feuille quadrillée imprimée - une gravure sur cuivre tirée à l'encre sépia claire - sur laquelle sont tracées au crayon des esquisses de plans, parmi lesquelles on reconnaît notamment un modèle étroitement inspiré de la villa Rotonda de Palladio (fig. 11). 
11. Louis Léger Vallée (1784-1864), Esquisses de plans sur papier quadrillé, [Travaux d'élèves à l'École polytechnique, Fortification, Architecture, Ponts et chaussées], 1801-1802.

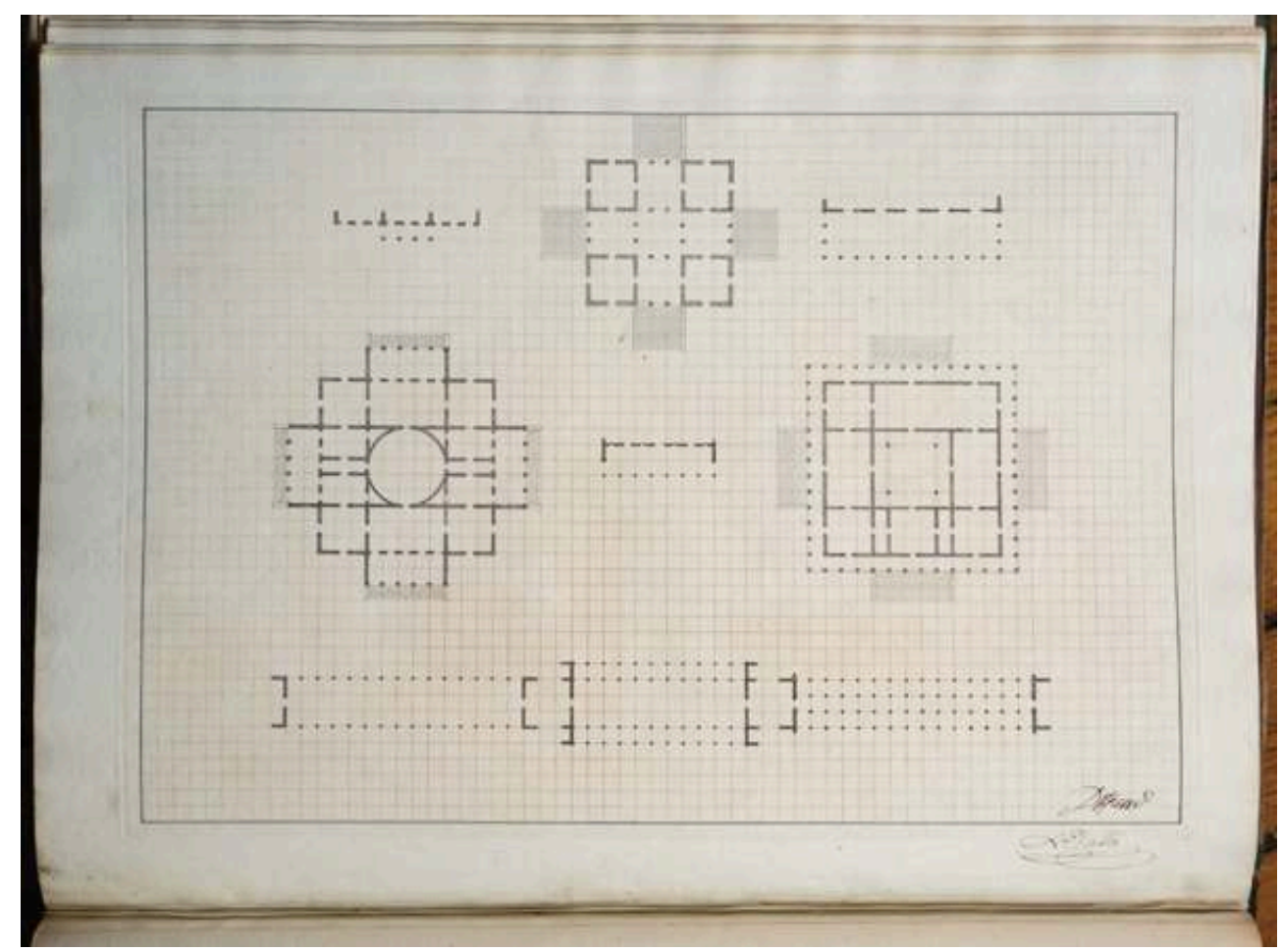

Atlas relié comprenant 31 grands dessins à la mine de plomb, à l'encre et à l'aquarelle, dont 17 doubles et 1 exécuté sur un feuille quadrillée imprimée d'après une plaque de cuivre ; 4 feuilles de modèles gravées sur cuivre et imprimées sur papier bleu.

H. 52,5, L. 38

Les élèves de l'École polytechnique faisaient souvent relier leurs travaux afin de les conserver. L'atlas ainsi réalisé par Louis Léger Vallée, particulièrement précoce, illustre les premières années de l'enseignement de Jean Nicolas Louis Durand, au moment où son Précis des leçons n'était pas encore publié. Dans la partie " architecture ", il comprend notamment une planche d'esquisse réalisée sur une feuille quadrillée obtenue à partir d'une gravure sur cuivre imprimée à l'encre bistre.

Paris, collection particulière.

La vingtième illustre, elle aussi, la méthode de projet imposée par Durand, puisqu'elle comprend de tout petits croquis correspondant à la recherche d'un parti pour la composition d'un escalier monumental, que les élèves représentaient ensuite à grande échelle en suivant étroitement le modèle publié par leur maître (fig. 12). 
12. Henri Nicolas Raimond Jeannest-Lanoue (1786 - 1844), [Exercice de l'École polytechnique. Étude pour un escalier monumental d'après le Précis des leçons de Durand, pl. 12, deuxième partie, tome 1], 1806-1807.

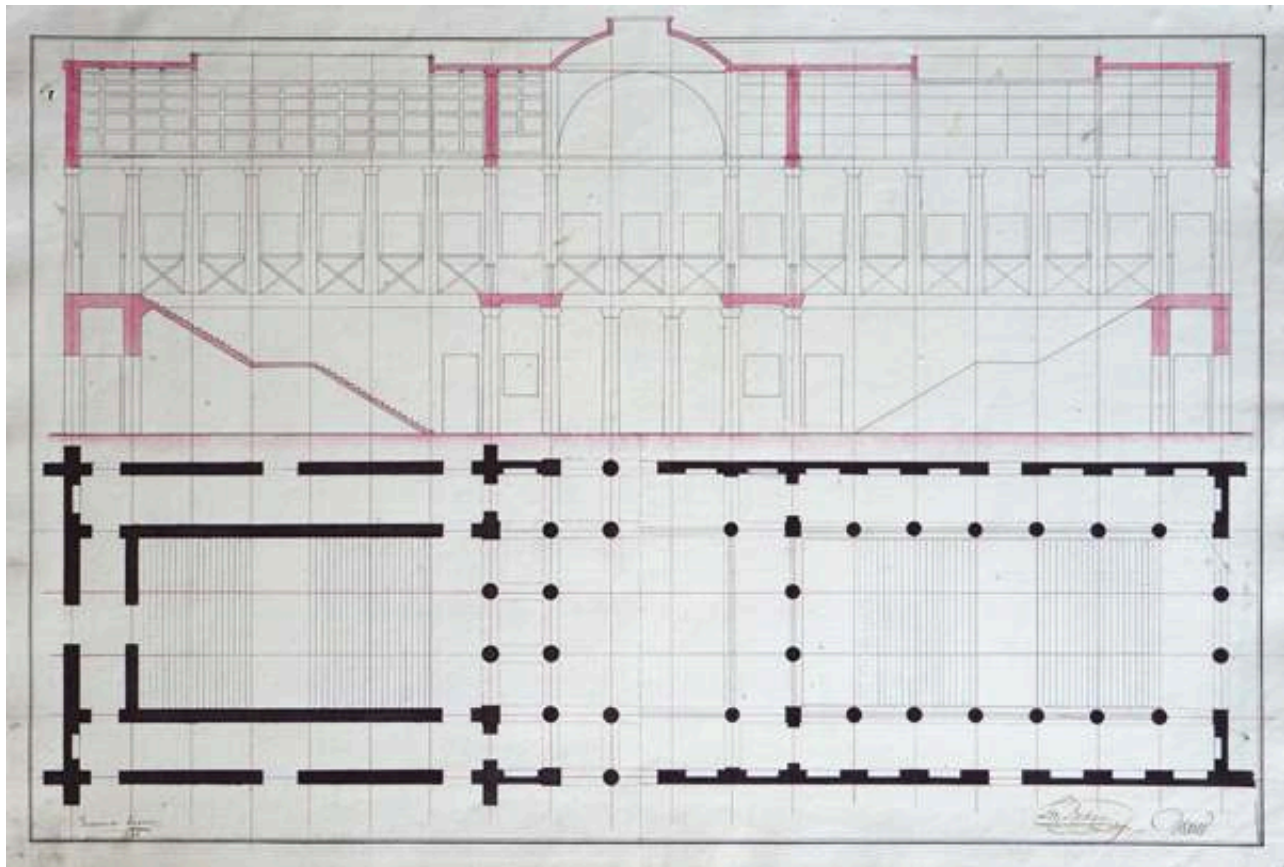

Dessin à la mine de plomb et au lavis contresigné par Durand.

H. 51,5, L. 35 .

Paris, collection particulière.

On peut s'étonner de voir ainsi enseignées différentes étapes de la conception d'un édifice : croquis pour la recherche d'un parti, esquisse mise au point sur papier quadrillé, puis dessin complété à plus grande échelle, alors que le résultat final attendu par le maitre était la reproduction à l'identique de ses modèles. Il faut néanmoins rappeler que la copie était alors une méthode d'enseignement communément admise, notamment pour former les débutants. Elle était, par exemple, la base de l'instruction à l'École gratuite de dessin ${ }^{29}$.

Enfin, un dernier document peut nous permettre de compléter cette description de la façon dont les cours étaient dispensés. Le programme de 1832 décrit une pratique de la prise de notes, qui existait sans doute dès les premières années : "Les élèves dessineront sur leurs cahiers, pendant la leçon, les esquisses que le professeur tracera sur le tableau. Dans l'étude qui suit, ils feront les esquisses ou dessins indiqués par le professeur. Les cahiers contenant les croquis tracés aux leçons feront partie du travail graphique ». Un de ces cahiers a été conservé dans les papiers d'André Joseph Jules Mondot de La Gorce (1791-1870), qui eut une brillante carrière d'ingénieur des Ponts et chaussées et qui fut l'élève de Durand l'année $1810-1811^{30}$. Il permet de constater que ce dernier dessinait au tableau les figures gravées dans son cours imprimé, que ses élèves recopiaient. Si quelques-unes de ces figures sont maladroites ou imparfaites, la plupart d'entre elles reproduisent fidèlement les modèles publiés, auxquels les élèves pouvaient se référer dans leurs exemplaires de l'ouvrage. On y reconnaît, entre autre, l'interprétation de la villa Rotonda, ou celle, plus radicale, du collège de la Sapienza (fig. 13 et 14). 
13. André Joseph Jules Mondot de La Gorce, Croquis évoquant le plan de la villa Rotonda, Carnet de notes de cours, 1810-1811.

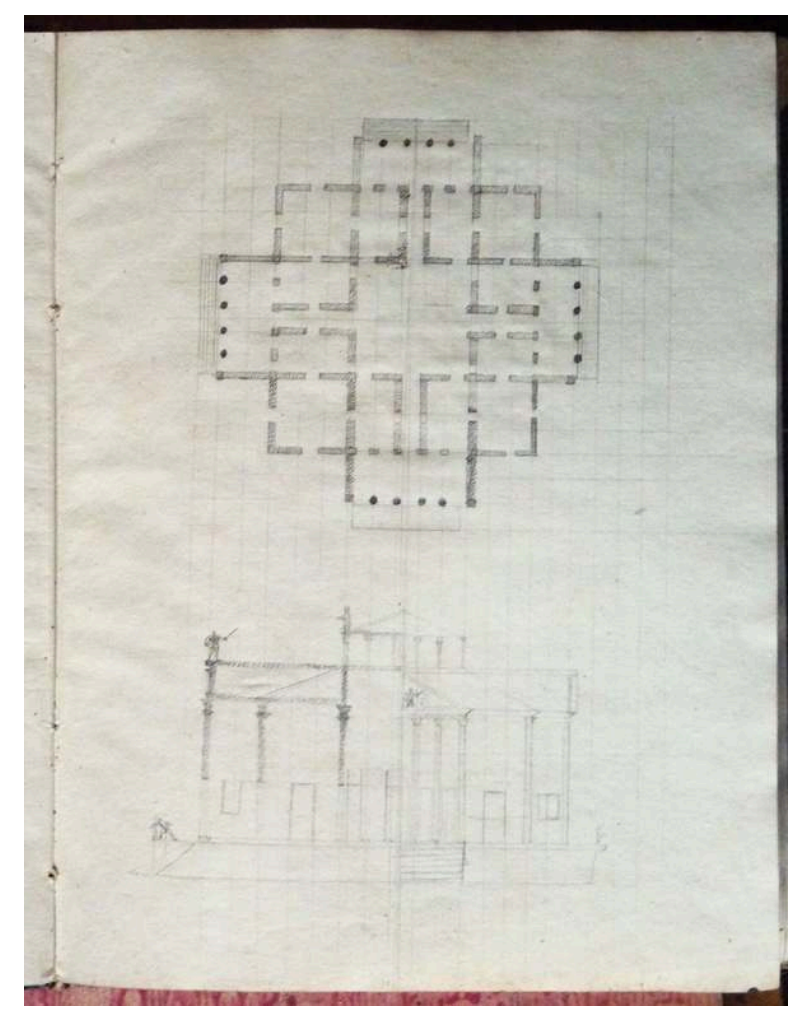

Paris, collection particulière. 
14. André Joseph Jules Mondot de La Gorce, Croquis évoquant le plan du collège de la Sapienza, Carnet de notes de cours, 1810-1811.

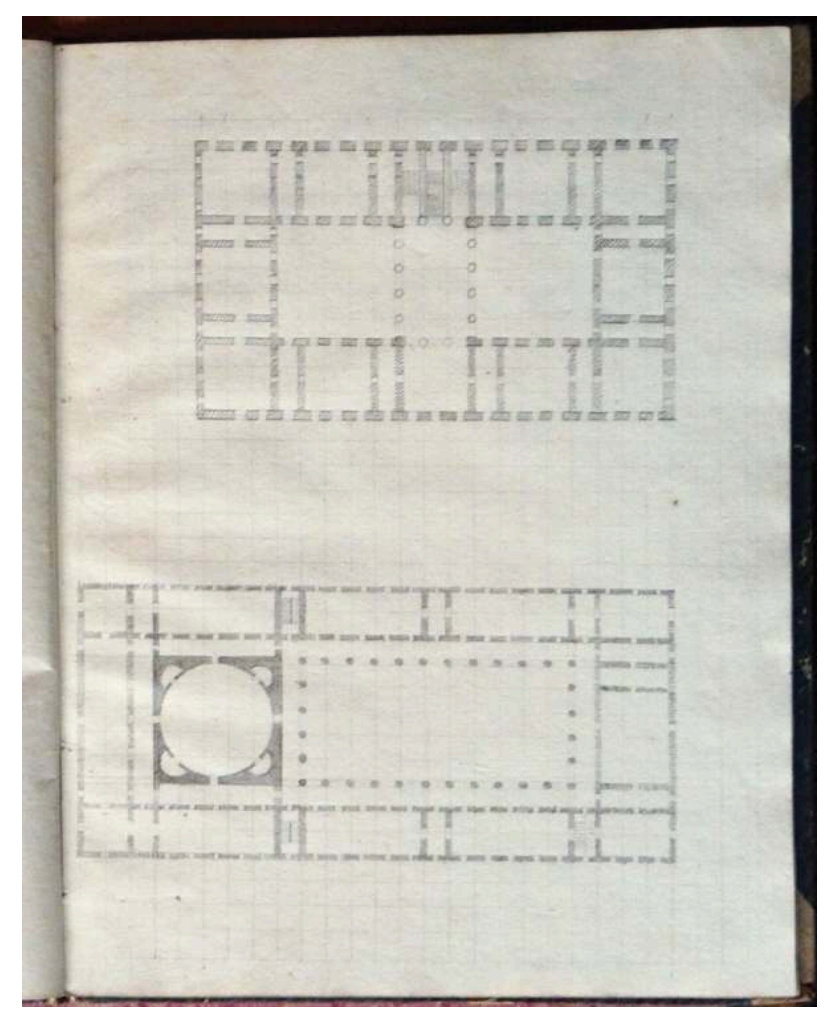

Paris, collection particulière.

En conclusion de ces quelques observations, il faut tout d'abord souligner combien il est important de comparer les publications pédagogiques aux exercices effectivement réalisés par les élèves. La relation entre théorie et pratique, toujours ambiguë en architecture, l'est encore davantage lorsqu'il s'agit d'enseignement et les déclarations d'intention sont toujours sujettes à caution. Au-delà de ces questions de méthode, on est confronté à un paradoxe : l'enseignement de Durand apparaît à la fois comme extrêmement proche, par son contenu, des principes exposés dans son ouvrage, mais aussi très contradictoire, par sa méthode, avec son idée générale d'une approche rationnelle du projet. Comment imaginer, en effet, que la transmission d'une approche rationaliste puisse se fonder sur la stricte copie de modèles formels intangibles ou sur la stricte reproduction d'une méthode graphique débouchant invariablement sur le même résultat attendu ? Il est vrai que la solution d'un problème géométrique ne dépend pas du sentiment personnel du dessinateur, mais il n'est pas certain, au-delà de son dédain affiché pour la beauté, que Durand soit vraiment parvenu à faire de l'architecture l'une des branches des mathématiques. 


\section{NOTES}

1. Werner Szambien, Jean Nicolas Louis Durand (1760-1834). De l'imitation à la norme, Paris, Picard, 1984. Szambien, qui avait publié en particulier les programmes des cours de l'École polytechnique (p. 155 et suiv.) n'avait pu utiliser que des travaux d'élèves des années 1830, longtemps après l'époque où cet enseignement s'était mis en place et participait de l'actualité de la théorie de l'architecture.

2. Pierre Fontaine avait appris la perspective pendant la première année de son séjour à Rome sous la houlette d'un aristocrate dilettante français, Monsieur de Nainville, qui résidait dans la cité pontificale, comme il le raconte dans son autobiographie inédite Mia Vita [version partielle dactylographiée par Albert Laprade], p. 13.

3. Voir Jean-Philippe Garric, Charles Percier et Pierre Fontaine, architectes de Napoléon, Paris, Belin, 2011, chap. 1 (à paraître).

4. Voir Werner Szambien, qui publie notamment la liste des prix décernés par le Jury des arts "en vertu de la loi du 9 frimaire de l'an troisième", où Durand et Thibault, plusieurs fois lauréats, forment équipe, op. cit., p. 152 et suiv.

5. Activité didactique qui trouve son reflet dans la publication posthume de son traité de perspective : Jean Thomas Thibault, Application de la perspective linéaire aux arts du dessin, ouvrage posthume... mis à jour par Chapuis, son élève, Paris, Thibault, Bance, Renouard et Carilian-Goeury, 1827.

6. Voir Charles Percier et Pierre Fontaine, Résidences de souverains, Paris, les auteurs, 1833. En particulier la notice sur Peyre, p. 164 et suiv.

7. Werner Szambien, Jean Nicolas Louis Durand, op. cit., p. 23.

8. Voir Jean-Philippe Garric, « Nouveaux programmes pour un empire futur. François Léonard Séheult élève de Peyre le jeune en l'an IV », dans Daniel Rabreau et Letizia Tedeschi, L'architecture de l'Empire entre France et Italie. Institutions, pratiques professionnelles, questions culturelles et stylistiques (1795-1815), Mendrisio, Mendrisio-Academy Press-Silvana, 2011, p. 3-14.

9. François Léonard Séheult, Recueil d'architecture dessiné et mesuré en Italie dans les années 1791, 92 et 93 par F. L. Schuelt [sic] architecte à Nantes, Paris, Bance aîné, 1821. La publication de ce volume, qui avait commencé en avril 1811, était prévue pour durer 18 mois, sous la forme de 18 livraisons de 6 feuillets. C'est finalement de 72 planches seulement que se compose la version terminée.

10. Voir Jean-Marie Pérouse de Montclos, Étienne Louis Boullée, Paris, Flammarion, 1994, p. 166 et suiv.

11. Jeanne Duportal, Charles Percier reproduction de dessins conservés à la bibliothèque de l'Institut, Paris, Maurice Rousseau, 1931, p. 79.

12. André Chastel, Palladiana, Paris, Gallimard, 1995, p. 89.

13. Jean Nicolas Louis Durand, Partie graphique des cours d'architecture faits à l'École royale polytechnique depuis sa réorganisation, Paris, l'auteur, 1821.

14. Armand Parfait Prieur, Pierre Louis Van Cléemputte, Collection des prix que la ci-devant Académie d'Architecture proposait et couronnait tous les ans, gravée au trait, imprimée sur papier propre à être lavé. Tome premier, Paris, les auteurs, [1787-1796].

15. Op. cit., cahier XIV, pl. IV.

16. Folio 26 verso.

17. Projets de marchés, de bourse, d'hôtel de ville, de halle, qui occupent les folios 42 à 45 .

18. Respectivement au recto du folio $17 \mathrm{du}$ cahier et dans Charles Normand, Le Vignole des architectes, t. 2, Paris, l'auteur, 1828, pl. 33. 
19. Durand publie le projet du Grand prix de Percier, pl. 9 de la $3^{\mathrm{e}}$ partie du Précis des leçons, et il reprend la composition de la partie centrale de cette même composition, pl. 8 de la Partie graphique des cours d'architecture.

20. Fontaine, Mia Vita, op. cit., p. 8.

21. Correspondance des directeurs, XV, 105. Cité par Louis Hautecoeur, Histoire de l'architecture classique en France, t. V, Paris, Picard, 1953, p. 156. Cette déclaration est toutefois sujette à caution, puisqu'il s'agissait alors de légitimer l'octroi d'une pension à Fontaine, bien qu'il n'ait été que Second Grand Prix.

22. Henri Lemonnier, Procès-verbaux de l'Académie d'architecture, t. IX, p. 182, cité in Jeanne Duportal, Charles Percier, Paris, Maurice Rousseau, 1931, p. 11.

23. Jean-Philippe Garric, "Présentation », dans Charles Percier et Pierre Fontaine, Palais de Rome. Palais, maisons et autres édifices modernes dessinés à Rome, Wavre, Mardaga, 2009, p. 22-27.

24. Louis Jean Hulot, "Fragments antiques ", dans Société des architectes diplômés par le gouvernement, L'Architecte. Revue mensuelle de l'art architectural, vol.1, Paris, Librairie centrale des beaux-arts, 1906, pl.1.

25. Aujourd'hui conservés à l'Institut de France.

26. Louis Léger Vallée a publié un grand nombre d'ouvrages. En plus des mémoires et travaux directement liés à son statut d'ingénieur des Ponts et chaussées, il s'est intéressé à la représentation en trois dimensions et à l'optique. On peut citer notamment les titres suivants : Traité de géométrie descriptive, Paris, Courcier, 1819; Traité de la science du dessin, Paris, Vve Coursier, 1821 ; Théorie de l'oeil, Paris, Baillères, 1844-1846 ; Précis sur l'oeil et la vision, Paris, MalletBachelier, 1854.

27. Durand, Précis des leçons, op. cit., $1^{\text {re }}$ part., pl. 2 ; Louis Léger Vallée, [Album manuscrit des travaux], pl. [17].

28. César Daly, Revue générale de l'architecture et des travaux publics, t.6, 1845-1846, p. 330.

29. Voir Ulrich Leben, L'École royale gratuite de dessin de Paris (1767-1815), Saint-Rémy-en-l'Eau, éditions Monelle Hayot, 2004.

30. Collection particulière, Paris. 


\title{
Dessins d'école, bibliothèques d'ateliers : une affaire de copies
}

\author{
Marie-Laure Crosnier-Leconte
}

1 Quand Armand Parfait Prieur grave vers 1787 les premières planches reproduisant les projets d'élèves couronnés par l'Académie royale d'architecture ${ }^{1}$, il consacre un fait accompli, la prééminence prise par le dessin sur la technique. Sa publication témoigne ainsi d'un divorce déjà largement entamé entre les deux composantes de l'art de bâtir : aux architectes reviendra désormais la conception, aux entrepreneurs et aux ingénieurs la mise en œuvre. Les architectes se revendiquent comme des artistes, et laissent aux ingénieurs le rôle de techniciens.

\section{Créer ou reproduire un dessin d'élève à la fin du XVIII siècle}

2 En 1758, l'Académie commence à réclamer aux lauréats des Grands Prix une copie en réduction de leurs dessins, afin que « d'un coup d'œil on pût voir les progrès de l'École d'architecture ${ }^{2}$ ». Cette demande, destinée à fournir des feuilles aisément consultables, consacre la valeur de modèles désormais attribuée à ces projets fictifs. Les sujets proposés pour le concours du Grand Prix tendent dans les années 1770 à devenir de plus en plus imposants, et les dessins des élèves larges et spectaculaires, paysagés, voire théâtralisés. En revanche, les problèmes de structure sont de plus en plus négligés. Les deux plus talentueux élèves de l'Académie, Charles Percier (1764-1838), pour Une ménagerie renfermée dans le parc du château d'un souverain (Second Grand Prix 1783) (fig. 1 et 2), et surtout Pierre François Léonard Fontaine (1762-1853) pour Un monument sépulcral pour les souverains d'un grand empire (Second Grand Prix 1785) (fig. 3), poussent la mise en scène à son extrême, au point que l'Académie, pourtant responsable de ces programmes grandiloquents, refusera d'accorder le prix à Fontaine pour les ciels d'orage qui envahissent l'élévation et la coupe de sa vaste composition par ailleurs simplifiée à l'extrême, ramenée aux effets contrastés d'un segment de cercle et d'un 
triangle, et trop inspirée par le Cénotaphe pour Isaac Newton, imaginé l'année précédente par Étienne Louis Boullée (1728-1799), qui n'est pourtant pas son maitre³

1. Charles Percier (Paris 1764 - Paris 1838), Une ménagerie renfermée dans le parc du château d'un souverain, plan des " arènes », $2^{\mathrm{e}}$ Grand Prix 1783.

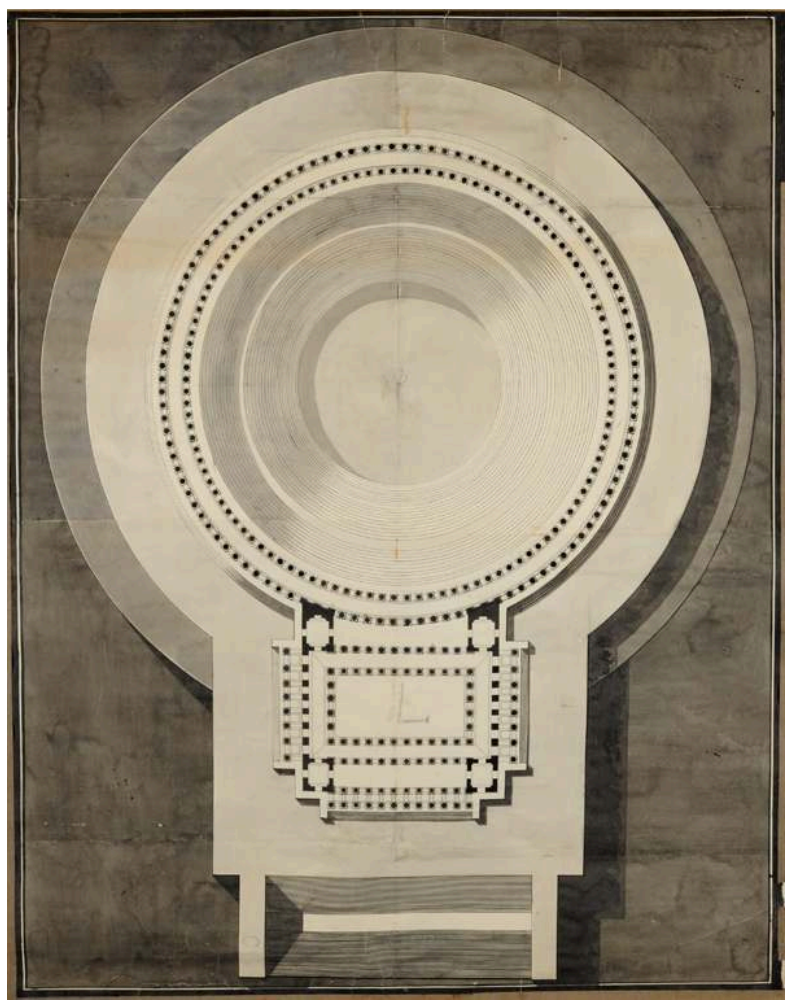

Mine de plomb, plume et encre noire, lavis gris.

H. 158,5, L. 124.

Paris, Ecole nationale supérieure des beaux-arts, PRA 104-10.

2. Charles Percier (Paris 1764 - Paris 1838), Une ménagerie renfermée dans le parc du château d'un souverain, coupe des " arènes ", $2^{\mathrm{e}}$ Grand Prix 1783.

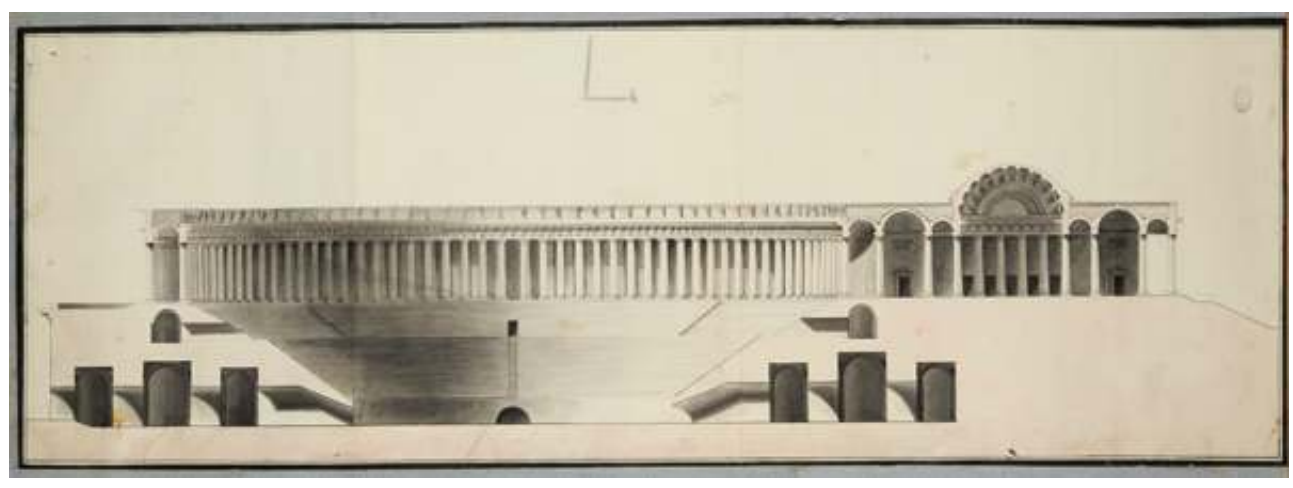

Mine de plomb, plume et encre noire, lavis gris et rose.

H. 50, L. 126,5

Paris, École nationale supérieure des beaux-arts, PRA 107-2. 
3. Pierre François Léonard Fontaine (Pontoise 1762 - Paris 1853), Un monument sépulcral pour les souverains d'un grand empire, élévation, $2^{\mathrm{e}}$ Grand Prix 1785.

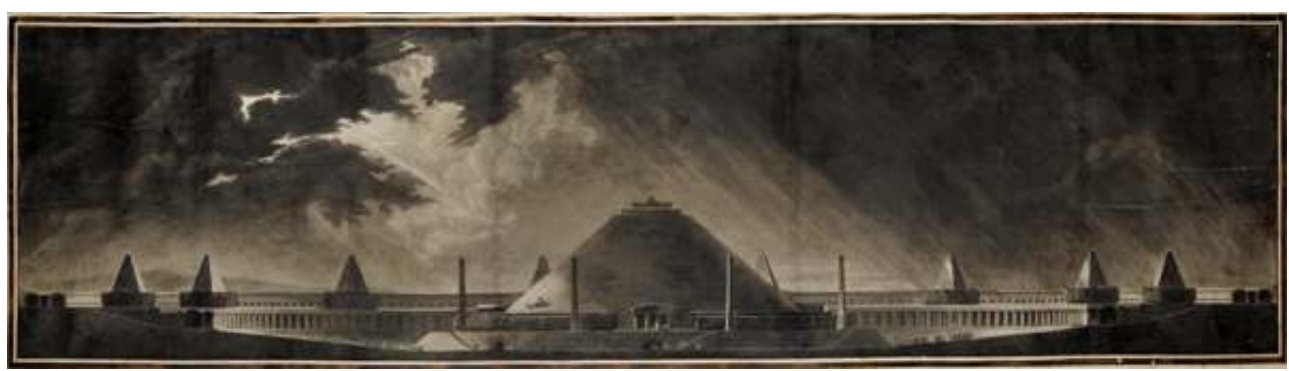

Mine de plomb, plume et encre noire, lavis gris avec rehauts de gouache. H. 76,6, L. 275.

Paris, École nationale supérieure des beaux-arts, PRA 107-2.

Il devient nécessaire pour les architectes artistes, dont le travail se concentre désormais sur la feuille, de rendre tactile par leurs talents de dessinateurs et d'aquarellistes la troisième dimension, voire une quatrième, celle du caché, que le dessin à la plume comme la gravure au trait, quelles qu'en soient les qualités graphiques, sont impuissants à traduire. Ce besoin amène à développer un système de conventions : dans les rendus les plus simples, notamment pour les plans et les coupes, deux teintes de lavis sont employées ${ }^{4}$. Le lavis gris, ou lavis d'encre, exprime les ressauts des surfaces, au moyen d'une ombre tombant idéalement d'une source de lumière venue d'un angle de 45 degrés à gauche ${ }^{5}$. Le lavis rose, fait de rouge carmin délayé avec de la gomme arabique, suggère pour sa part la présence de l'invisible : les épaisseurs de maçonnerie, de charpente, les soubassements. C'est le «rose de la coupe», dans lequel les architectes rejettent les parties qu'ils ne veulent plus traiter et abandonnent aux constructeurs, et qui s'étale de plus en plus sur le dessin.

Les graveurs se trouvent confrontés aux mêmes problèmes de représentation : la gravure au trait restreint les originaux à leurs lignes essentielles, de plus dans un format réduit. Aux prises avec un contexte éditorial fragile, ils usent de toutes les formes de diffusion, à tous les tarifs. Cela va de la gravure brute, proposée à la feuille, à la vente par cahiers de six feuilles vendus mensuellement, et enfin, aux volumes reliés, sur papier ordinaire ou de Hollande ${ }^{6}$. La formule la plus coûteuse, proposant des feuilles lavées ou aquarellées à la main, vaut cinq fois le prix de l'édition ordinaire ${ }^{7}$. Les demandes de souscription faites par Athanase Détournelle (1766-1807), qui poursuit la publication de Prieur et Cléemputte avec une nouvelle série publiée en $1806^{8}$, sont explicites quant aux intentions des éditeurs : «Ces productions du génie de nos jeunes Artistes, une fois déposées aux Archives, ne revoyoient point le jour, il était intéressant de les rendre utiles à l'Art, en les publiant ", afin de faire connaître à toutes les nations «la pureté et le bon gout qui Caractérisent particulièrement l'Architecture de Votre paÿs ${ }^{9}$ »

5 Les feuilles brutes sont aussi susceptibles de servir aux élèves à s'exercer à la technique du lavis ${ }^{10}$ (fig. 4). 
4. Charles Percier (Paris 1764 - Paris 1838), Une ménagerie renfermée dans le parc du château d'un souverain, plan et coupe des " arènes ", $2^{\mathrm{e}}$ Grand Prix 1783.

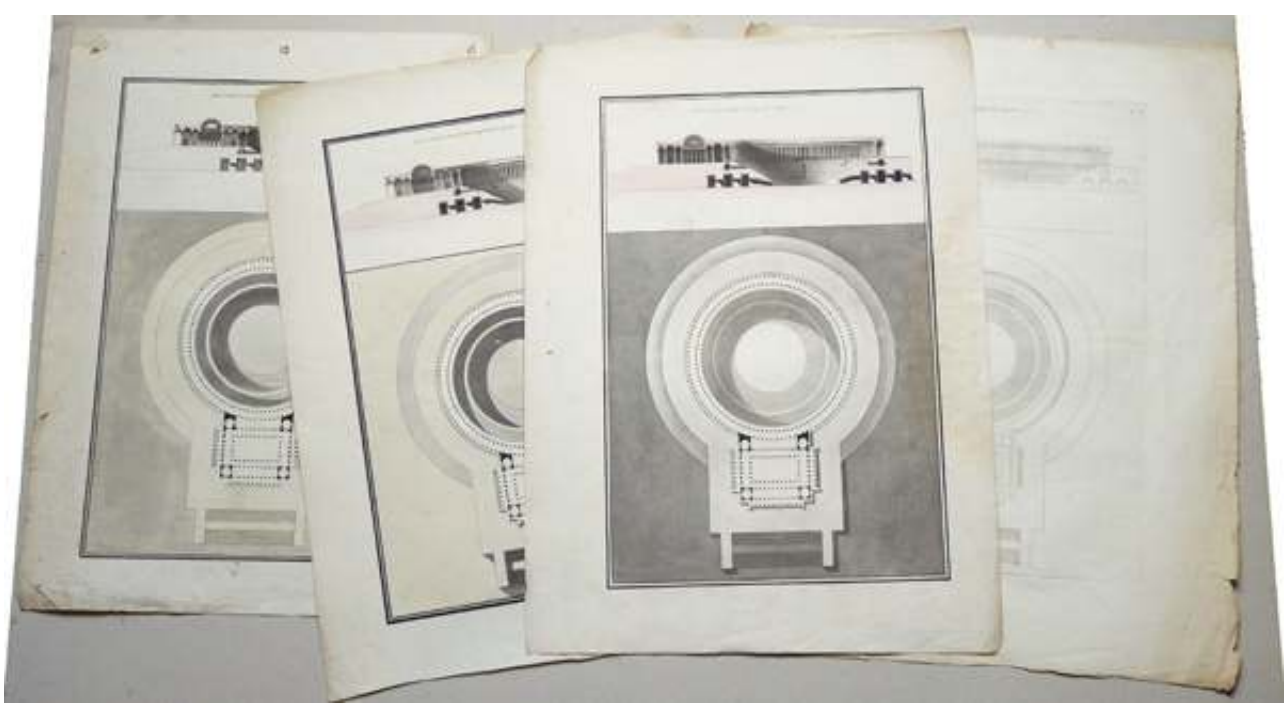

Quatre exemplaires de la planche gravée par Armand Parfait Prieur, IVe cahier, pl. 6, dont trois rehaussés de lavis gris et rose.

Provenance : fonds François Léonard Séheult (Nantes 1771 - Nantes 1840).

Cette planche correspond à la planche 6 du IV cahier du recueil de Prieur et Van Cléemputte. Ce groupe de quatre planches était conservé parmi plusieurs autres du même type dans le fonds de l'architecte nantais François Léonard Séheult. II témoigne sans doute d'une activité pédagogique. Les planches des recueils des prix étaient vendues à l'unité, lavées et aquarellées, pour servir de modèles, ou vierges, afin que les élèves puissent les utiliser pour s'entraîner à l'aquarelle.

Paris, collection particulière.

6 Mais le résultat de leur travail, allié à celui d'aquarellistes plus confirmés, aura aussi contribué à l'embellissement des exemplaires de luxe (fig. 5 et 6). Le report des ombres au lavis, disparate d'une feuille à l'autre, et souvent inexact, montre que leurs auteurs n'ont pas vu les dessins originaux. 
5. Charles Percier (Paris 1764 - Paris 1838), Une ménagerie renfermée dans le parc du château d'un souverain, plan et coupe des « arènes », $2^{\mathrm{e}}$ Grand Prix 1783.

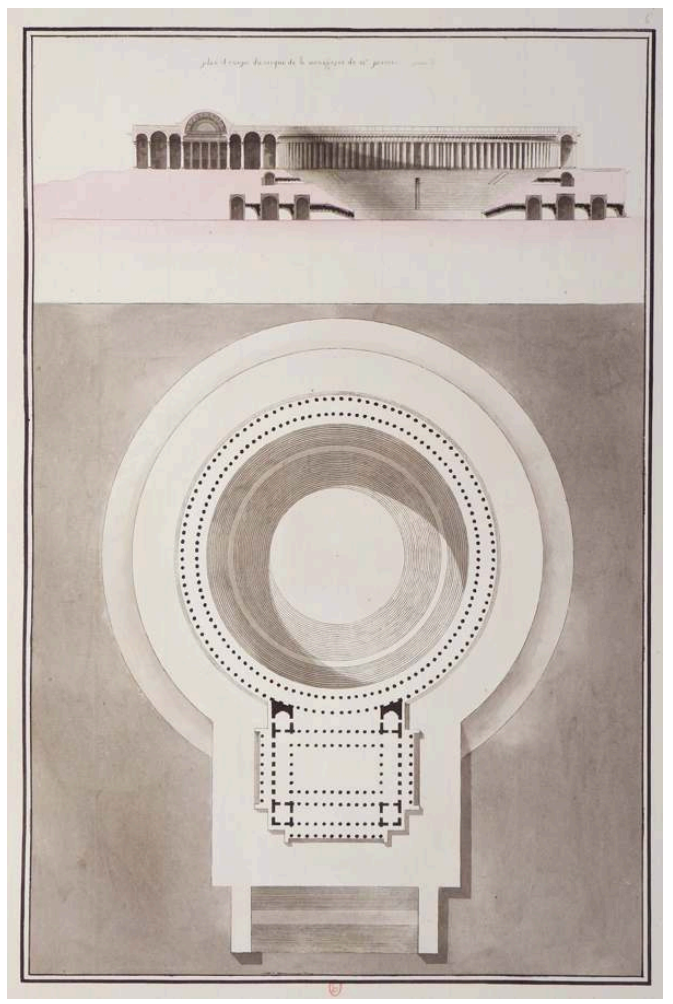

Gravure rehaussée à l'aquarelle et au lavis dans Armand Parfait Prieur (? - ?) et Pierre Louis Van Cléemputte (1792 - 1834) [Collection des prix que la ci-devant Académie d'architecture proposait et couronnait tous les ans].

Recueil unique des planches du recueil de Prieur et Cléemputte réunies sous un titre factice, rédigé à la plume et encre noire, et lavis gris : "Recueil des prix proposés et couronnés par l'Académie d'Architecture: enrichi des plans, coupes et vues des plus Jolies Maisons de Paris, A Paris, Chez Joubert Graveur, Ruë des Mathurins, aux deux Piliers d'Or».

745 planches gravées sur cuivre imprimées sur papier de Hollande, lavées, aquarellées et rehaussées au pastel pour les plans des «maisons ».

Exemplaire exceptionnel qui comprend une très rare addition de $30 \mathrm{pl}$. consacrée aux « maisons de Paris ». C'est l'un des deux exemplaires entièrement rehaussés à l'aquarelle et au lavis qui se trouvent à la Bibliothèque de I'INHA, collections Jacques Doucet.

Paris, Bibliothèque de l'INHA-collections Jacques Doucet, Fol. Est 441. $4^{\mathrm{e}}$ cahier, pl. VI. 
6. Pierre François Léonard Fontaine (Pontoise 1762 - Paris 1853), Un monument sépulcral pour les souverains d'un grand empire, élévation, $2^{\mathrm{e}}$ Grand Prix 1785.

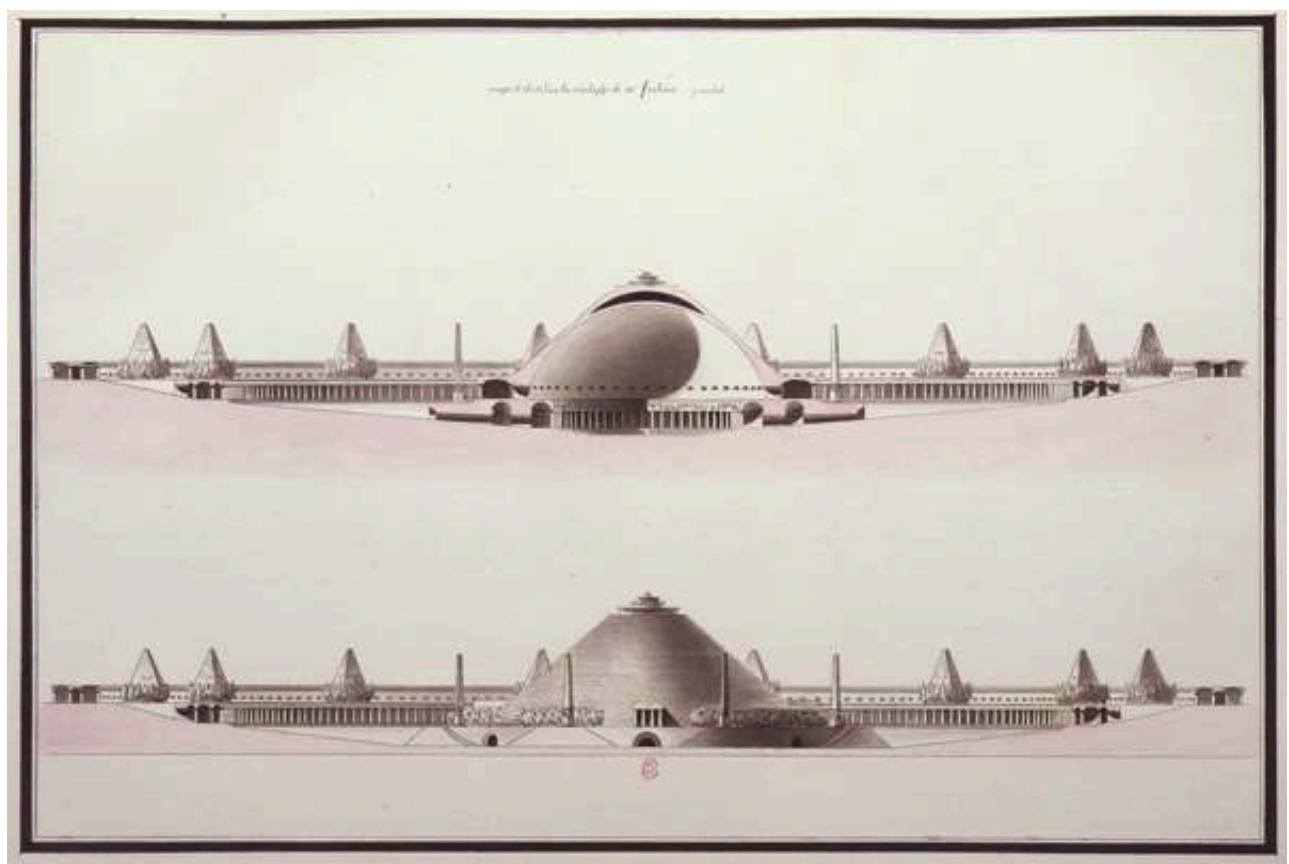

Gravure rehaussée au lavis et à l'aquarelle, dans Armand Parfait Prieur ( ? - ? ) et Pierre Louis Van Cléemputte (1792 - 1834). Collection des prix que la ci-devant Académie d'architecture proposait et couronnait tous les ans. Se vend à Paris chez Basan, Joubert et Van Cléemputte, 1787-1796, VIe cahier, pl. 4.

121 planches gravées sur cuivre imprimées sur papier de Hollande et aquarellées.

La publication de la Collection des prix de l'Académie d'architecture se décline de la simple feuille volante, au recueil relié dont les planches gravées au trait étaient imprimées sur papier de France, ou sur papier de Hollande, lorsqu'elles devaient être rehaussées de lavis ou d'aquarelle. Ce n'est qu'après l'achèvement des 80 premières planches - un peu avant que leur auteur, Armand Parfait Prieur, s'associe en mars 1790 avec Pierre Louis Van Cléemputte -, que chaque feuille reçut un numéro, correspondant à une commercialisation par cahiers de six planches. Les deux exceptionnels volumes en couleur achetés par Jacques Doucet, montrent une production artisanale et peu homogène. Les grammages des papiers et leurs filigranes attestent de l'emploi de petits lots successifs de feuilles. La qualité de la mise en couleurs varie. Le tracé des ombres au lavis témoigne d'une diversité d'interprétation, par des exécutants qui n'ont pas vu les originaux et font preuve d'une certaine fantaisie, comme dans la coupe du Cénotaphe de Fontaine. Deux filets-cadres masquent la cuvette de la plaque de cuivre, donnant l'illusion d'un original.

Le Fol Est 442 comporte un dessin original qui remplace une gravure.

Paris, Bibliothèque de l'INHA, collections Jacques Doucet, Fol. Est 442.

\section{Un tarissement éditorial de trente ans}

Antoine Laurent Thomas Vaudoyer (1756-1846) et Louis Pierre Baltard (1764-1846) continuent à graver et publier les concours de Rome et certains prix d'émulation jusqu'en $1831^{11}$. Puis la veine se tarit, et on constate un grand trou éditorial jusque dans les années 1860. Très peu de dessins d'élèves de cette période ont fait l'objet de reproductions. Seule exception, et encore est-elle rétrospective, Jean Marie Boussard (1844-1923) publiie $^{12}$, parmi de nombreux recueils d'architecture, deux volumes, édités en 1874-75 et composés de 72 planches reproduisant des dessins d'élèves dont les plus anciens remontent à 1802. Les planches, gravées à l'eau-forte, sont, pour des raisons liées à cette technique, mais aussi peut-être en raison du caractère fantasque de leur auteur, fortement interprétées. Pour les fonds notamment, le passage de l'aquarelle au trait gravé a nécessité des adaptations, d'ailleurs revendiquées dans les légendes ${ }^{13}$ (fig. 
7 et 8). Le recueil de Boussard ne semble pas avoir été très largement diffusé, trop coûteux sans doute.

7. Gabriel Auguste Ancelet (Paris 1829 - Paris 1895), Une fontaine pour l'Algérie, Concours d'émulation d'octobre 1848.

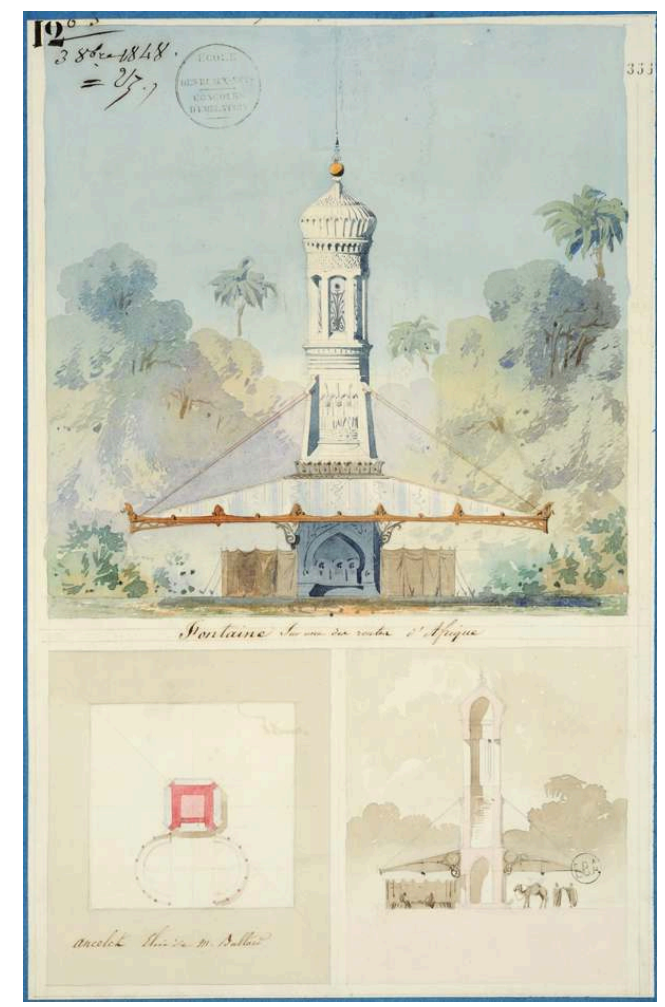

Esquisse de $1^{\text {re }}$ classe. Mine de plomb, plume et aquarelle. Montage H. 75, L. 58.

Paris, École nationale supérieure des beaux-arts, Esq. 355. 
8. Gabriel Auguste Ancelet, Une fontaine pour l'Algérie, Concours d'émulation d'octobre 1848, esquisse de $1^{\text {re }}$ classe.

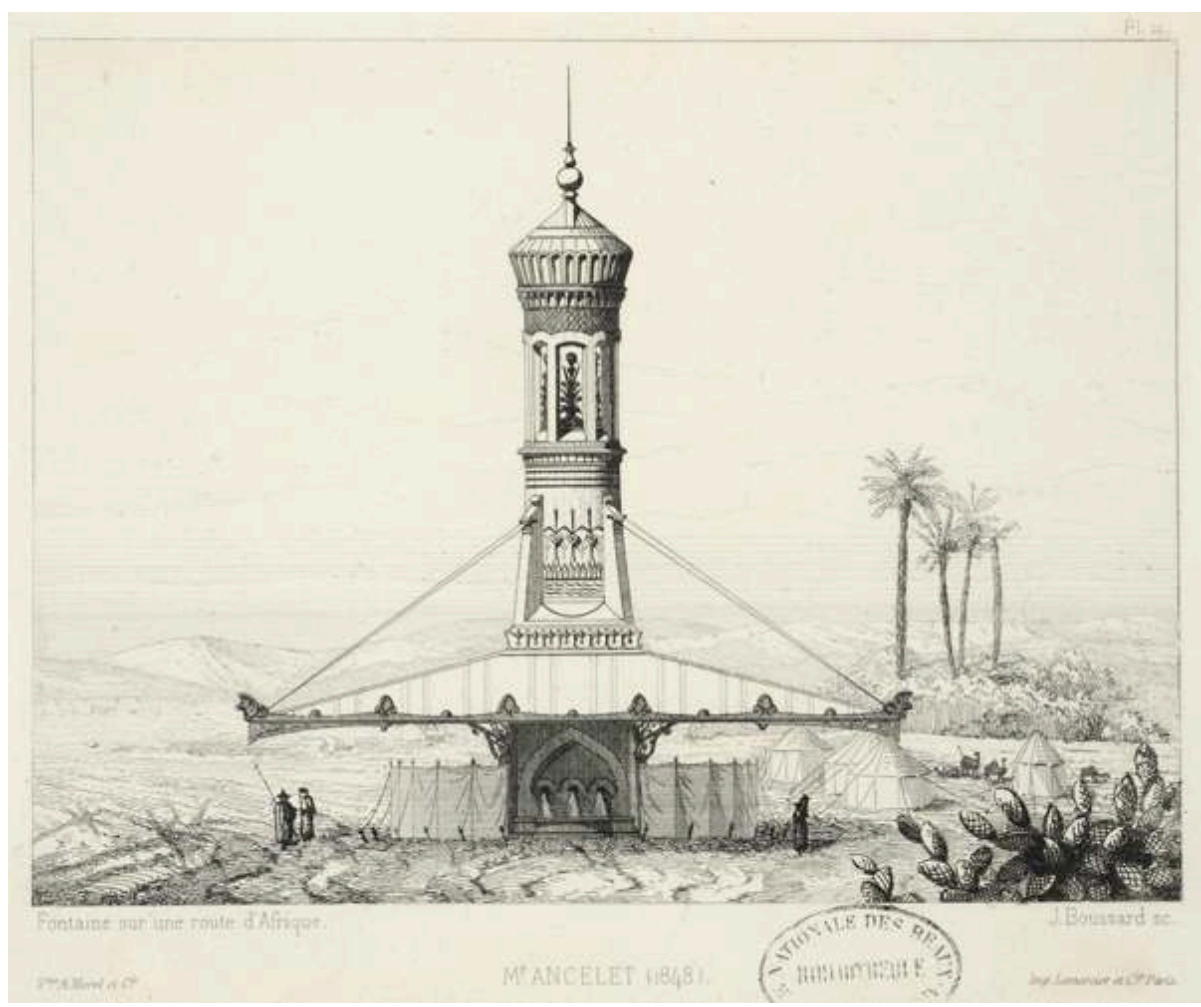

Gravure à l'eau-forte Jules Boussard, Concours de l'École des beaux-arts. Paris, Morel, 1874-1875, vol. 1, pl. XII.

Au moment où Jean Marie Boussard publia ce recueil gravé à l'eau-forte, l'édition architecturale avait opté depuis une trentaine d'années pour la gravure sur acier, dont le trait précis et fin se prêtait bien à la reproduction du dessin d'architecture et dont la solidité de la plaque permettait des tirages importants. Ce choix s'explique donc par un souci d'ordre artistique. Le procédé ancien offrait plus de contraste que la gravure sur acier, grise et uniforme. Il était particulièrement approprié pour le rendu du paysage, qui a fait ici l'objet d'une attention particulière. Boussard précise dans sa légende que : "les fonds ont été entièrement refaits ».

Paris, bibliothèque de l'École nationale supérieure des beaux-arts, 00547 D 0000 BIS 4

8 La question du coût éditorial peut être avancée pour expliquer ces trente années detarissement de l'édition des dessins de l'École des beaux-arts. Mais on peut tenter une autre hypothèse : les énormes projets de la première moitié du XIX ${ }^{e}$ siècle, pompeux et lourdement chargés d'allusions antiques, ont peut-être fini par lasser le lectorat. On voit émerger une presse périodique spécialisée dans les années 1840, avec la Revue générale de l'architecture et des travaux publics, et le Moniteur des architectes. Ces deux revues commentent les concours organisés par l'École et l'Académie des beaux-arts, mais sans illustration et souvent sur un ton critique. Pour la première, publiée par César Daly, la modernité est ailleurs, dans la production bâtie, comme les deux bibliothèques construites par Henri Labrouste, - Labrouste dont les succès comme patron d'atelier ont été plus que limités, au point qu'il a fini par abandonner celui-ci en 1855. 


\section{Reprise sous le Second Empire}

9 Mais, dans les années 1860, un chantier parisien bouleverse la routine de l'École. Le nouvel Opéra de Paris, monument phare de la Ville-Lumière, dont la reconstruction était attendue avec une impatience grandissante depuis la destruction de la salle Louvois, consécutive à l'assassinat du duc de Berry en 1820, émerge enfin de terre. La nouvelle salle, découverte par le public en 1863 sous la forme d'une énorme maquette de plâtre, voit sa façade libérée des échafaudages qui la masquaient à l'occasion de l'Exposition universelle de 1867. Charles Garnier a attiré dans son agence les plus brillants dessinateurs de l'École. Gavés de références archéologiques, les élèves découvrent à travers son œuvre une nouvelle manière, beaucoup plus libre, de concevoir un projet, en jonglant avec les emprunts divers et les échelles. Mais ils ont plus que jamais besoin de références pour nourrir leur créativité.

C'est dans cette même décennie que la bibliothèque de l'École des beaux-arts s'organise enfin, avec la nomination, le 17 décembre 1862, d'un bibliothécaire, Ernest Vinet (1804-1878). Elle ouvre ses portes le 25 janvier $1864^{14}$. Deux ans plus tard, un groupe d'élèves de l'atelier de Charles Questel, parmi lesquels François Roux, Gaspard André, Eugène Chenantais et surtout Gustave Raulin (1837-1910), se constitue en janvier 1866 sous le nom d'Intime Club, et lance au mois de mai suivant une publication mensuelle intitulée Croquis d'architecture, constituée de six feuilles in-plano autographiées directement par les auteurs des dessins originaux ${ }^{15}$ (fig. 9). Imprimée à coût minimal, cette revue, dont l'ambition est de faire connaître les meilleurs projets réalisés dans le cadre des concours théoriques de l'École des beaux-arts, remporte un vif succès. Elle élargit très vite son champ d'activités au suivi des concours publics d'architecture, alors nombreux. Elle aura une durée de vie d'une trentaine d'années, cessant de paraître à la fin du siècle. 
9. Gustave Raulin (Paris 1837 - Paris 1910), Frontispice dans Croquis d'architecture, Intime-Club, $1^{\text {re }}$ année, $\mathrm{n}^{\circ} 1, \mathrm{~F}^{\circ} 1$, mai 1866 .

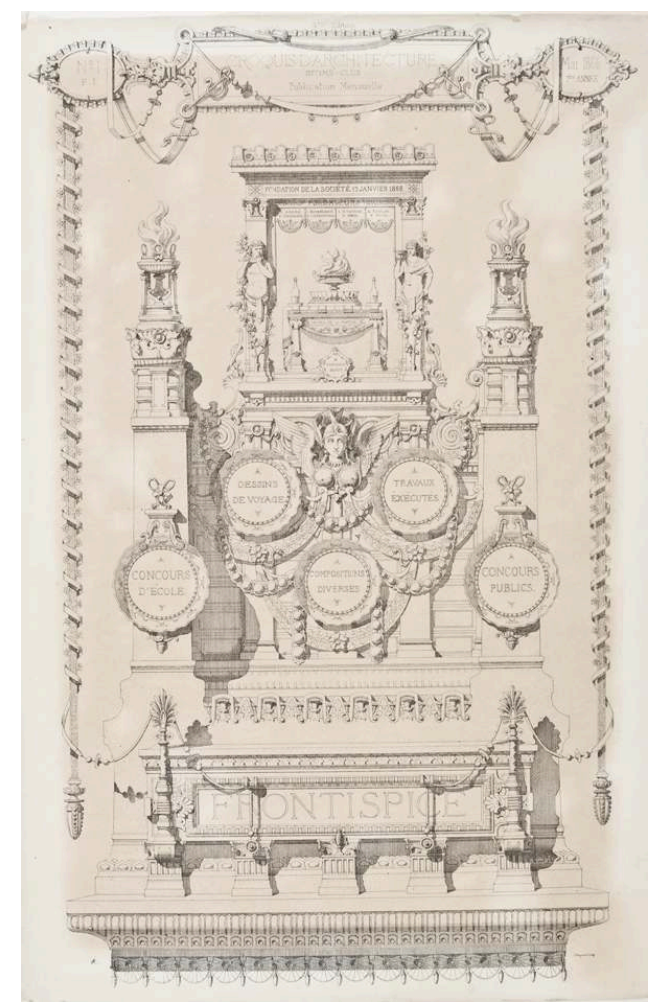

Périodique mensuel édité par les élèves de l'atelier Questel. Autographié

H. 0,56 ; L. 0,375.

C'est sous ce nom qu'un groupe de huit élèves de l'atelier Questel se constitue en société, en janvier 1866. Quelques mois plus tard, il fonde une revue mensuelle intitulée Croquis d'architecture. Par souci d'économie et de simplicité, elle utilise l'autographie, procédé d'impression dans lequel les dessins sont tracés directement par leurs auteurs sur un papier spécial à l'aide d'une encre grasse dite encre autographique, puis transposés sur la pierre lithographique. L'image imprimée est identique au tracé original, et non pas retournée comme dans la gravure traditionnelle. Elle n'exige donc aucune technicité particulière et permet des tirages rapides et peu coûteux. Son inconvénient tient au nombre limité de tirages et à son manque de précision.

Tradition oblige, la revue ouvre par un frontispice, dessiné par Gustave Raulin, et chaque livraison et constituée de six feuilles.

Paris, Bibliothèque du musée d'Orsay.

\section{La photographie, copie fidèle}

11 C'est aussi au printemps 1866 qu'apparaissent les premières demandes faites à la bibliothèque de l'École des beaux-arts d'emprunter, pour les photographier, les dessins primés et déposés par obligation à la bibliothèque ${ }^{16}$. Il a pu cependant exister déjà quelques initiatives isolées. Ainsi, l'élève architecte Ambroise Baudry (1838-1906), qui travaille depuis 1861 à l'agence des travaux du nouvel Opéra de Paris, tout en poursuivant ses études à l'École, commande au photographe Louis Émile Durandelle (1839-1917), qui fait le suivi du chantier de l'Opéra depuis 1863, une photographie de son dessin récompensé par le $1^{\mathrm{er}}$ Prix Rougevin en $1864^{17}$ (fig. 10 et 11 ). 
10. Ambroise Baudry (La Roche-sur-Yon 1838 - Paris 1906), Une cheminée dans une galerie, ${ }^{\text {er }}$ Prix Rougevin 1864.

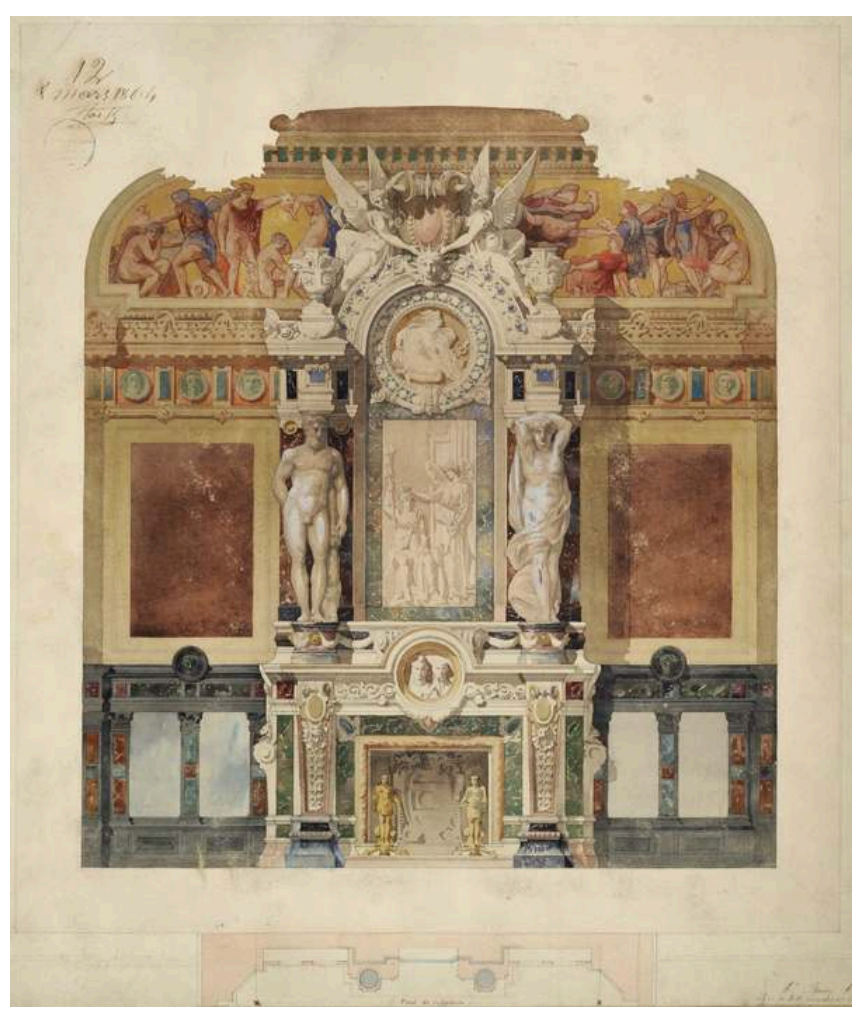

Mine de plomb, plume et encre noire, et aquarelle. H. 65, L. 58 .

Paris, École nationale supérieure des beaux-arts, Rou 15. 
11. Ambroise Baudry (La Roche-sur-Yon 1838 - Paris 1906), Une cheminée dans une galerie, ${ }^{\text {er }}$ Prix Rougevin 1864.

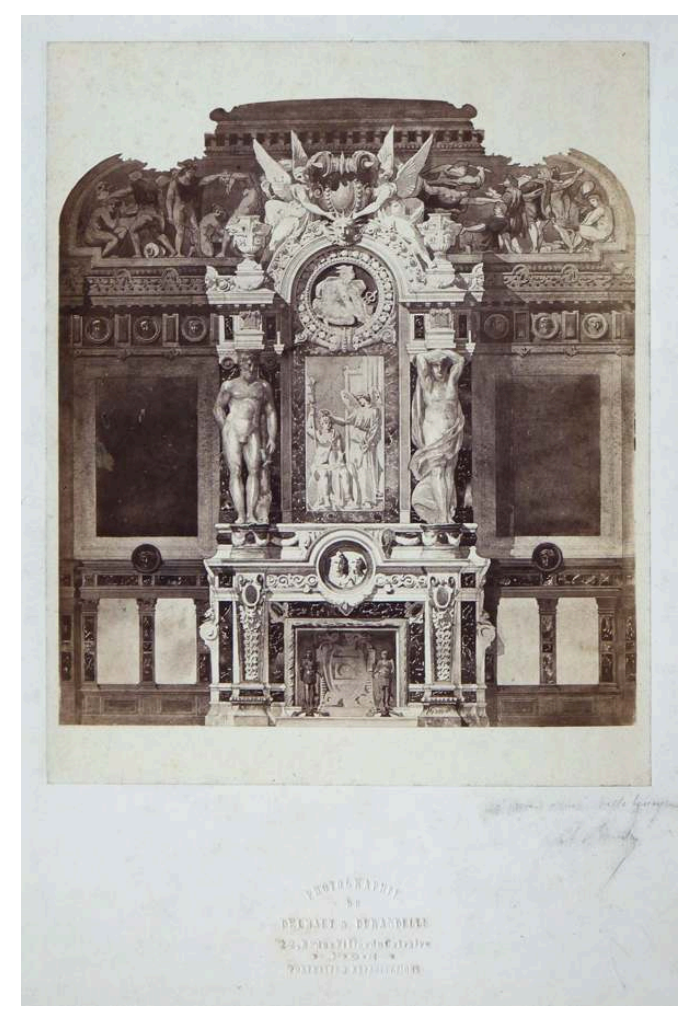

Reproduction photographique (tirage albuminé) par Louis Émile Durandelle (timbre sec Delmaet et Durandelle sur le montage), portant une dédicace d'Ambroise Baudry.

H. 22,2, L. 18 (épreuve), H. 40, L. 31,5 (montage).

Paris, collection particulière.

12 Les demandes d'autorisation de photographier se multiplient dans les années 1870-1880 : un photographe du nom de Pierre Jean Philippe Lampué (1836-1924) se fait même une spécialité de la reproduction photographique des dessins d'élèves (fig. 12). 
12. Ambroise Baudry (La Roche-sur-Yon 1838 - Paris 1906), Une cheminée dans une galerie, $1^{\text {er }}$ Prix Rougevin 1864.

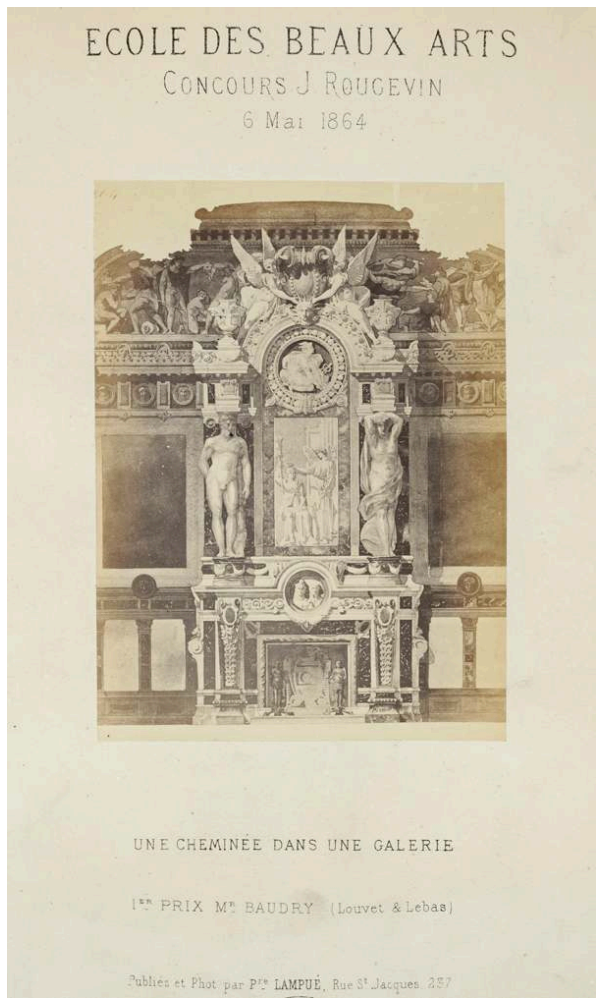

Photographie (tirage albuminé), Prix Rougevin, album de photographies de Pierre Jean Philippe Lampué (1836-1924), pl. XIII.

Dès les années 1860, la photographie devient un moyen commode de reproduction des dessins d'architecture. À la fois rapide d'exécution et parfaitement exacte, elle avait néanmoins l'inconvénient de ne pouvoir rendre la couleur et de ne pas permettre la production rapide d'un grand nombre d'épreuves. Ce procédé qui consistait à réaliser des tirages albuminés à partir de négatifs verre au collodion, puis à les monter sur des feuillets cartonnés, ne pouvait pas être automatisé. Les exemplaires de ce type de recueils sont donc peu nombreux.

Paris, Bibliothèque de l'École nationale supérieure des beaux-arts, 00547 D 0029.

Désormais, ceux-ci sont reproduits avec fidélité, sans se prêter à la moindre interprétation du graveur. Et cela ne concerne pas uniquement les meilleurs projets déposés à la bibliothèque de l'École : les élèves peuvent grâce à la photographie conserver une copie fidèle de leurs dessins, ce qu'ils font pour eux-mêmes, mais aussi pour présenter leurs travaux sous forme de reproductions dans des salons, ou, plus souvent, offrir un cliché dédicacé à leurs amis. Dans les années 1890, des éditeurs comme Laurent Farge ou Armand Guérinet ${ }^{18}$, s'emparent de ces images et les éditent en héliotypie dans de grands in $-4^{\circ}$ regroupant les meilleurs dessins de chaque année scolaire. Mais c'est finalement un troisième éditeur, Auguste Vincent, qui s'installe en 1906 dans un local jouxtant l'École, au 4, rue des Beaux-arts, et s'impose en publiant des recueils de plus petit format, imprimés à moindre prix sur du papier de qualité moyenne ${ }^{19}$. Ces images fourniront à des générations d'élèves des modèles à reproduire pour leurs propres créations. La photographie, qui est désormais fidèle à l'original, même si elle n'en rend pas les couleurs, entraîne un glissement progressif vers un rendu plus pictural que dessiné, et qui touchera à l'excès avec Fernand Janin (1880-1912) et son Grand Prix de 1910, qui fut critiqué pour son trop grand pittoresque, écho tardif de la sanction qui avait frappé Fontaine en $1785^{20}$. 


\section{La bibliothèque d'atelier, réservoir à « tubards »}

14 l'architecture de l'antiquité gréco-romaine et de la France classique, les manuels pour tracer les ordres d'architecture et les ouvrages de théorie de Julien Guadet et Georges Gromort, l'essentiel des livres réunis dans chaque atelier à l'usage des élèves. Ils y sont aussi les plus utilisés, si l'on en juge par les planches manquantes, les taches d'encre qui les maculent et les morceaux de calque qui s'y sont glissés ${ }^{21}$. Ces fonds d'atelier, qui contiennent souvent des trésors accumulés au fil des transmissions d'un chef d'atelier à l'autre ${ }^{22}$, ne sont pourtant guère consultés, et encore moins respectés, par les élèves, qui n'y voient que des réservoirs à "tubards ", ou poncifs à copier. Les publications contemporaines n'y sont pas toujours les bienvenues, au moins dans certains ateliers, si l'on se réfère à l'anecdote bien connue des élèves obligés de claquer la porte de l'atelier de Charles Lemaresquier (1870-1972) en 1923, pour avoir fait circuler sous les tables l'ouvrage de Le Corbusier, Vers une architecture, acte fondateur de l'atelier du Palais de Bois d'Auguste Perret (1874-1954). Et la petite bibliothèque, souvent reléguée dans un local attenant à l'atelier, sert souvent plus de salon de repos et de conversation que de lieu de travail.

\section{« Ne soyez donc pas seulement livresques »}

Le petit format des images facilite aussi leur introduction frauduleuse dans les loges à l'occasion des concours, notamment d'admission. Un ancien élève de Victor Laloux, Gaston Lafore (1870-?), dénonce sans succès au secrétaire d'État aux Beaux-Arts, en 1910, cette tricherie qui favorise la copie au détriment de la créativitée ${ }^{3}$. Des patrons d'atelier, comme Emmanuel Pontremoli (1865-1956), encouragent, mais bien mollement, leurs pupilles à préférer aux livres l'observation directe des œuvres d'architecture ${ }^{24}$. En se réjouissant avec complaisance des publications de Vincent, la direction de l'École porte celle-ci à s'auto-reproduire, sans chercher à se renouveler. Ce laisser-faire porte les prémices d'une mort annoncée, qui s'exprimera notamment par le rejet des livres chez les élèves de l'École en 1968.

\section{NOTES}

1. Ces planches seront par la suite regroupées en 20 cahiers de 6 planches (sauf le 18 qui en renferme 7), soit un total de 121 feuilles reproduisant des projets de Grands Prix, mais aussi des concours mensuels, entre 1774 et 1789 : Armand Parfait Prieur et Pierre Louis Van Cléemputte, Collection des prix que la ci-devant Académie d'architecture proposait et couronnait tous les ans, Paris, 1787-1796. Les six premières planches ont été présentées par Prieur à l'Académie lors de sa séance du 8 juillet 1787 . 
2. Henry Lemonnier, Procès-verbaux de l'Académie royale d'architecture, 1671-1793, publiés pour la Société de l'histoire de l'art français sous les auspices de l'Institut. Paris, Jean Schemit-Armand Colin, 1911-1926, t. IX, p. 35, 36, 41, cité par Jean-Marie Pérouse de Montclos, "Les Prix de Rome », concours de l'Académie royale d'architecture au XVIII siècle. Paris, Berger-Levrault / École nationale supérieure des beaux-arts, 1984, p. 12.

3. Fontaine est élève de Peyre le Jeune, et Boullée n'enseigne pas à l'Académie, mais il intervient dans la rédaction des programmes. Fontaine a cherché à lui plaire.

4. Buchotte, Ingénieur ordinaire du Roy, Les Règles du dessein et du lavis, pour les Plans [...], tant de l'Architecture Militaire que Civile, Paris, Claude Jombert, 1722. Les conventions de mise en couleur des plans sont différentes dans l'architecture militaire et civile.

5. Comme il paraît plus esthétique de présenter un cadran de montre aux aiguilles orientées sur 10 heures et 10 minutes. Selon Charles Normand (1765-1840), Grand Prix 1792 (Méthode abrégée du tracé des ombres dans l'Architecture à l'usage des élèves de cet art, Paris, l'auteur, 1827) : «Ce fut dans le siècle dernier que les Élèves de l'académie d'architecture en offrirent les premiers exemples dans leurs projets destinés aux concours ». Cette affirmation est à relativiser si l'on s'en réfère à Buchotte : dans sa $1^{\text {re }}$ édition, en 1722, il remarque qu'il est «toujours mieux \& de meilleur goût dans tous les Desseins, de faire venir le jour à gauche plutôt qu'à droite » - une affaire de droitiers -, et dans la seconde, en 1743, il « suppose que le corps lumineux est élevé à 45 degrés au-dessus de l'horizon ".

6. La page de titre précise que les gravures sont imprimées « sur papier propre à être lavé ».

7. Jean-Philippe Garric a étudié ces problèmes de diffusion : «La Diffusion des livres d'architecture français au début du xix ${ }^{\mathrm{e}}$ siècle, à travers les listes de souscripteurs ", in Olga Medvedkova (dir.), Bibliothèques d'architecture, Paris, INHA / Alain Baudry et Cie 2009 , p. 83-94 ; «Palais, maisons et autres édifices modernes de Percier et Fontaine : mode de production et forme d'un archétype ", in Daniel Rabreau et Dominique Massounie (dir.), Claude Nicolas Ledoux et le livre d'architecture en français, les écrits sur la ville, les programmes et la nature de l'architecture, Paris, Éd. du Patrimoine, 2006, p. 176-183.

8. Guillaume Édouard Allais, Athanase Détournelle et Antoine Laurent Thomas Vaudoyer, Projets d'architecture et autres productions de cet art qui ont mérité les grands prix accordés par l'Académie, par l'Institut national de France et par des jurys du choix des artistes et du gouvernement, Paris, chez Détournelle, 1806.

9. Propositions de souscription au consul Cambacérès et au président de l'Académie, minutes manuscrites de courriers (coll. part.).

10. Jean-Philippe Garric, «Nouveaux programmes pour un empire futur : François Léonard Séheult, élève de Peyre le jeune en l'an IV », in Daniel Rabreau et Letizia Tedeschi (dir.), L'architecture de l'Empire entre France et Italie. Institutions, pratiques professionnelles, questions culturelles et stylistiques (1795-1815), Mendrisio, Mendrisio-Academy Press-Silvana, 2011, p. 3-14.

11. Antoine Laurent Thomas Vaudoyer et Louis Pierre Baltard, Grands prix d'architecture, projets couronnés par l'Académie royale des beaux-arts de France, 2 vol., Paris, 1818 et 1834 . Ces deux ouvrages, vendus par livraisons de 6 planches chacune, complètent la série entamée par Prieur et poursuivie par Détournelle, constituant un total de 4 volumes de 120 planches chacun.

12. Auteur de curieuses constructions aux façades compliquées ornées de statues-colonnes inspirées des hôtels du XVII ${ }^{\mathrm{e}}$ siècle à Dijon, comme la maison dite des Cariatides.

13. L'éditeur précise, à propos du dessin d'Ancelet reproduit dans son ouvrage : « Les fonds ont été entièrement refaits ".

14. Elle est l'exacte contemporaine de la bibliothèque de l'Union centrale des beaux-arts appliqués à l'industrie (Bibliothèque des Arts décoratifs), ouverte aussi en 1864. primitivement installée place des Vosges, cette dernière s'adressait surtout aux artisans. 
15. Cette initiative d'atelier a connu un précédent utilisant une technique proche : il existe un rare recueil de planches lithographiées par les élèves de l'atelier d'Achille Leclère : Recueil d'architecture, lithographié en l'année 1826 par [...], anciens élèves de M. Achille Leclère.

16. La toute première demande d'autorisation de photographier émane de Louis Boitte (1830-1906), et date du 6 avril 1866 (Archives nationale de France, AJ52 819, École des beaux-arts, bibliothèque et collections, demandes d'autorisation de photographies, 1866-1902). Elle concerne son envoi de Rome, ou plutôt d'Athènes.

17. Il est logique que Baudry ait fait appel au photographe de l'Opéra pour son propre usage. Il a fait aussi photographier par Durandelle ses relevés archéologiques du site de Troesmis (Valachie) en 1865. Intime avec son frère le peintre Paul Baudry (1828-1886) du couple Garnier, le jeune Ambroise a dédicacé à son maître et ami deux de ces clichés. Ces photos font partie du fonds Garnier donné à l'École des beaux-arts par sa veuve en 1903. On y trouve aussi onze reproductions photographiques de la restitution de l'Acropole d'Athènes de Louis Boitte, également dues à Durandelle et marquées d'une dédicace de Boitte à Garnier (voir l'article de Stéphanie Guilmeau-Shala, § 9, http://inha.revues.org/3194).

18. L. Farge, Les Concours d'école, Section d'architecture de l'École nationale des beaux-arts. Paris, Lib.Imp. Réunies. $1^{\text {re }}$ et $2^{\mathrm{e}}$ années, 1899-1900, et 1901-1902; Les Médailles des concours d'architecture, $1^{\text {re }}$ année, 1898-99 à 15e année, 1912-1913. Paris, Armand Guérinet.

19. École des beaux-arts, Les Concours d'architecture de l'année scolaire, 1906-07 (1 ${ }^{\text {re }}$ année) à 1966-67 (dernière année), Paris, A. Vincent.

20. À noter que Janin a refusé de communiquer un cliché de son Grand Prix à La Construction moderne, estimant que le caractère monochrome de la photographie trahissait son œuvre.

21. Noémie Lesquins, "La Bibliothèque de l'atelier Pontremoli : fragments d'histoire de bibliothèques des ateliers d'architecture de l'École des beaux-arts ", in Le Livre d'architecture, $X V^{e}$ $X X^{e}$ siècle, édition, représentation et bibliothèques, Paris, École des Chartes, 2002, p. 199-245 ; Béatrice Gaillard et Jörn Garleff, « Les Bibliothèques d'ateliers des Beaux-Arts à Versailles redécouvertes », eaV, $\mathrm{N}^{\circ} 14,2008-2009$, p. 22-43.

22. Certains ouvrages remontent au XVIII ${ }^{\mathrm{e}}$ voire au XVII ${ }^{\mathrm{e}}$ siècle.

23. La copie de sa lettre au sous-secrétaire d'État aux beaux-arts et la réponse du directeur de l'École des beaux-arts sont insérées dans son dossier d'élève (Archives nationales de France, AJ52 395).

24. Emmanuel Pontremoli, Propos d'un solitaire, Vanves, imp. Kapp, 1959, p. 23 : « Ne soyez donc pas seulement livresques » (cité par N. Lesquins, op. cit. note 52). 


\title{
Architecture et construction dans les cours de l'École centrale des arts et manufactures (1833-1864) et du Conservatoire national des arts et métiers (1854-1894)
}

\author{
Valérie Nègre
}

1 L'architecture doit-elle s'enseigner comme un art? Comme une science? Comme une technique ? Le génie s'enseigne $\mathrm{t}$-il ? Et comment le transmettre à des ingénieurs et des entrepreneurs? L'examen des deux cours de «constructions civiles » créés à Paris, à l'École centrale des arts et manufactures (1829) et au Conservatoire national des arts et métiers (1854), offrent quelques éléments de réflexion pour penser ces questions qui hantent encore aujourd'hui l'enseignement de l'architecture. Les choix pédagogiques adoptés dans ces deux institutions par rapport à une discipline hybride, partagée, comme le soulignait Quatremère de Quincy, entre «les lois du besoin \& celles du plaisir », formée de " deux natures en quelque sorte ennemies, ou du moins sans union, ni rapport direct qui les lient »invitent à s'interroger sur la séparation souvent fixée entre deux domaines, la construction d'une part, enseignée comme une science, et l'architecture de l'autre, transmise comme une discipline à la fois intellectuelle et pratique $^{1}$.

2 Comme la plupart des cours de construction donnés dans les écoles ne possédant pas d'enseignements autonomes de l'architecture, le premier parti de ces deux cours était de lier composition architecturale (programmes et disposition des édifices) et construction (matériaux et techniques de mise en œuvre). Le cours de «Constructions civiles » du Conservatoire des arts et métiers professé par le futur fondateur de l'École spéciale d'architecture, Émile Trélat (1821-1907), avait clairement pour objectif de "guider en les unissant» les deux professions d'architecte et d'ingénieur ; combler les lacunes dont souffraient les élèves architectes dans la « connaissance des nombreux et récents progrès apportés dans les moyens de la construction " et montrer aux 
ingénieurs qu'ils avaient à tort "abandonné les satisfactions spirituelles de leur mission en rejetant, comme futiles et gratuites [...] la décoration et l'ornementation ${ }^{2}{ }$. Pour le cours de «Constructions civiles » de l'École centrale dispensé par Louis Charles Mary (1791-1870), les élèves devaient aussi bien réaliser «un projet complet de chauffage pour un édifice public » qu'un «projet complet d'architecture ${ }^{3}$ ». Comment concrètement se répartissaient ces domaines (composition et construction)? Sur quels modèles ces ingénieurs avaient-ils construit leur enseignement?

3 Le deuxième parti consistait à accorder une place déterminante à la pratique. Les cours de « Sciences appliquées aux arts » du Conservatoire national des arts et métiers, libres, gratuits, professés le soir, parce qu'ouverts à la "classe laborieuse », se voulaient essentiellement pratiques". Pour le cours de « Géométrie descriptive » dispensé à partir de 1819, suivi en majorité par des tailleurs de pierre, des conducteurs de travaux, des commis, des dessinateurs et des "élèves architectes ", Jules Maillard de la Gournerie se proposait de rapidement « laisser de côté la géométrie descriptive » et d'expliquer les tracés concrets de coupe des pierres et des bois ${ }^{5}$. Il défendait la "méthode pratique » pour la perspective, celle qui est « la plus facile et la moins longue » : la méthode des points de concours pour la perspective conique et la perspective cavalière ou axonométrie, injustement rejetée, selon lui, à l'École polytechnique par Monge, alors qu'elle offrait l'avantage de «s'établir facilement » et « d'être accompagnée d'une échelle ${ }^{6}$ ».

4 L'École centrale, fondée en 1829, affichait également, au départ, une orientation pratique. Son objectif était de former des ingénieurs destinés au secteur privé, par opposition aux ingénieurs d'État qui exerçaient dans des corps (ponts et chaussées, génie, mines), mais aussi des architectes et des entrepreneurs : "comme les élèves sortant de l'École n'ont pas de corps spéciaux qui puissent leur servir de tuteur, pouvait-on lire dans le programme du cours de construction de 1830, il fallait leur donner autant que possible la connaissance des affaires ; les nourrir d'idées économiques ; leur enseigner le grand art d'ordonner les travaux, de former et de diriger les ouvriers ${ }^{7}$ ». Dans le débat ouvert à l'occasion de la création de l'École polytechnique, sur la part du théorique et du pratique dans l'enseignement de la technologie, les deux établissements avaient ainsi pris parti. Les savoirs véhiculés dans le cours de construction étaient peu mathématisés et ouverts à des questions économiques et sociales. Mais comment enseigner la pratique? Quelles méthodes pédagogiques correspondaient à cet objectif? Quel rapport les enseignements théoriques (cours magistraux) tissaient-ils avec les travaux graphiques, les «manipulations », les « démonstrations » et les visites?

\section{Composition / construction}

\section{Le cours de "Constructions civiles » de Louis Charles Mary (1833-1864).}

5 On connaît le cours de "Constructions civiles $^{8}$ " donné par le polytechnicien et ingénieur des Ponts et chaussées Louis Charles Mary grâce à deux documents lithographiés (un Cours d'architecture et un atlas lithographiép) et des carnets de notes prises par les élèves. Ces documents montrent que ce cours dispensé aux élèves de deuxième année mêlait composition (18 cours) et construction (22 cours). De manière traditionnelle, la théorie de la composition était divisée en deux parties; la première 
(«Principes fondamentaux de l'architecture ») exposait des principes « applicables à la cabane comme au palais »; la deuxième ("Examen de divers édifices») analysait des exemples. Le cours n'avait pas l'ambition de proposer une théorie du projet spécifiquement adapté aux ingénieurs civils, il combinait des parties empruntées à différents cours d'architecture et de construction donnés à l'École polytechnique et à l'École des ponts et chaussées ${ }^{10}$.

Les « Principes fondamentaux de l'architecture » (7 cours) étaient ainsi un résumé du cours d'architecture (1795 -1834) de Jean Nicolas Louis Durand que Mary avait luimême suivi à l'École polytechnique. Le cours débutait avec les "éléments des édifices " (4 cours) puis abordait les « combinaison des éléments des édifices » (3 cours). Les six premières planches de l'atlas témoignent de ce travail de réduction du cours de Durand; elles reproduisent, soit à l'identique, soit en les combinant, les planches du Précis des Leçons d'architecture données à l'École polytechnique (1802-1805) (fig. 1).

1. Louis Charles Mary (1791 - 1870), "Combinaison de piliers, de colonnes, de contreforts et de combles ", [Cours d'architecture], s.I. [Paris], s.n. [École centrale des arts et manufactures], s.d. [c. 1834].

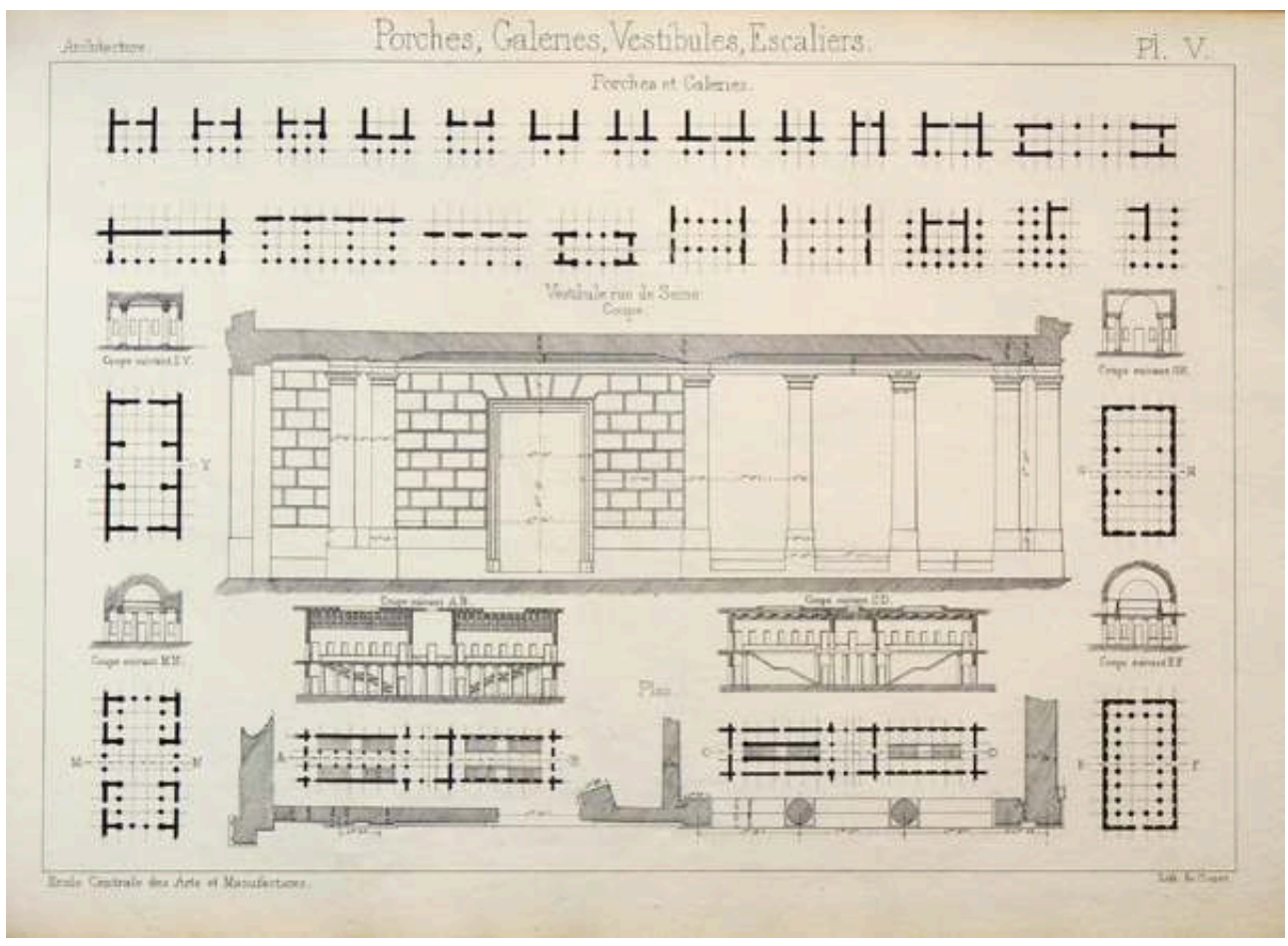

Atlas lithographié, pl. V.

La planche combine des éléments empruntés aux planches IX, XI et XII de la $2^{\mathrm{e}}$ partie du

Précis des leçons d'architecture de Durand.

Album oblong de 50 planches lithographiées numérotées I à L.

H. 30, L. 45.

II s'agit de l'atlas accompagnant le Cours d'architecture (voir fig. 2).

Louis Charles Mary voulait diffuser ce recueil destiné aux élèves, dans le commerce, mais le Conseil des études de l'École centrale s'y opposa en mars 1837. L'atlas connut plusieurs impressions, les noms des lithographes variant selon les exemplaires, mais le contenu restant identique. Les planches reproduisent des dessins extraits de publications et de cours d'architecture et de construction. Les emprunts les plus nombreux sont faits au Précis des leçons d'architecture (1809) de Jean Nicolas Louis Durand (6 planches), aux Études relatives à l'art des constructions (1822-28) de Louis Bruyère (9 planches) et au Traité théorique et pratique de l'art de bâtir de Jean Rondelet (1802-1817)

Châtenay-Malabry, Bibliothèque de l'École centrale 3388. 
7 Le «travail de la composition" s'effectuait par étapes en commençant par un «croquis» exécuté sur papier quadrillé; après avoir déterminé les surfaces nécessaires, l'entre-axe des murs, la « combinaison » des corps de bâtiments (fig. 2), on passait à l'étude détaillée ${ }^{11}$.

2. Sur la page de gauche, Louis Charles Mary $(1791-1870)$, «Principales combinaisons que l'on peut faire avec des bâtiments droits ou circulaires", Cours d'architecture, s.I. [Paris], École centrale des arts et manufactures, 1840-41.

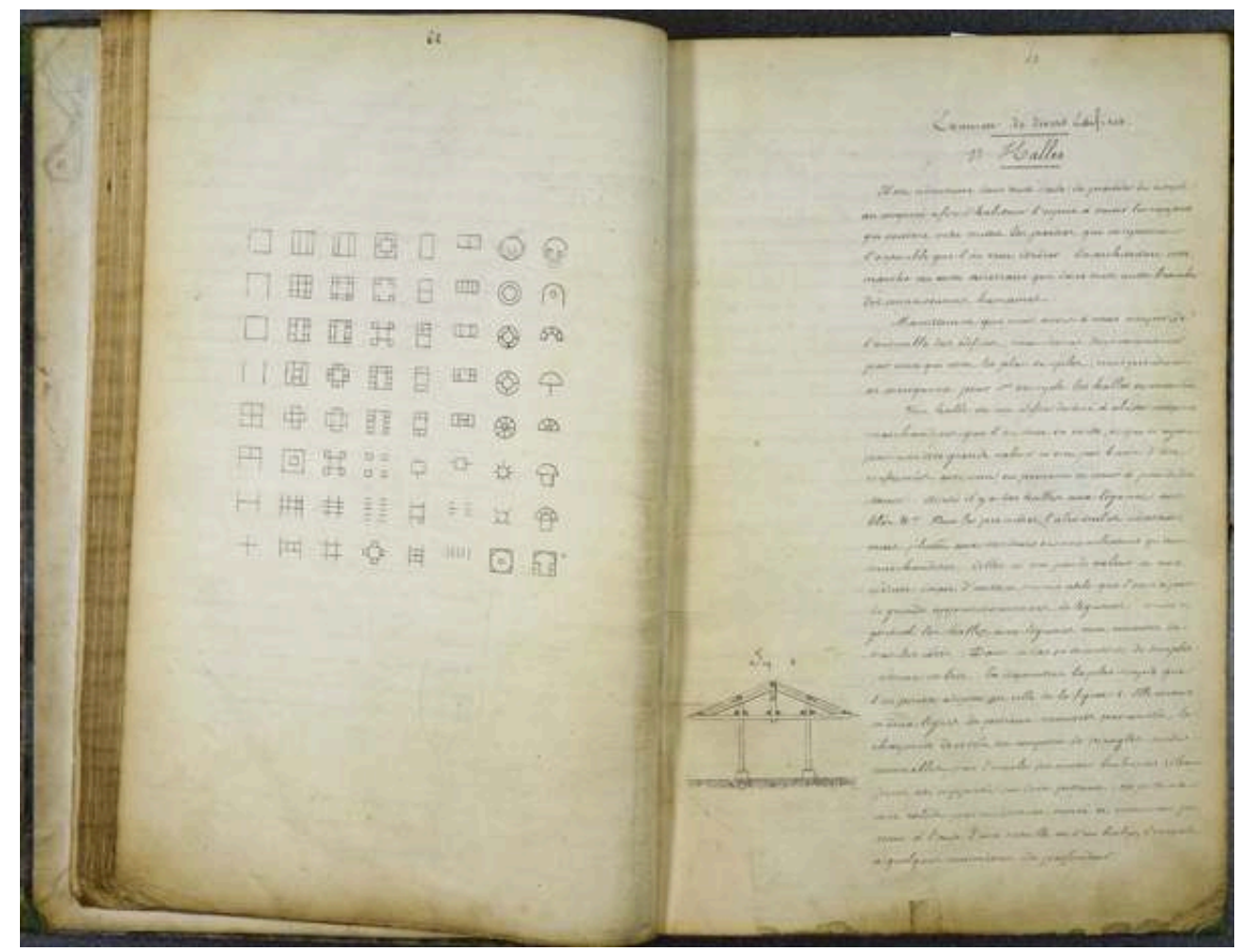

Lithographie de Clouet, p. 62-63.

371 pages lithographiés avec de nombreuses figures dans les marges.

H. $34 \times$ L. 23,5.

Quatre impressions du cours lithographié sont connues : 1834-35, 1840-41 ; 1844-45 ; 1852-53.

Elles correspondent à deux versions réalisées de façon manuscrite par des élèves de l'École

centrale, à partir des notes de Mary et à la demande du Conseil des études. De l'une à l'autre, Mary

introduit des changements qui ne concernent cependant que la partie sur les matériaux et les

techniques de mise en œuvre. La partie consacrée aux "Principes fondamentaux de l'architecture " est un résumé du Précis des leçons d'architecture (1802-1805) de Jean Nicolas Louis Durand.

Châtenay-Malabry, Bibliothèque de l'École centrale. 3383.

8 La deuxième partie consacrée à l'« Examen de divers édifices » (11 cours), s'inspirait en revanche des cours de "Construction» et d'« Architecture» de l'École des ponts et chaussées. Les édifices étaient bien classés par programme, comme dans le cours de Durand, mais les modèles abstraits étaient remplacés par des exemples réels, récemment construits pour la plupart, et ordonnés «du simple au composé » (marchés, entrepôts, forges, abattoirs, hôpitaux, bains publics, filatures, salles de spectacles, édifices particuliers). Les planches de l'atlas témoignent à nouveau de ces emprunts : neuf planches sont directement copiées sur les études relatives à l'art des constructions (1822-28) du professeur du cours de "Construction » de l'École des ponts et chaussée, Louis Bruyère ${ }^{12}$. Mary présente également le projet de maison particulière 
que Charles François Mandar avait lithographié en 1818 pour son cours d'« Architecture » de l'École des ponts et chaussées ${ }^{13}$ (fig. 3).

3. Louis Charles Mary (1791 - 1870), Projet de maison particulière d'après Mandar, Cours d'architecture, s.I. [Paris], École centrale des arts et manufactures, 1840-1841.

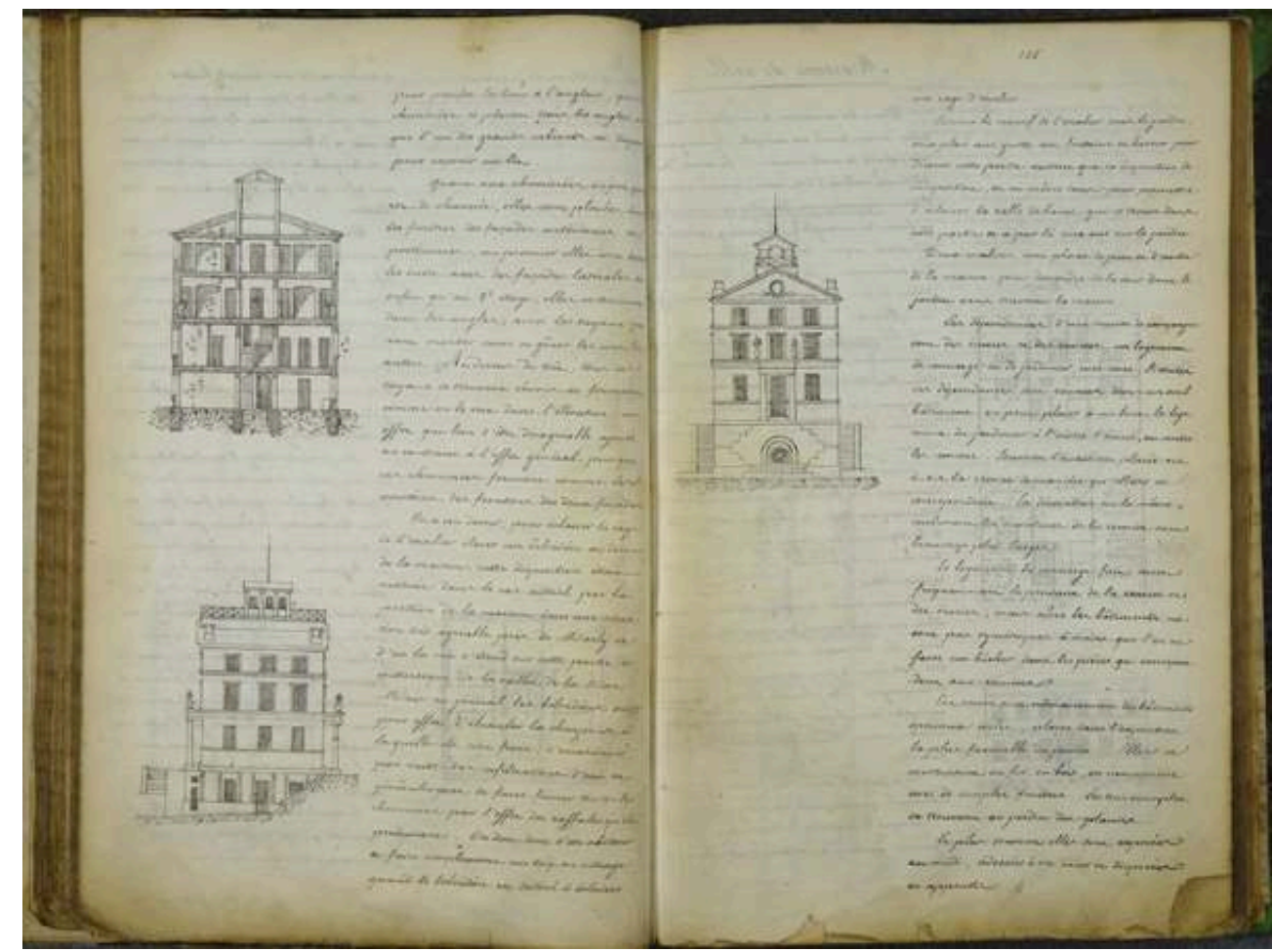

Lithographie de Clouet, p. 134-135.

371 pages lithographiés avec de nombreuses figures dans les marges.

H. $34 \times$ L. 23,5.

Quatre impressions du cours lithographié sont connues : 1834-35, 1840-41; 1844-45; 1852-53.

Elles correspondent à deux versions réalisées de façon manuscrite par des élèves de l'École centrale, à partir des notes de Mary et à la demande du Conseil des études. De l'une à l'autre, Mary introduit des changements qui ne concernent cependant que la partie sur les matériaux et les techniques de mise en œuvre. La partie consacrée aux « Principes fondamentaux de l'architecture " est un résumé du Précis des leçons d'architecture (1802-1805) de Jean Nicolas Louis Durand.

Châtenay-Malabry, Bibliothèque de l'École centrale.

La troisième partie consacrée à la construction traitait d'abord des matériaux, puis de leur mise en œuvre par corps de métiers (maçonnerie, charpente, serrurerie, couverture). L'ensemble était largement inspiré des cours de construction donnés par Jean Rondelet à l'École des beaux-arts sans cependant accorder autant de place aux approches physico-mathématiques que les élèves développaient par ailleurs dans les cours parallèles de mécanique, de physique et de géométrie descriptive. L'évaluation des ouvrages occupait une place réduite à une unique leçon.

\section{Le cours de « Constructions civiles » d'Émile Trélat (1854-1894)}

C'est en plein essor de la construction, entre 1852 et 1854, dans la période de gestation des travaux de rénovation urbaine entrepris par le baron Haussmann, que se dessine le projet de créer un cours de "Constructions civiles $^{14}$ » au Conservatoire national des arts et métiers. À un moment où, comme il le souligne lui-même, «les campagnes se 
dépeuplent et les villes s'emplissent ${ }^{15}$ ", Trélat, qui avait suivi le cours de Louis Charles Mary à l'École centrale, entendait former des constructeurs accomplis dont les connaissances concernaient aussi bien la «science» que «l'art». De 1854 à 1863, les leçons dispensées sur trois ans se divisaient en trois parties : «matériaux de construction », procédés ou "moyens de construction » et " composition et exécution des édifices ». D'un côté donc, un cours de construction professé en deux ans, divisé en deux parties : "matériaux» et «moyens de construction». De l'autre, un cours d'architecture d'une durée d'une année abordant à la fois la composition et l'exécution.

11 Construction et architecture étaient en réalité étroitement mêlées dans ce programme. Les procédés de constructions étaient classés et enseignés en fonction de ce que Trélat désignait par « éléments » ou « organes des édifices » (à partir de 1873), c'est-à-dire les parties des édifices : fondations, "parois verticales » (murs, baies, saillies), «soutiens isolés » (piliers colonnes), " parois horizontales et courbes » (plancher, voûtes, combles et couvertures). Ce classement faisait référence au cours d'architecture de Durand, mais bien au-delà, à une tradition architecturale ancienne dont témoignent de nombreux traités, consistant à diviser l'architecture en éléments.

12 Le cours de "composition » et «exécution » donné en troisième année était divisé quant à lui par types d'édifices. Il débutait avec l'«habitation de l'homme » qui occupait une place très importante ${ }^{16}$ et se poursuivait avec les édifices publics, les hôpitaux et les prisons, puis les salles d'asile, les écoles, les palais de justice, les hôtels de ville, les théâtres.

13 On ne connaît pas le contenu exact de ces cours, mais les notes qu'Émile Trélat avait rédigées pour la partie « composition » permettent, ce qui est précieux, de restituer sa méthode d'exposition. Les exposés s'appuyaient sur l'analyse et la critique d'édifices construits en France ou à l'étranger, récemment publiés dans les recueils ou les revues d'architecture. Après avoir dessiné l'exemple choisi au tableau, analysé ses parties en les confrontant aux "données du besoin", le professeur se livrait à une critique détaillée de l'édifice en portant des jugements sur l'économie générale du projet, sa disposition, sa construction et sa décoration (fig. 4 et 5). 
4. Victor Calliat, " Maison rue de Vintimille, par Navarre Archte ", Parallèle des maisons de Paris construites depuis 1830, Paris, Bance, 1850, pl. XXV.

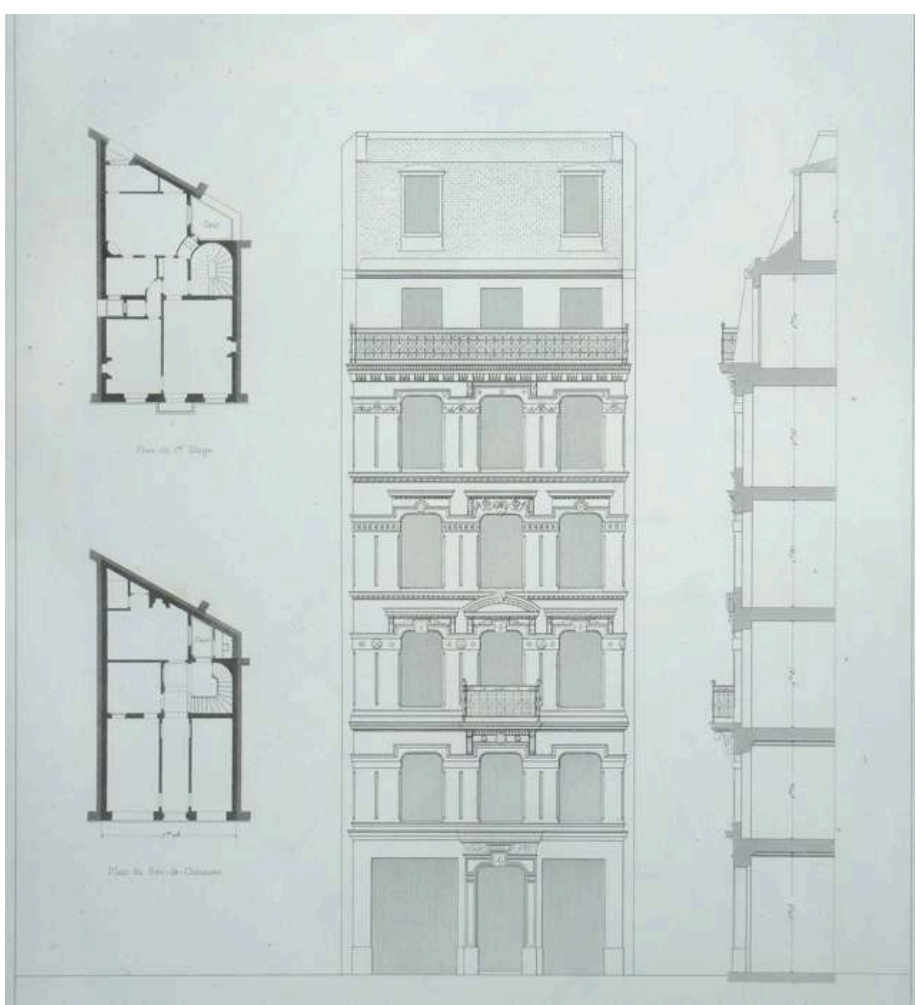

Émile Trélat se sert, pour illustrer son cours sur les habitations du Conservatoire des arts et métiers, de nombreux projets publiés dans le recueil de Victor Calliat ; en particulier : « Maison rue de Paradis Poissonnière, par Sédille Archte», (pl. 13) ; « Maison rue de Vintimille, par Navarre Archte», (pl. 25) ; «Maison boulevard Beaumarchais, par Davrange Archte et Durup Vérifr», (pl. 88) ; « Maison rue de l'Échiquier, par Mr Equer, Archte », (pl. 34) ; « Maison boulevard Malesherbes, par Charpentier, Archte », (pl. 38).

Paris, Bibliothèque de I'INHA, collections Jacques Doucet, Fol I 77 
5. Émile Trélat (1821 - 1907), " Maison rue de Vintimille », Notes du cours de "Constructions civiles » donné au Conservatoire national des arts et métiers (1857-1858), 13e leçon, " Habitation », p. 9.

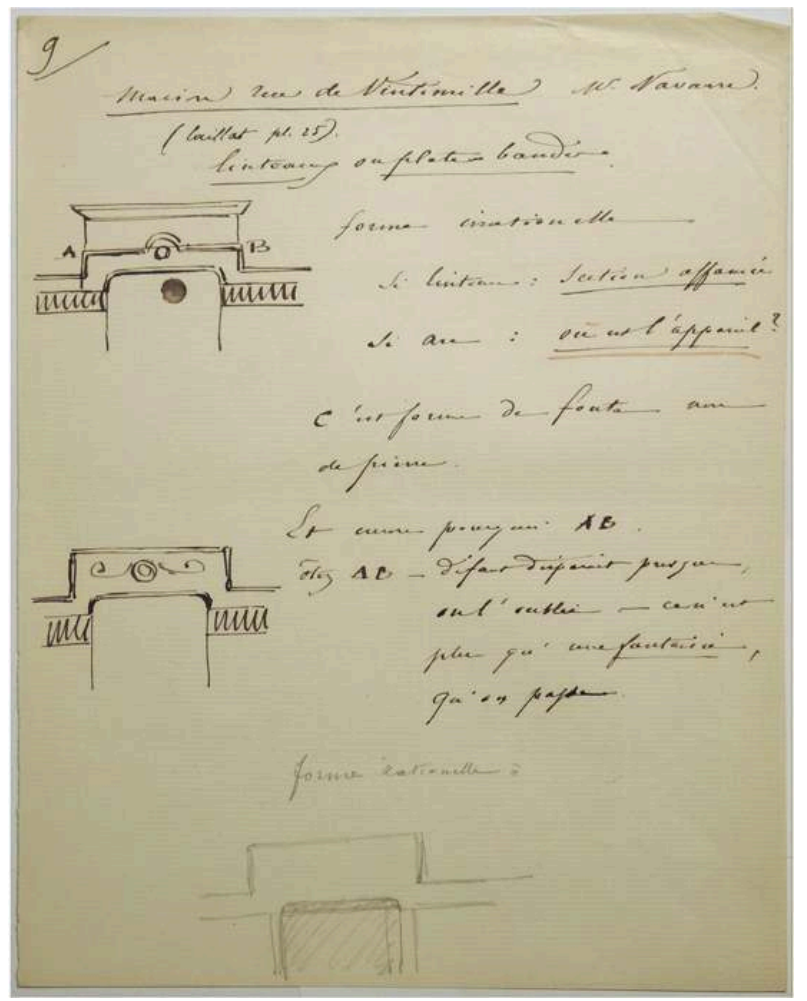

[Chaire de Construction civiles du CNAM. Cours d'Émile Trélat (1857-1858), de la 6e à la 39e leçon] (Manque la 10 leçon).

33 chemises, $342 \mathrm{f}^{\circ}$ dont 23 calques.

H. 27,5, L. 21,5.

Notes manuscrites et dessins. Encre, crayon gris et crayon de couleur sur différents papiers et calques.

Paris, Archives du Conservatoire national des arts et métiers, 1 BB/1 [catalogue 19].

14 Dans sa vingt-septième leçon, consacrée aux hôpitaux, il faisait ainsi un parallèle détaillé entre les surfaces, les prix et le nombre de places de cinq établissements, se livrant à un véritable calcul de rentabilité ${ }^{17}$. À propos de l'hôtel du prince Napoléon, il notait: "chambres non aérées sur serre et au milieu de tout cela tricherie décrochements de murs"; ou encore «Façades latérales invisibles, inutilité de s'astreindre à leur symétrie », "si couleur dehors - l'abriter ${ }^{18}$ ». Dans la leçon sur les «Façades des maisons », il dénonçait la forme "irrationnelle » des linteaux : "Où est l'appareil ? consignait-il, c'est forme de fonte, non de pierre » ou encore : "Où est l'appareil possible ? (fig. 6). 


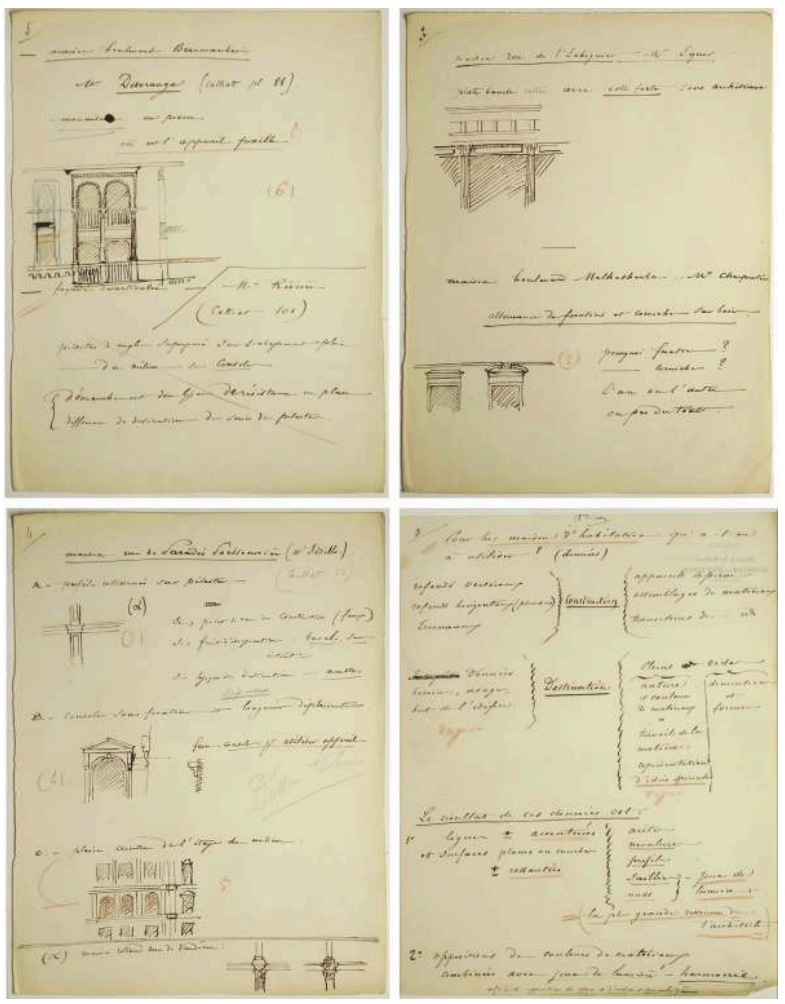

En haut à gauche, « Maison boulevard Beaumarchais», 16e leçon, « Habitation », p. 5.

En haut à droite, "Maison rue de l'échiquier » et « Maison boulevard Malesherbes », 16e leçon, « Habitation», p. 3.

En bas à gauche, « Maison rue de Paradis Poissonnière »16e leçon, « Habitation », p. 4.

En bas à droite, " Pour la maison d'habitation qu'a-t-on à utiliser? », 15e leçon, « Habitation », p. 3. Tous ces exemples sont extraits du recueil de Victor Calliat, Parallèle des maisons de Paris construites depuis 1830 (1850), pl. 25, 34, 38, 88.

II s'agit de notes manuscrites et de dessins d'Émile Trélat destinés à la préparation de son cours de "Constructions civiles " (1857-58) du Conservatoire des arts et métiers (1854 à 1894). Les notes ne concernent que la partie "Composition et exécution des édifices». II manque les cinq premières et la dixième leçons. Les notes de chaque leçon sont regroupées dans une chemise (du même papier que les notes). Les chemises contiennent entre 3 et 18 feuillets. Émile Trélat a rédigé ces notes sur des papiers de récupération, et en particulier des formulaires d'invitation à ses cours. Un texte imprimé ("Monsieur Émile Trélat à l'honneur d'inviter M.... à la leçon d'ouverture de son Cours qui aura lieu le.... à 7 heure 1/4 du soir dans le grand amphithéâtre du Conservatoire impérial des arts et métiers ") figure au verso de nombreux feuillets. L'écriture à l'encre est abondamment enrichie d'annotations, ratures, modifications au crayon, réalisées au fil du temps.

Paris, Archives du Conservatoire national des arts et métiers.

Proche de la pensée de Durand et de celle de Viollet-le-Duc, Trélat privilégiait la «construction» et la «destination» (fig. 9); l'architecture étant, pour lui, «l'expression complète du besoin satisfait » et non la recherche « d'un beau absolu ou la défense exclusive de tel ou tel système architectural au détriment des autres ${ }^{19} »$. Tout ce qui ne satisfaisait pas à ces deux «données» était sévèrement condamné. Ainsi dénonçait-il les plates bandes « collées avec de la colle forte ", la présence conjointe à un même étage de frontons et de corniches, les ressauts inexplicables de bandeaux sur des pilastres (fig. 7 et 8 ).

Le cours de construction de Trélat était ainsi, dans sa partie « composition » beaucoup moins théorique et beaucoup plus innovant que celui de son professeur Mary. Les principes de composition et de proportion, le dessin des ordres ne formaient plus de parties autonomes (les fameux "éléments des édifices»). Le cours s'organisait 
directement en fonction des types d'édifices, et, dans ces types, Trélat accordait une très grande importance aux habitations, autrement dit, à un programme qui intéressait en priorité ses auditeurs (architectes, entrepreneurs, vérificateurs, inspecteurs). Trélat s'attachait à leur donner des connaissances historiques (en 1862-63, huit cours étaient consacrés aux "habitations anciennes»), mais aussi à leur faire part des réflexions contemporaines en matière de logements économiques. Les exemples comprenaient les maisons ouvrières de la Société Mulhousienne d'Émile Müller, les « maisons anglaises » que César Daly détaillait dans la Revue générale de l'architecture en $1855^{20}$, et les projets d'Henry Roberts et de la Society for Improving the Condition of the Labouring Classes ${ }^{21}$ (fig. 10 et 11$)$.

10. Henry Roberts, « Model Houses for 48 families », dans The Dwellings of the Labouring Classes, Londres, 1850.

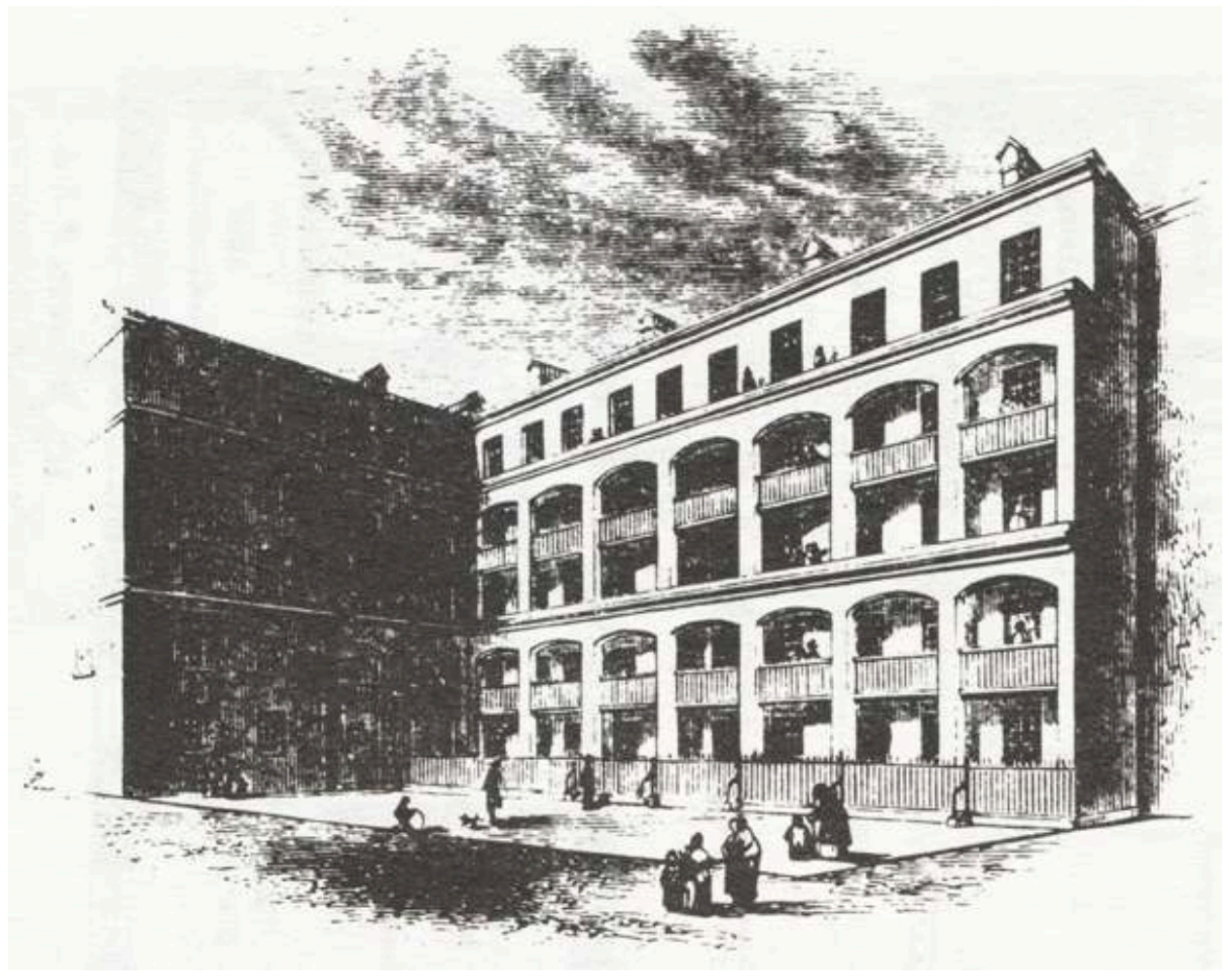


11. Émile Trélat, Notes du cours de «Constructions civiles » (1857-58), $11^{\mathrm{e}}$ leçon « Maisons anglaises ».

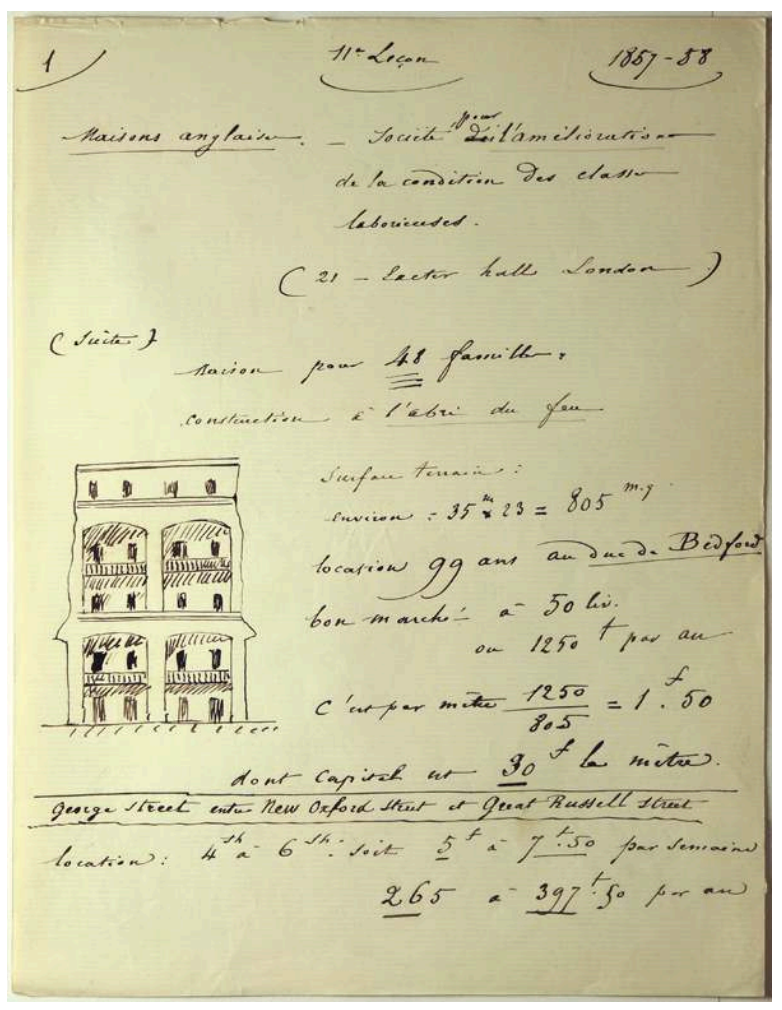

Paris, Archives du Conservatoire national des arts et métiers

À partir de 1866, date à laquelle Émile Trélat abandonna, non par conviction, mais parce qu'il venait de fonder l'École spéciale d'architecture, la partie « composition » du cours de construction, furent progressivement introduites des connaissances sur la salubrité. Quatre cours sur le chauffage figurent au programme de 1869-70; treize en 1874. Le confort et les "grands facteurs de la salubrité »: l'air, la lumière, la chaleur, l'eau et le sol prennent ainsi de plus en plus d'importance jusqu'à occuper une année entière. «Refaire la salubrité dans les installations urbaines » devient progressivement pour cet ingénieur-architecte, fils et frère de médecins experts en matière d'hygiène, le problème principal du constructeur ${ }^{22} »$. Trélat intégrait clairement son enseignement de l'architecture dans un discours économique et politique.

Le cours de mise en œuvre des matériaux accordait beaucoup de place aux matériaux métalliques récents, le fer et la fonte en premier lieu, puis l'acier à partir de 1872, mais aussi le cuivre, le zinc et le plomb ${ }^{23}$. Comme à l'École centrale, le professeur était attentif à restituer la connaissance des matières et l'enchaînement des opérations de fabrication, mais peu de place était faite aux savoirs physico-mathématiques. L'orientation physico-mathématique qu'allaient prendre les cours de construction ne s'opéra ainsi que tardivement, après les années 1870. Contrairement au cours de construction professé par Jean Rondelet et François Jay à l'École des beaux-arts, Trélat, comme son professeur Mary accordait peu de place à la construction dans l'Italie antique et moderne. C'est l'Angleterre et la Hollande qui fournissaient désormais la majorité des modèles étrangers. 


\section{Pratiques de l'enseignement pratique}

19 Les descriptions qui précèdent montrent clairement l'orientation peu scientifique des deux cours de construction sous le Second Empire. Ces cours ne rendaient pas compte des savoirs physico-mathématiques récents; ils décrivaient des édifices ou des parties d'édifices concrets et abordaient des questions d'économie et de rentabilité. Mais, malgré leur approche concrète, ils ne pouvaient fournir aux élèves les savoirs nécessaires pour exercer les métiers d'ingénieur, d'architecte et d'entrepreneur. Comment enseigner la pratique?

20 À l'École centrale, comme à l'École des ponts et chaussées dans la première moitié du XIX ${ }^{e}$ siècle, une série d'exercices destinés à prendre contact avec la matière et le monde du travail complétait les cours théorique ${ }^{24}$ : les travaux graphiques en premier lieu (croquis, dessins, épures et projets), mais aussi les «manipulations» et les «démonstrations"; l'ensemble occupait plus de la moitié du temps des élèves ${ }^{25}$.

21 En 1831, les élèves du cours de construction de deuxième année devaient dessiner quarante « épures » de charpente, planchers, voûtes, plans d'édifices. À cela s'ajoutait l'enseignement du dessin qui débutait en première année par le dessin d'ornement (au trait et au lavis) et de levé de plan. À partir de 1836, à la demande de Théodore Olivier, particulièrement attentif à la partie graphique de l'enseignement, un cours de « dessin architectural » assuré par l'architecte et ancien élève de l'École des beaux-arts Auguste Thumeloup (entre 1836 et 1854) devait exercer les élèves aux techniques de représentation à partir de "formes architecturales ». Le Conseil des études estimait en 1841 que ce cours, qui abordait l'architecture par éléments (moulures, portes et fenêtres, arcades, ordres) attachait "trop de prix à l'érudition architecturale ${ }^{26}$ ». Comme le montre la version lithographiée de ses leçons, Thumeloup faisait de nombreuses références à Quatremère de Quincy et à Percier et Fontaine ; il présentait des réalisations anciennes et récentes basées sur l'emploi des ordres et des arcades mêlant ainsi étroitement pratique du dessin et pratique du projet (fig. 12). 


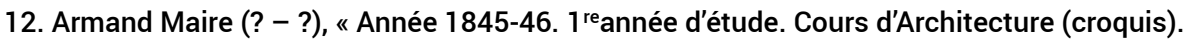
Professeur Mr Thumeloup. Nom de l'élève Maire».

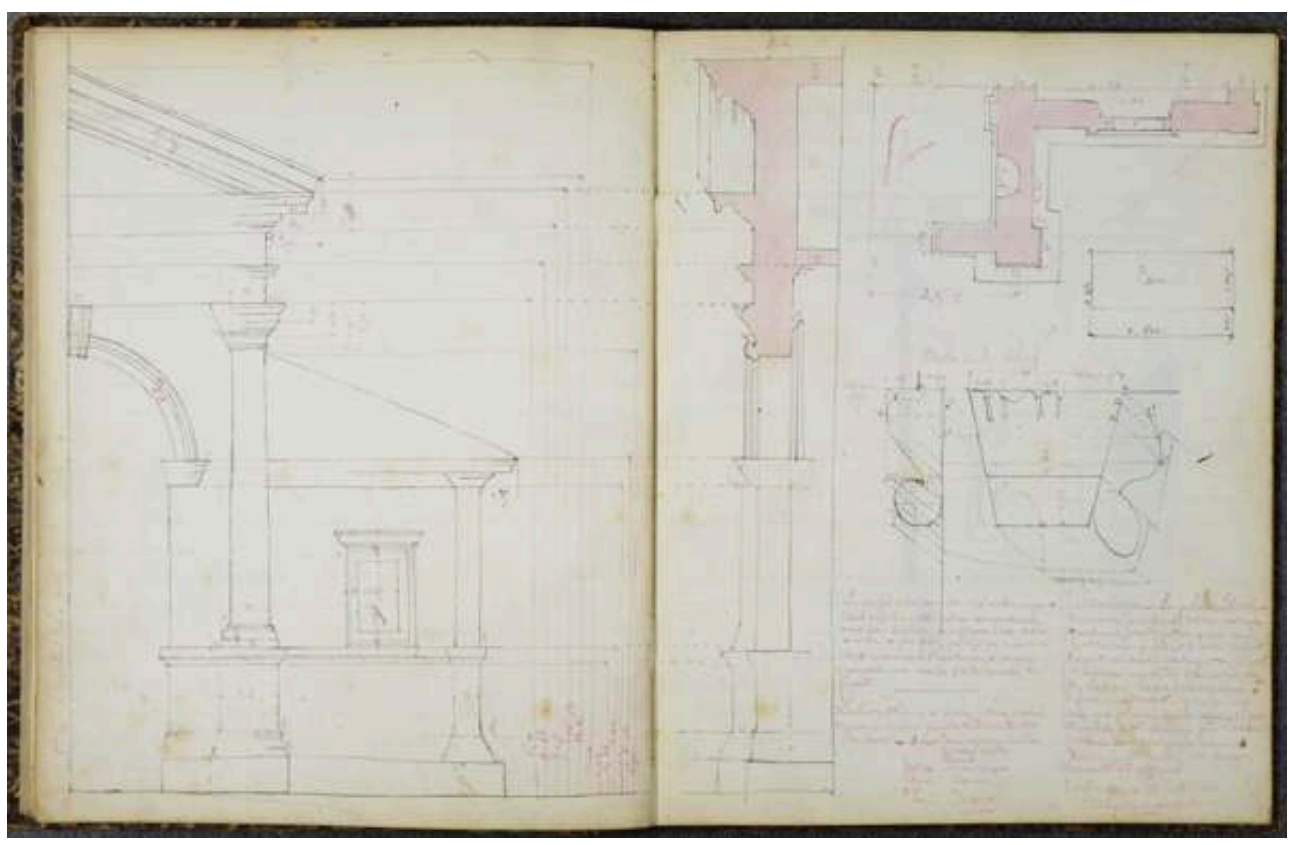

Notes prises par l'élève Armand Maire (promotion de 1848) au cours d'architecture de $1^{\text {re }}$ année d'Auguste Thumeloup.

Cahier de cours. Notes manuscrites et dessins sur [58] fºn non numérotés.

Encre et crayon sur papier.

H. 22,5, L. 18.

Notes prises par l'élève Armand Maire (promotion de 1848) au cours de dessin d'architecture de 7 re année d'Auguste Thumeloup. La tenue de cahier de cours était imposée par l'école centrale. Le format du cahier était imposé. Une Instruction sur la tenue des cahiers de notes (s.I.n.d.) précisait : "Ces cahiers ne doivent pas être rédigés dans l'intervalle des leçons. [...] ils doivent être écrits à l'amphithéâtre en laissant une large marge et des blancs, au besoin, pour compléter. Les épures ou dessins faits au tableau par le Professeur et les modèles mis sous les yeux des élèves à l'amphithéâtre doivent être copiés sur le cahier de notes au crayon. Le soir, les cahiers doivent être complétés et étudiés [...] les lacunes seront comblées... soit enfin en consultant les cours lithographiés ou les ouvrages recommandés par le Professeur [...] Enfin les croquis seront mis à l'encre à main levée et avec le plus grand soin. La mise à l'encre d'un croquis ne consiste pas à repasser les traits faits au crayon, elle exige que l'on comprenne parfaitement l'objet que l'on dessine, afin de coter exactement... ».

Châtenay-Malabry, Bibliothèque de l'École centrale, document non coté

L'apprentissage du dessin était basé jusqu'à la fin du XIX siècle sur la copie: «Les élèves avaient devant eux, placés dans des cadres fermés, des dessins d'architecture, qu'ils devaient reproduire à l'échelle donnée, en plan, coupe et élévation et y appliquer des teintes conventionnelles, dont ils avaient préalablement dessiné une feuille, dès leur entrée à l'École ${ }^{27} »$. Ces séances de copies étaient souvent précédées de séances de "démonstrations » dans lesquelles le chef de travaux graphiques exécutait sous les yeux des élèves le dessin qu'ils avaient la tâche de copier. Il faut ainsi souligner la place importante accordée aux "démonstrations", dans le travail de copie ou dans les enseignements plus théoriques comme la géométrie descriptive. Théodore Olivier, apprend-on, « cultivait la mémoire des yeux » « en construisant les épures au moyen de deux châssis recouverts de liège et reliés par des charnières ; il représentait la position des lignes dans l'espace avec des baguettes de bois armées de pointes ${ }^{28}$ ».

À ces démonstrations s'ajoutaient des "manipulations » exécutées par les élèves (relevés, levés de terrain, nivellements, stéréotomie). Le Prospectus de 1829 annonçait : «Il y aura dans l'École, des ateliers de menuisier, de tourneur et un atelier de monteur. 
Des ouvriers y exécuteront sous les yeux des élèves des modèles de collections et de pièces de machines. Les élèves y apprendront quelques notions sur le maniement des outils...29 ». Comme à l'École des mines et à l'École des ponts et chaussées, à partir de 1840 , les élèves devaient réaliser des relevés à l'occasion de leurs «travaux de vacances $^{30} »($ fig. 13).

13. Carnet de travail de vacances de l'élève d'Armand Maire ( $2^{\mathrm{e}}$ année), 1845.

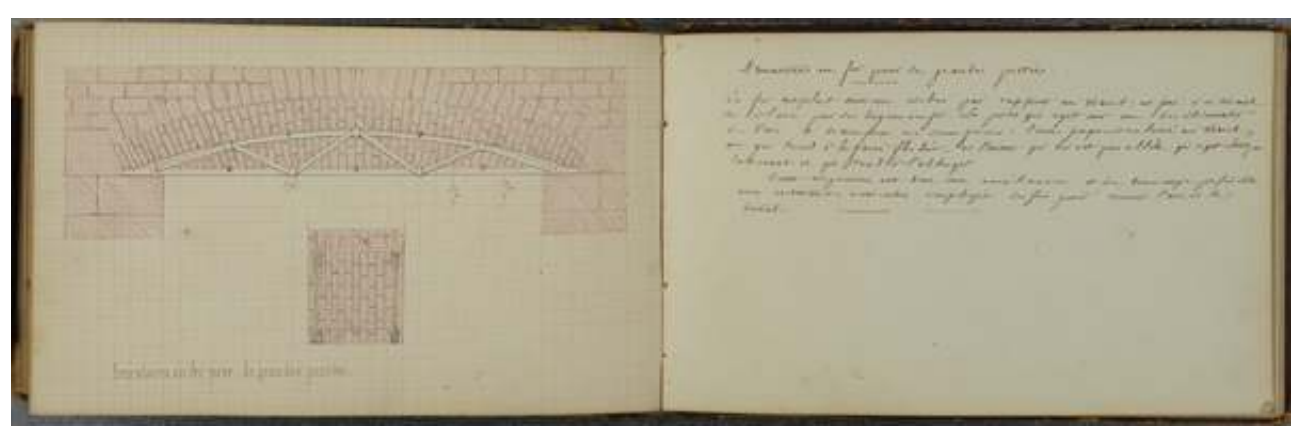

«Armatures de fer pour grandes portées ».

Le dessin coté, réalisé sur du papier quadrillé, est accompagné d'un texte descriptif.

Châtenay-Malabry, Bibliothèque de l'École centrale.

24 Enfin, les élèves s'exerçaient par la pratique des «projets de concours ${ }^{31}$ ». Ces projets étaient systématiquement accompagnés d'un «mémoire » destiné à faire connaitre les motifs qui les avaient « engagés à adopter les dispositions générales et particulières ${ }^{32}$ ». Les projets pouvaient porter sur des édifices (écoles, hôtels de ville, palais de justice, usines) ou sur des travaux publics (ponts, voies ferrées, routes) ${ }^{33}$ (fig. 14). 
14. Félix Rousseau (? - ?), Projet de pont suspendu pour le concours spécialité des Constructeurs, 1840.

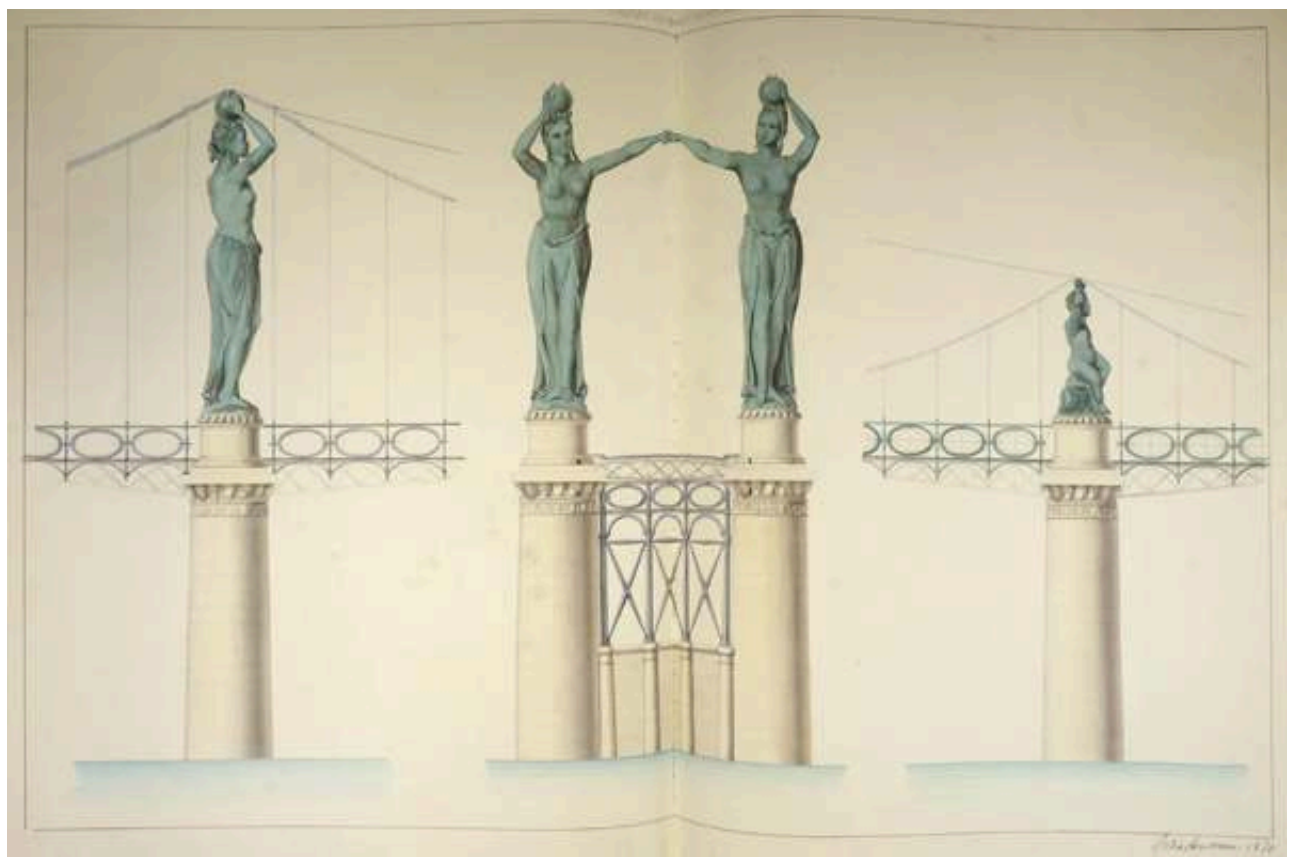

Quatre planches. Encre, crayon et aquarelle sur papier.

H. 70, L. 53.

Dans son «mémoire » accompagnant le projet, Rousseau écrit : "Mes efforts ont eu pour but de rester fidèle au caractère de légèreté qui est le propre des ponts suspendus ; tout en cherchant à m'éloigner le moins possible de la solution la plus économique [...] on a abandonné les piliers en pierre comme formant par leur masse un contraste désagréable avec le reste de la construction ».

Le «Mémoire » rédigé par Rousseau pour présenter son projet précise : "On demande le projet d'un pont suspendu sur la rivière dont le profil est ci-dessus. Ce pont à construire dans l'intérieur d'une ville se rattachera d'un côté à une culée isolée, de l'autre à un quai au pied duquel sera établi un égout latéral. Un trottoir de $2 \mathrm{~m} 50$ de large sera établi le long du parapet du quai. La distance entre les culées sera de $275 \mathrm{~m}$ [...] le sol est du rocher d'un côté dans la partie la plus profonde, de sable indéfini de l'autre côté ». Sur les treize élèves qui se présentent au concours, cinq obtiennent la plus haute distinction (un diplôme), 7 un certificat (dont Rousseau) et un élève n'obtient rien.

Châtenay-Malabry, Bibliothèque de l'École centrale, Concours « Constructeurs » 34.

L'orientation pratique que l'École centrale des arts et manufactures et le Conservatoire national des arts et métiers entendaient donner aux enseignements, se concrétisait donc par des exercices qui conjuguaient activités manuelles et intellectuelles. Parmi ces exercices, il faut souligner l'importance du dessin, des manipulations et de l'analyse d'exemples.

Dans les cours de dessin architectural de l'École centrale, en 1836, l'usage du compas était interdit, les élèves étaient « tenus d'exécuter sept dessins [...], sur une échelle plus grande que celle du modèle, de $1 / 10$ au moins » à main levée ; le trait devait être " aussi net que si le dessin devait rester au crayon ", puis il était passé à l'encre de Chine à l'aide d'une plume fine et pour certains traits, d'une plume forte ${ }^{34}$. L'habileté manuelle était donc un objectif primordial. Le temps nécessaire pour représenter à la main levée des formes courbes parfaites, permettait à l'élève d'expérimenter les difficultés d'exécution, faire des allers-retours entre la forme abstraite et la forme sensible ${ }^{35}$. Ces manipulations permettraient de réduire l'intervalle qui séparait les connaissances abstraites du monde physique (ou la conception de l'exécution). 
L'analyse d'exemples (édifices ou parties d'édifices), pratiquée dans les cours de théorie par le professeur, et par les élèves à travers la copie des projets, constituait un autre dispositif central. Les collections de modèles choisis dans les deux établissements avaient en commun d'être concrètes, elles correspondaient à des édifices existants. Le professeur se livrait à une décomposition du projet en éléments puis reliait ces éléments aux données de l'usage et de la construction. Les notes de cours d'Émile Trélat montrent aussi l'importance jouée par la critique. Le futur fondateur de l'École spéciale d'architecture n'hésitait pas à porter des jugements défavorables sur des projets récemment construits et redessinait même les parties considérées comme défectueuses en apprenant ainsi aux élèves non seulement l'analyse, mais l'exercice du jugement. La copie ou la reproduction des projets par les élèves, soit dans les carnets de notes de cours, soit dans des séances de dessin, était considérée comme essentielle. À l'École centrale, les carnets de notes de cours, obligatoires, tous du même modèle, étaient, selon le Conseil des études, "une des parties les plus importantes des études», les « modèles » mis sous les yeux des élèves «à l'amphithéâtre » devaient être copiés sur le cahier de notes au crayon, puis complétés et « mis à l'encre à main levée et avec le plus grand soin ${ }^{36} »$ (fig. 15).

15. Armand Maire (? - ?), "Année 1846-47. $2^{\mathrm{e}}$ année d'étude. Cours d'Architecture civile. Professeur Mr Mary. Nom de l'Élève Maire ».

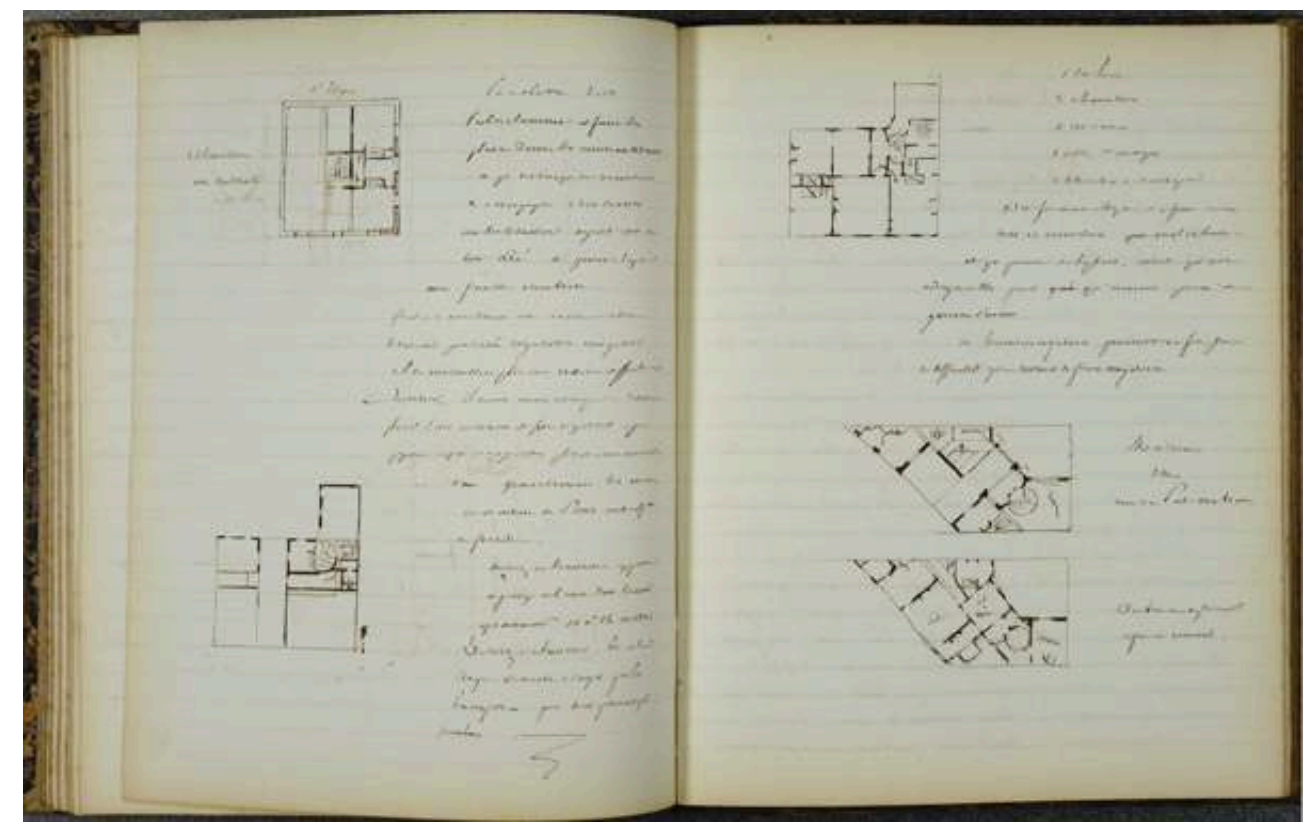

Cahier de cours. Carnet de notes prises par l'élève Armand Maire (promotion de 1848) au cours d'architecture civile de $2^{\mathrm{e}}$ année de Louis Charles Mary.

Notes manuscrites et dessins sur [137] f non numérotés.

H. 22,5, L. 18.

Carnet de notes prises par l'élève Armand Maire (promotion de 1848) au cours d'architecture civile de $2^{e}$ année de Louis Charles Mary en 1846-47. Les notes et les dessins montrent que Mary suivait son cours lithographié (voir cat. 17).

Quatre impressions du cours lithographié sont connues : 1834-35, 1840-41; 1844-45; 1852-53. Elles correspondent à deux versions réalisées de façon manuscrite par des élèves de l'École centrale, à partir des notes de Mary et à la demande du Conseil des études. De l'une à l'autre, Mary introduit des changements qui ne concernent cependant que la partie sur les matériaux et les techniques de mise en œuvre. La partie consacrée aux «Principes fondamentaux de l'architecture » est un résumé du Précis des leçons d'architecture (1802-1805) de Jean Nicolas Louis Durand.

Châtenay-Malabry, Bibliothèque de l'École centrale, document non coté. 
La copie permettait de mémoriser les exemples pour ensuite, par remémoration, comparaison et analogie conduire à l'élaboration d'autres projets. Ces quelques remarques nous rappellent la profonde altérité, en architecture, entre les livres et les cours. Si les cours imprimés ou lithographiés nous livrent des connaissances, ils ne nous restituent pas l'enseignement ; d'où la laborieuse nécessité de s'intéresser aux pratiques : aux formes de l'oralité, aux gestes et aux « communications non verbales » (planches, maquettes, instruments).

\section{NOTES}

1. Antoine Chrysostome Quatremère de Quincy, Encyclopédie Méthodique. Architecture, t. I, Paris, Panckoucke, 1788, article « Art », p. 141.

2. «Conservatoire des arts et métiers, Cours de construction civile. Monsieur Émile Trélat professeur. Programme lu le 28 novembre 1854 au Conseil de perfectionnement ». Archives du Conservatoire national des arts et métiers, 1 BB6.

3. Léon Guillet, Cent ans de la vie de l'École centrale des arts et manufactures, 1829-1929, Paris, Brunoff, 1929, p. 125.

4. Les premiers enseignements dispensés par le Conservatoire national des arts et métiers étaient basés sur le "faire voir», trois "démonstrateurs» étaient chargés d'actionner les machines, les modèles et les outils en public. Dans son rapport de 1798 sur le Conservatoire, le député Alquier déclarait : «Le Conservatoire enseigne aux ouvriers à qui il faut faire voir et dont il ne faut pas obscurcir les conceptions par des discours abstraits et scientifiques ». Cité par Claudine Fontanon, "Conviction républicaine pour une fondation", dans M. Le Moël (dir.), 1794-1994, le Conservatoire national des arts et métiers au cour de Paris, Paris, Conservatoire national des arts et métiers, Délégation à l'Action artistique de la Ville de Paris, 1994, p. 62.

5. Les cours de "Géométrie descriptive » du Conservatoire national des arts et métiers furent d'abord assurés par Théodore Olivier (1839-1854) qui enseignait aussi à l'École centrale, puis par Jules Maillard de la Gournerie (1854-1883). En 1855, ce dernier consacrait une année à la représentation (perspective et tracé des ombres), une année aux notions de géométrie descriptive nécessaires pour comprendre la coupe des pierres et enfin une année à la coupe des bois. Jules Maillard de la Gournerie, « Mémoire sur l'enseignement des arts graphiques », Annales du Conservatoire des arts et métiers, 1874, $2^{\mathrm{e}}$ série, t. X, p. 297.

6. Ibid., p. 294.

7. École centrale des arts et manufactures, Programme de l'année 1830-31, «Construction et travaux publics ", p. 11-12.

8. Sur l'enseignement de l'architecture à l'École centrale, voir l'excellente étude de Françoise Hamon, «Construire pour l'industrie. L'enseignement de l'architecture industrielle à l'École centrale des arts et manufactures. 1832-1914 ", université de Paris-Sorbonne, Paris IV, 3 vol. oct. 1997. Les professeurs du cours de constructions civiles furent : Charles Gourlier (1830-1), Antoine Raucourt de Charleville (1831-1833), Louis Charles Mary (1833-1864), Émile Müller (1864-1889), Jules Denfer (1889-1909). En 1872 fut créé, parallèlement au cours de « Constructions civiles », un cours d'« Éléments d'architecture» dispensé par René Deminuid (1872-1881), Jules Denfer (1881-1889) et Fernand Delmas (1890-1910). 
9. Quatre impressions du cours lithographié sont connues : 1834-35, 1840-41; 1844-45 ; 1852-53. Selon Françoise Hamon, Mary introduit peu de changements, les rares actualisations concernent les matériaux de construction (mis à part le chapitre sur le fer qui reste identique). L'Atlas, non daté, sans titre, comporte 50 planches. Bibliothèque de l'École centrale, 3383 et 3388.

10. Le cours de "Constructions civiles " professé en deuxième année était suivi en troisième année par un cours de "Routes et Ponts ». À l'École centrale, comme à l'École des ponts et chaussées (à partir de 1832), le cours de «Routes et ponts » était donc distinct du cours de «Constructions civiles».

11. Louis Charles Mary, Cours d'architecture, [Paris], École centrale, 1840-41, p. 61. Bibliothèque de l'École centrale, 3383.

12. Louis Bruyère occupe ce poste de 1804 à 1811. Les planches empruntées à ses Études sont : pl. VII Nouvelle halle du Mans ; pl. VIII Marché Saint-Germain de Paris ; pl. IX Marché des Blancs Manteaux (Saint-Gervais) ; pl. X Halle au blé de Paris ; pl. XIV Entrepôt des vins de Paris ; pl. XVI Abattoirs de Ménilmontant ; pl. XXIV Maison particulière ; pl. XXV Distribution dans un terrain irrégulier ; pl. XXXVII Charpente du comble de la salle d'Armes de Moscou.

13. Charles François Mandar fut le professeur d'" Architecture " de l'École des ponts et chaussées de 1800 à 1820. Le projet de maison particulière est emprunté à Détail de construction d'une maison, Paris, École des Ponts et Chaussées, 1818. Mary utilise également certains édifices relevés par les élèves de l'École des Ponts et rassemblés par Barnabé Brisson dans Recueil de dessins ou Feuilles de Textes Relatifs à l'Art de l'Ingénieur, s.l. [Paris], École des ponts et chaussées, s.d. [1820-25].

14. La création de la chaire est évoquée dès 1852. Les professeurs titulaires jusqu'en 1964 sont : Émile Trélat (1854-1893), Jules Pillet (1894-1912), Augustin Mesnager (1913-1933), Jacques Mesnager (1934-1964). Voir Frédéric Seitz, «L'Enseignement de la construction, de l'architecture et du dessin à la fin du XIX ${ }^{\mathrm{e}}$ siècle et au début du $\mathrm{XX}^{\mathrm{e}}$ siècle. L'Apport d'Émile Trélat et de Jules Pillet ", Cahiers d'histoire du CNAM, n²/3, 1994, p. 157-176

15. Émile Trélat, «L’Enseignement des constructions civiles au Conservatoire des arts et métiers. Leçon d'adieux, du lundi 5 novembre 1894 ", Annales du Conservatoire des arts et métiers, 1895, $2^{\mathrm{e}}$ série, t. 7, p. 107-124.

16. 17 leçons sur 39 en 1857-58; 20 leçons sur 30 en 1862-63. Voir « Cours publics. Sommaires des leçons, 1862-1865 ", Archives du Conservatoire national des arts et métiers 1CC/16.

17. Il s'agit des hôpitaux de Bordeaux, Villeneuve-sur-Lot, Lariboisière à Paris, Vincennes, Bruxelles.

18. « $8^{\circ}$ leçon. Habitation, 1857-58 ", p. 2. Archives du Conservatoire national des arts et métiers, $1 \mathrm{BB} / 1$.

19. "Conservatoire des arts et métiers, Cours de construction civile... ». Archives du Conservatoire national des arts et métiers, 1 BB6.

20. César Daly, "Maison d'habitation de Londres ", dans Revue générale de l'architecture, $\mathrm{t}$. XIII, 1855, col. 57-63 et pl. XIII à XVI ; XXVI, XXVII ; XXX à XXXII. C'est à partir de l'article de César Daly qu'Émile Trélat construit sa neuvième leçon de 1857-58 sur l'habitation.

21. Notamment les Model Houses for 48 families, ou encore The lodginghouse for unmarried labourers, publiés dans Henry Roberts, The Dwellings of the Labouring Classes, London, 1850 ; ouvrage traduit en 1850 sous le titre Des habitations des classes ouvrières, Paris, Gide et Baudry, 1850

22. Émile Trélat, art. cit., p. 117.

23. En 1863-64, 17 cours sur 40 sont consacrés aux matériaux métalliques, 7 à la pierre et 4 au bois. En 1865-66, 13 cours sur 34 sont consacrés aux matériaux métalliques, 7 à la pierre et 5 au bois. Voir : "Cours publics. Sommaires des leçons, 1862-1865", Archives du Conservatoire national des arts et métiers $1 C C / 16$ et "Cours publics. Sommaires des leçons, 1865-1870". Archives du Conservatoire national des arts et métiers $1 \mathrm{CC} / 17$. Ces registres contredisent ainsi ce 
que Frédéric Seitz a pu écrire sur ce cours, en affirmant qu'il accordait peu de place aux matériaux métalliques.

24. Antoine Picon, L'Invention de l'ingénieur moderne. L'École des Ponts et Chaussées, 1747-1851, Paris, Presses de l'ENPC, 1992, p.111 et suiv. « La formation pratique des élèves de Perronet ».

25. En première année, en $1830: 18 \mathrm{~h}$. de dessin et $4 \mathrm{~h}$. 30 de manipulations, pour $16 \mathrm{~h}$. de cours théoriques; en deuxième année $14 \mathrm{~h}$. de dessin et $9 \mathrm{~h}$. de manipulations pour $18 \mathrm{~h}$ de cours théoriques. Francis Pothier, Histoire de l'École centrale des arts et manufactures, Paris, Delamotte fils et Cie, 1887.

26. «Mr Thumeloup fait un cours bon pour les élèves de l'École des beaux-arts qui étudient l'architecture, mais ne convient pas à ceux de Centrale qui ne peuvent s'appesantir sur tous les détails dans lesquels Mr Thumeloup est entré et ne doivent point attacher de prix à l'érudition architecturale dont il a fait preuve. Il n'a pas compris les vues du Conseil et a fait un cours élémentaire d'architecture au lieu de se borner à substituer les formes architecturales aux ornements dans les modèles à donner aux élèves ". Cité par Françoise Hamon, op. cit., p. 44. Le cours de Thumeloup consistait en leçons théoriques et travaux pratiques. Le contenu des cours théoriques est connu grâce à la version lithographiée des leçons : Aperçu sur le dessin architectural, École centrale des arts et manufactures, 1840-41 (217p., 16 pl. dont 1 dépl.). Bibliothèque de l'École centrale 3321.

27. L. Guillet, op. cit., p. 143.

28. Francis Pothier, op. cit., p. 54.

29. Premier Prospectus publié en mars 1829.

30. D'après Françoise Hamon, l'École centrale ne conserve que cinq de ces "Albums de voyages " pour les années 1845 et 1858. Il s'agit de petits albums de format oblong (environ 15 x $25 \mathrm{~cm}$ ). À partir de 1853, l'École constitue un portefeuille multigraphié de travaux d'été des élèves (1853-1914).

31. Il est décidé le 8 septembre 1832 par le Conseil des études : "On donnera aux élèves de chaque spécialité un projet dont les éléments et les bases devront être établis par eux en huit heures. Ce travail sera timbré et déposé à l'administration. Chaque élève prendra un calque et une copie de son travail et aura ensuite un mois au plus pour étudier son projet, le mettre au net et rédiger un mémoire. Ensuite, dans les premiers jours de novembre, les élèves soutiendront leurs projets en présence de leurs camarades et de leurs professeurs. Pendant cette thèse, de 1 heure et demie à 2 heures, les professeurs pourront faire à l'élève des questions ", Francis Pothier, op. cit., p. 97.

32. «1833-34. Projets de constructions publiques donnés par MM. Mary et Perdonnet», Bibliothèque de l'École centrale des arts et manufactures, document non coté.

33. Voir le rapport de Françoise Hamon pour l'analyse de ces sujets de concours. Jusqu'en 1855, les deux cours «Routes et ponts" et "Constructions civiles» ont un concours commun ; les sujets sont le plus souvent consacrés aux travaux publics. Après 1855, un sujet de concours est donné pour chaque section.

34. L. Guillet, op. cit., p. 93.

35. Selon Joël Sakarovitch la géométrie descriptive " gère d'une manière tout à fait originale, et extrêmement forte, les rapports abstrait/concret ou théorie/pratique ", elle "réalise ainsi une alliance intime entre géométrie spéculative et activité manuelle», J. Sakarovitch, «De la modernité de la géométrie descriptive», dans «La Géométrie dans l'enseignement de l'architecture ", In Extenso, 2000, p. 19 et 22.

36. «Instruction sur la tenue des cahiers de notes », s.l.n. 


\title{
En quête de la couleur : publication de dessins réalisés lors de voyages d'études en Grèce
}

\author{
Stéphanie Guilmeau-Shala
}

\begin{abstract}
« Les envois de quatrième année des Pensionnaires de la Villa Médicis forment à la Bibliothèque de l'École des beaux-arts une collection, unique au monde, d'études et de restaurations d'après l'antique. On a souvent regretté qu'un pareil trésor ne fût pas mis à la disposition et à la portée du public international ${ }^{1}$. »
\end{abstract}

1 Institué en 1720 par l'Académie royale d'architecture, le Prix de Rome d'architecture offre à son lauréat l'opportunité de séjourner pendant une durée limitée à Rome ${ }^{2}$. En contrepartie, le règlement exige des pensionnaires l'envoi annuel de relevés et restitutions archéologiques réalisés in situ, communément appelés " envois ». L'envoi de dernière année, appelé aussi " restauration », est généralement le plus volumineux. D'abord strictement restreint aux monuments de Rome, le terrain de prospection des architectes pensionnaires n'eut de cesse de s'étendre sous la pression des architectes eux-mêmes. Après Naples, Pompéi et la Sicile, c'est finalement la Grèce tout entière qui s'offrit à eux en 1845. Parmi les nombreux élèves ayant consacré leurs envois à des sites grecs, cette étude porte plus particulièrement sur trois architectes dont les dessins, produits lors de leurs voyages en Grèce, firent l'objet d'une large diffusion par leur reproduction et leur publication, Charles Garnier (1825-1898), Jacques Martin Tétaz (1816-1865) et Louis François Philippe Boitte (1830-1906)3. Si le premier est une figure bien connue, les deux autres, aujourd'hui quelque peu oubliés, n'en demeurent pas moins deux architectes dont les dessins, aux grandes qualités plastiques, connurent un grand succès.

\section{De l'importance du dessin dans la formation à l'École des beaux-arts}

2 Élément essentiel de l'enseignement au sein de l'École des beaux-arts, la pratique du dessin domine l'apprentissage du métier d'architecte jusqu'au milieu du $\mathrm{xx}^{\mathrm{e}}$ siècle. Les 
ouvrages essentiels à la formation des élèves architectes sont bien connus. Au côté des Édifices antiques de Rome dessinés et mesurés très exactement de Desgodets (1682), circulent des planches du traité de Vignole ou d'autres extraites du Cours d'Architecture de François Blondel ${ }^{4}$. Autant d'ouvrages passant de maître à élèves, d'atelier en atelier, ayant pour vocation l'apprentissage des ordres et la grande composition d'après les Anciens.

3 Si cette pratique du dessin d'après les sources imprimées constitue la base du système et demeure incontournable pour la majorité des élèves-architectes, les lauréats du Grand Prix ont eux l'opportunité de parfaire leur formation au contact direct des vestiges. Rome est la destination imposée et l'envoi de relevés de monuments, choisis par les architectes avec l'approbation du directeur de l'Académie de France à Rome, est obligatoire. Il s'agit pour l'élève de se constituer une culture visuelle et formelle tout en confrontant des théories et des modèles, ce que souligne Albert Louvet dans L'art d'architecture et la profession d'architecte : «Et tout cela n'empêchera nullement l'architecte de rapporter de ses voyages une ample provision de documents, dessins, relevés, aquarelles qui formeront son bagage intime et le résumé de ses études ${ }^{5}$ ». C'est ce que Garnier conseillait déjà à ses « jeunes camarades » quelques années auparavant : "Rapportez beaucoup de dessins ; plus tard, ils vous délasseront des ennuis des affaires $^{6} »$. Ainsi, Louis Boitte, dessinateur brillant et prolifique, rapporte de son séjour à Rome plusieurs milliers de dessins exécutés lors de voyages en Italie et en Grèce. « Il faut voir aussi que les Envois de Rome ne profitent pas seulement à leur auteur, mais à tous les artistes et les savants [...]. Les grandes Restaurations ont une inestimable valeur $^{7} »$. Le voyage, qui complète pleinement l'apprentissage personnel du pensionnaire, participe ainsi également à la constitution d'une collection de modèles réutilisables par ceux qui n'ont pas la chance de franchir les Alpes.

\section{La restitution de la polychromie grecque : entre archéologie et choix esthétique}

4 Jusqu'au milieu des années 1840 , statutairement, les pensionnaires ne pouvaient proposer à l'envoi des relevés et restaurations de monuments situés hors d'un périmètre défini par une distance maximum de 36 à 40 milles autour de Rome avant leur troisième année, mais certains n'hésitaient pas à enfreindre le règlement ${ }^{8}$. Deux pôles d'attraction se dessinent alors : Pompéi et la Grèce. Si l'Acropole restait hors d'atteinte, les sites des anciennes colonies grecques de Paestum et de Sicile étaient nettement plus accessibles.

5 Cet intérêt pour la Grèce et cette fascination pour l'architecture coloriée étaient renforcés par les travaux de Jacques Ignace Hittorff (1792-1867) sur la polychromie antique. Leur publication trouva un écho important chez ses jeunes confrères, en encourageant ou en confortant leur attrait pour l'art grec. Hittorff, lui-même ancien élève de l'École des beaux-arts, voyagea à Rome et en Sicile entre 1822 et 1824 . De ce voyage en Sicile, il livra dès 1826 ses découvertes d'une architecture au décor polychrome dans Architecture antique de la Sicile, ou recueil des plus intéressans monumens d'architecture des villes et des lieux les plus remarquables de la Sicile ancienne, mesurés et dessinés (1826 et suivantes) ${ }^{9}$ (fig. 1 ). 
1. Jacques Ignace Hittorff (Cologne 1792 - Paris 1867), Restitution en couleur d'une partie de l'entablement et de la couverture d'un temple, [Architecture antique de la Sicile, recueil des monuments de Ségeste et de Sélinonte, mesurés et dessinés par J.-I. Hittorff et L. Zanth. Suivi de Recherches sur l'origine et le développement de l'architecture religieuse chez les Grecs,par J.-I. Hittorff], [Paris], [Jules Renouard], [1826 et suivantes], pl. 40.

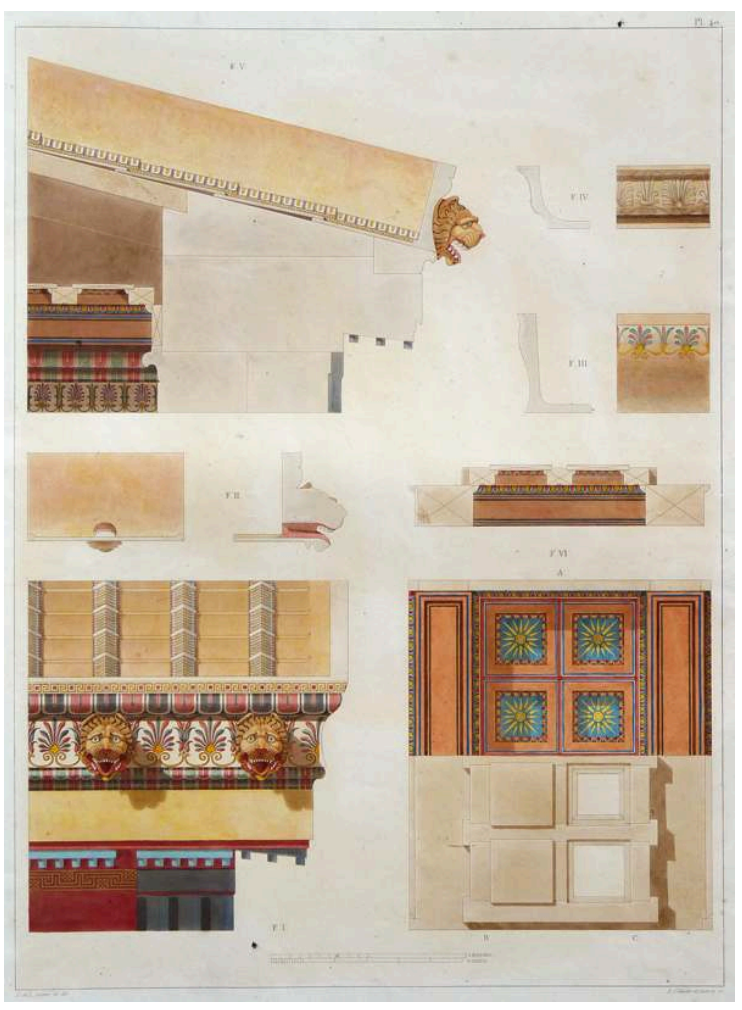

Gravure au trait, gravure sur cuivre en noir et en couleur et rehaut manuel à l'aquarelle. Ouvrage inachevé. 48 planches.

De cette première version de l'ouvrage de Hittorff sur l'architecture antique de la Sicile, il n'a paru que les 8 cahiers de six planches numérotées 2 à 49. Certaines planches, comme la 40, offrent un mélange de gravure au trait, de gravure en couleur et de rehaut manuel. Les possibilités techniques dont disposait l'auteur ne lui permettaient pas encore à cette époque de publier facilement les conclusions de ses études sur le coloris.

Paris, collection particulière.

6 Cette première publication restée inachevée, largement inspirée de travaux des archéologues britanniques Thomas Donaldson, William Harris et Samuel Angel, est suivie vingt-cinq ans plus tard par la Restauration du temple d'Empédocle à Sélinonte, ou l'architecture polychrome chez les Grecs (fig. 2), ouvrage luxueux où il défend, avec des planches hautement colorées, la polychromie totale des temples grecs ${ }^{10}$. Il s'agit aussi de la première restitution complète présentant un temple entièrement peint. 
2. Jacques Ignace Hittorff (Cologne 1792 - Paris 1867), Frontispice, chromolithographie, Restitution du temple d'Empédocle à Sélinonte, ou l'architecture polychrome chez les Grecs. Par J. J. Hittorff, architecte. Atlas, Paris, typographie de Firmin Didot Frères, MDCCCLI [1851].

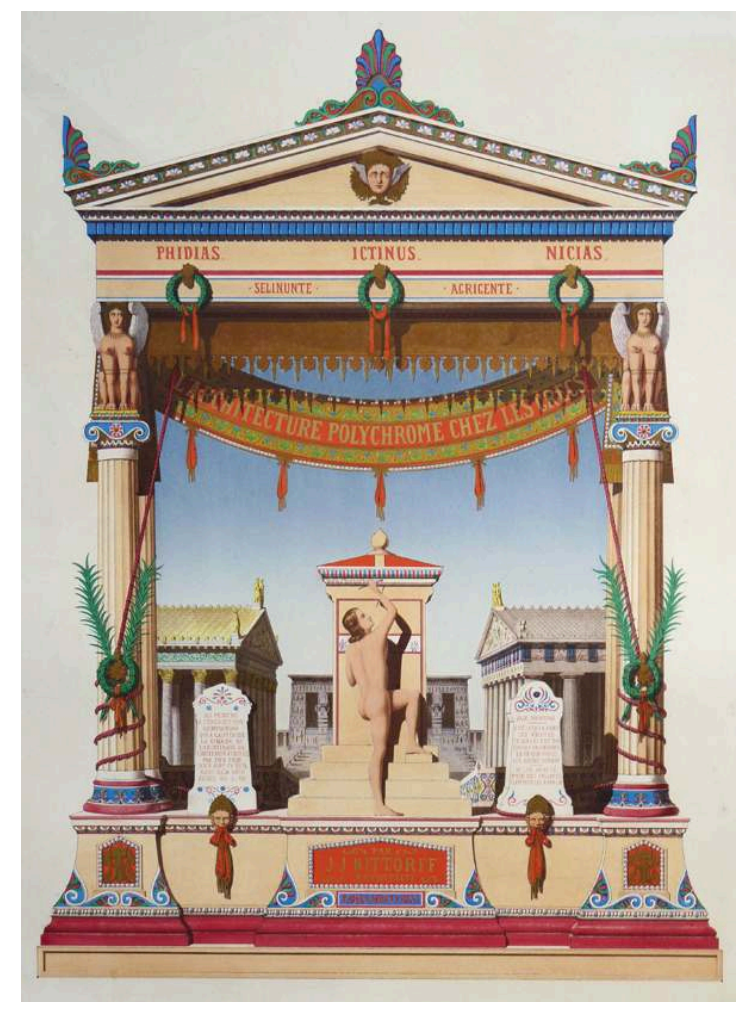

H.61, 2, L.44.

Vingt ans après sa première tentative avortée de dédier un ouvrage partiellement en couleur aux édifices antiques de la Sicile, Hittorff pouvait désormais utiliser le procédé de la chromolithographie pour répandre ses idées. Cette technique n'avait ni la douceur, ni les nuances de l'aquarelle, mais elle offrait un résultat brillant et permettait des tirages en série.

Paris, collection particulière.

7 Sur le terrain, les fouilles de l'Acropole d'Athènes reprennent en 1832, les Propylées furent dégagés et révélèrent des vestiges colorés. Le temple d'Athéna Niké fut extrait des remparts et reconstruit, son ordre ionique paré de couleurs fut mis à jour. Les pensionnaires ne tardèrent pas à s'emparer de ces découvertes ${ }^{11}$.

Les travaux de Hittorff, la publication de L'Expédition scientifique de Morée d'Abel Blouet, publiée entre 1831 et 1838 , ou encore la traduction en français d'ouvrages étrangers suscitent toujours plus d'intérêt chez les pensionnaires ${ }^{12}$. En 1835, la demande de séjour en Grèce de Victor Baltard fut refusée. En 1844, Théodore Ballu fut plus chanceux, précédant ainsi d'un an la réforme adoptée le 22 février 1845, aux termes de laquelle les pensionnaires étaient autorisés à effectuer un voyage d'études de quatre mois pendant leur troisième année. La création de l'École française d'Athènes, le 11 septembre $1846^{13}$, renforçait le caractère institutionnel du séjour.

9 Les premiers pensionnaires à bénéficier de cette ouverture portèrent assez logiquement leur choix sur l'Acropole d'Athènes où ils pensaient trouver «l'essence même de l'architecture grecque ${ }^{14} »$. C'est le cas de Tétaz qui, à la suite de Théodore Ballu, consacra son envoi à l'Érechthéion (1848). Il fut suivi par Louis Boitte dont le travail de troisième année (1863) s'inspire largement des travaux de son prédécesseur (fig. 3). 


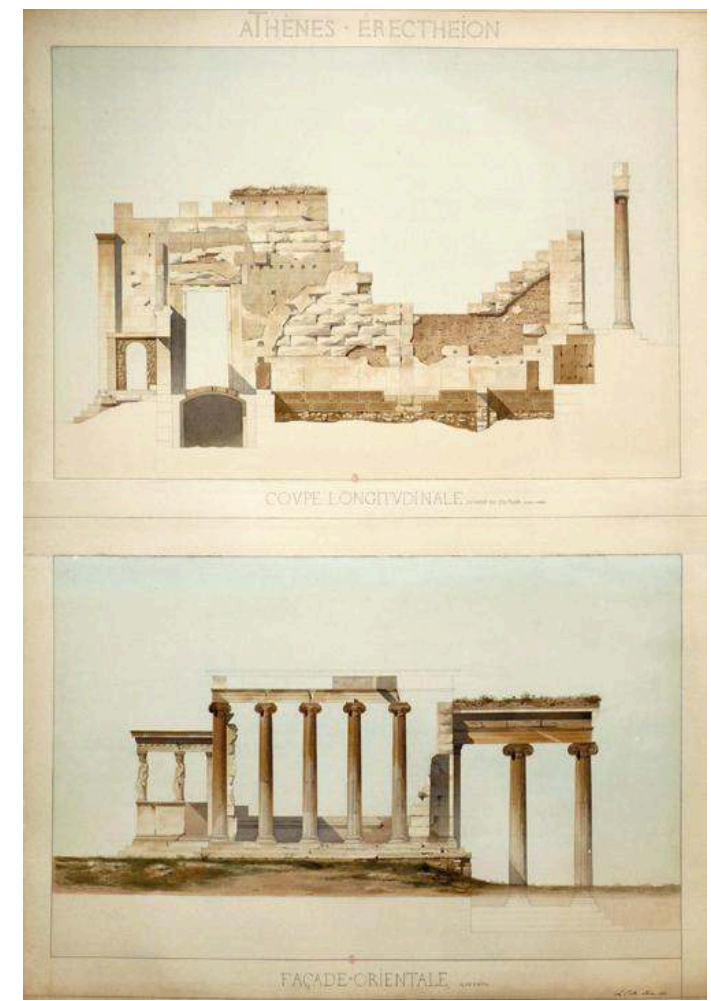

Dessin original aquarellé sur papier.

H. 95,3, L. 67, 1.

Paris, Bibliothèque de l'INHA, collections Jacques Doucet, PI Est 7 (29).

Garnier fut l'un des premiers à se distinguer en s'intéressant au temple dit « de Jupiter Panhellénien » de l'île d'Égine (1852) - en réalité temple d'Aphaïa - tout en s'inscrivant dans la tradition académique par le choix d'un temple dorique classique, exemple typique de l'architecture monumentale se prêtant parfaitement à l'exercice de la Restauration.

11 Dès les années 1840, la théorie de Hittorff trouva un écho favorable chez les jeunes architectes, chez les pensionnaires de l'Académie de France en particulier : « Le fait, c'est qu'on trouve de la couleur sur les monuments grecs, à Paestum comme en Sicile, en Sicile comme en Grèce, sur les grands comme sur les petits édifices, sur les tombeaux aussi bien que sur les temples » écrivit Charles Ernest Beulé ${ }^{15}$. Néanmoins, le traitement de la polychromie dans les restitutions proposées par les pensionnaires relevait davantage d'un choix esthétique que d'un constat archéologique. Dans sa restauration de l'Érechthéion, Tétaz optait pour une restitution colorée de l'architecture intérieure, aux teintes toutefois discrètes et subtiles. Quant à Garnier, il adoptait pleinement le parti hautement coloré de l'architecture grecque telle que définie par Hittorff, qui, en retour, se montra très élogieux dans son rapport sur les envois présenté à l'Académie en octobre 1853. Garnier proposa des restitutions richement colorées où dominent les couleurs primaires, tranchant ainsi avec la sobriété des états actuels (fig. 4). 
4. Charles Garnier (Paris 1825 - Paris 1898), Façade angulaire du temple, pl. 24, Revue générale de I'Architecture et des Travaux publics, vol. XVI, 1858.

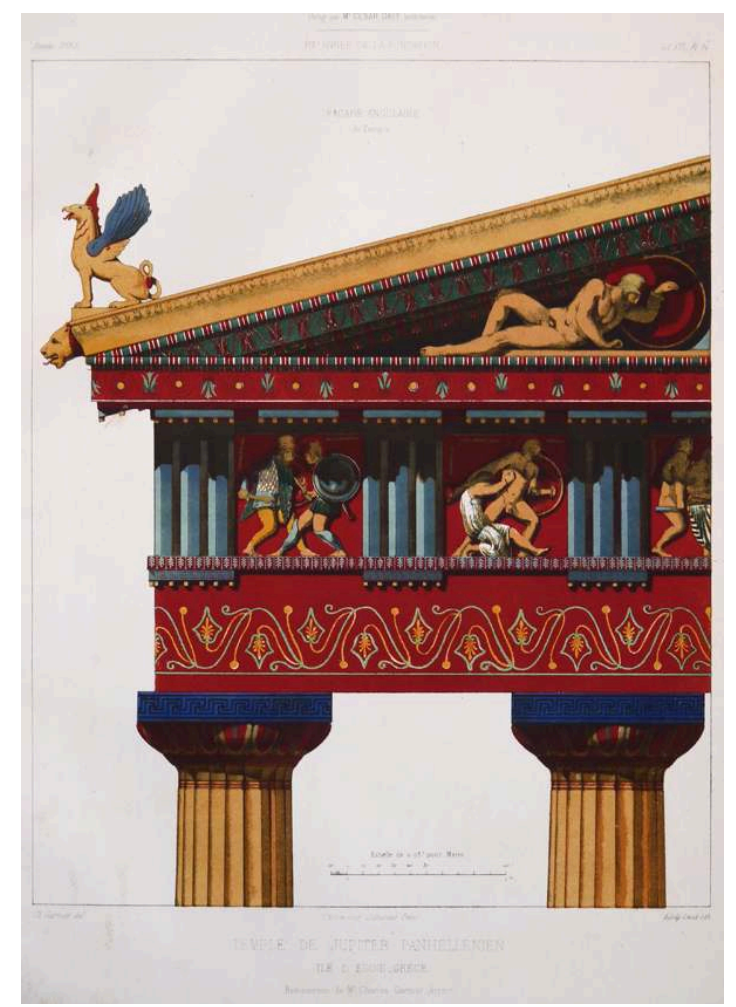

Chromolithographie

Paris, Bibliothèque de I'INHA, collections Jacques Doucet.

12 Quant à Louis Boitte et sa restauration des Propylées, il tempère davantage les tendances de ses contemporains en limitant la couleur aux chapiteaux et aux entablements (fig. 5). 


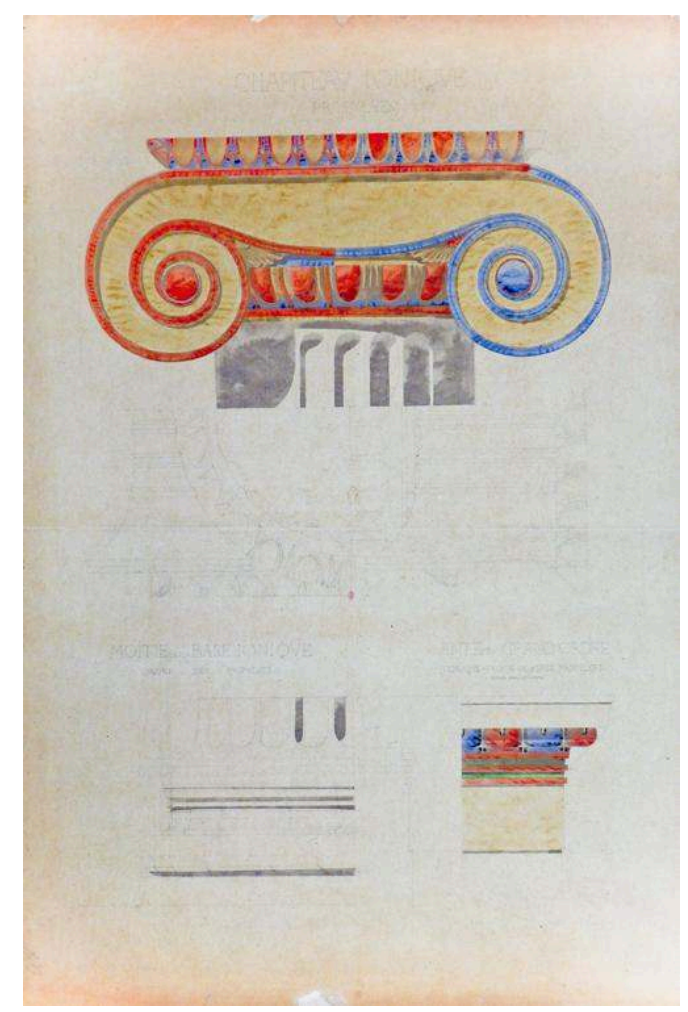

Dessin original aquarellé sur calque collé sur papier H. 105, L. 74.

Paris, Bibliothèque de l'INHA, collections Jacques Doucet, PI Est 7 (37).

Garnier a lui-même livré dans À travers les arts un commentaire mitigé de l'envoi de Boitte, critiquant les états actuels «un peu trop jaunes» tout en en louant les restaurations proposées par l'architecte ${ }^{16}$. Signalons la présence, parmi le millier de clichés donnés par Louise Garnier à l'École des beaux-arts, de onze tirages albuminés de Durandelle, dédicacés à Garnier par Boitte, reproduisant l'envoi consacré aux Propylées. Dans les relevés et restitutions de Boitte, et en dépit des réserves de Garnier, le rendu subtil des marbres tend à se substituer aux effets de la polychromie. Il se révèle ainsi plus proche du parti admis aujourd'hui, selon lequel la couleur se trouvait limitée aux parties hautes.

\section{Diffusion et fortune des dessins}

$14 \mathrm{Au}$ milieu du $\mathrm{XIX}^{\mathrm{e}}$ siècle, les ouvrages relatifs à l'archéologie monumentale, intrinsèquement liés aux grandes campagnes de fouilles, se multiplient. Trois grands types de publication se distinguent : essais, recueils de planches et monographies. Des publications auxquelles les architectes participèrent largement aux côtés de leurs collègues archéologues.

En effet, de nombreux archéologues réutilisent les conclusions développées par les architectes dans leurs travaux, qui ne sont, du moins en ce qui concerne les restaurations, que des propositions de restitution. À titre d'exemple, Charles Ernest Beulé (1826-1874), ancien élève de l'École française d'Athènes, utilise dans l'Acropole d'Athènes «le texte explicatif, les notes, les commentaires que Tétaz, Paccard et 
Desbuissons avaient joints à leur envoi ${ }^{17}$.» Il précise : "Aussi les résultats que je présenterai seront-ils exactement empruntés au travail d'un architecte ${ }^{18}$. » La planche 3 du second volume, intitulée Coupe et plan restaurés de l'Érechthéion reproduit deux dessins issus de l'Envoi (1848) de Tétaz ${ }^{19}$ (fig. 47).

6. Jacques Martin Tétaz (Paris 1818 - Rueil-Malmaison 1865), Coupe et plan restaurés de l'Érechthéion, pl. 3, dans Charles Ernest Beulé, L'Acropole d'Athènes, vol. 2, Paris, Firmin-Didot, 1854.

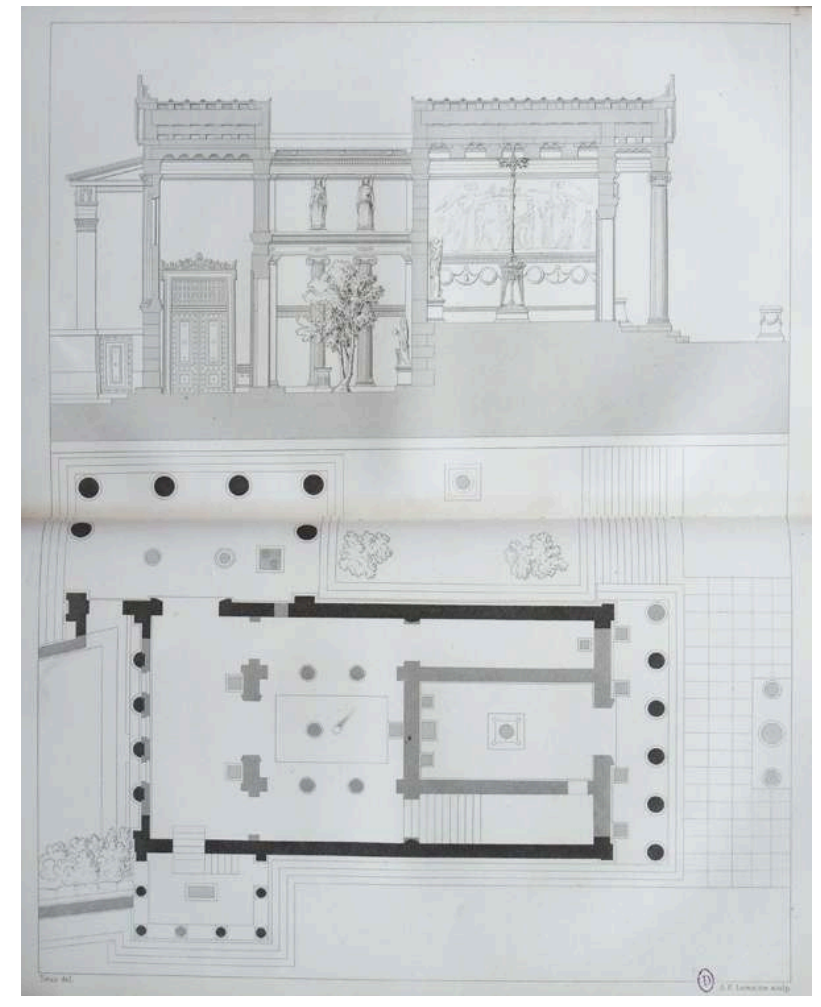

Gravure sur acier.

Paris, Bibliothèque de l'INHA, collections Jacques Doucet. subtilité et une délicate polychromie du décor intérieur restitué, que ne traduit pas le rendu sec de la gravure sur acier. D'un autre côté, Beulé, dans le chapitre XIV sobrement intitulé "La Polychromie", de L'Architecture au siècle de Pisistrate, publié dans la Revue générale de l'architecture,loue l'ensemble du travail mené par son ami Charles Garnier ${ }^{20}$. Il lui reproche toutefois les libertés prises dans sa restauration du temple d'Égine, en particulier la restitution des chapiteaux doriques d'après la « Grande Tombe » étrusque de Corneto. Sans doute plus artiste qu'archéologue, Garnier a livré une série flamboyante de dessins qui ont fait l'objet d'une attention particulière tout au long du XIX ${ }^{e}$ siècle. Son envoi a d'ailleurs été présenté à l'Exposition universelle de Paris en 1855 .

Tandis que les ouvrages d'archéologie classique et la presse spécialisée offrent une tribune aux envois des pensionnaires, parfois peu de temps après leur exécution, il est intéressant de signaler que la publication dans les revues d'architecture de planches réalisées d'après les travaux, n'a souvent aucun rapport avec l'actualité scientifique. En ce sens, ces dessins peuvent alors être perçus comme des œuvres autonomes. Ainsi, en 1872 Le Moniteur des architectes publie-t-il des détails de la tribune des Cariatides de 
l'Érechthéion exécutés par Boitte, et l'année suivante, la même revue reproduit trois planches extraites de son envoi consacré aux Propylées d'Athènes ${ }^{21}$ (fig. 7).

7. Louis Boitte (1830 - 1906), Restauration des Propylées de l'Acropole d'Athènes [élévation restaurée], pl. 20, Le Moniteur des architectes, vol. VII, 1873.

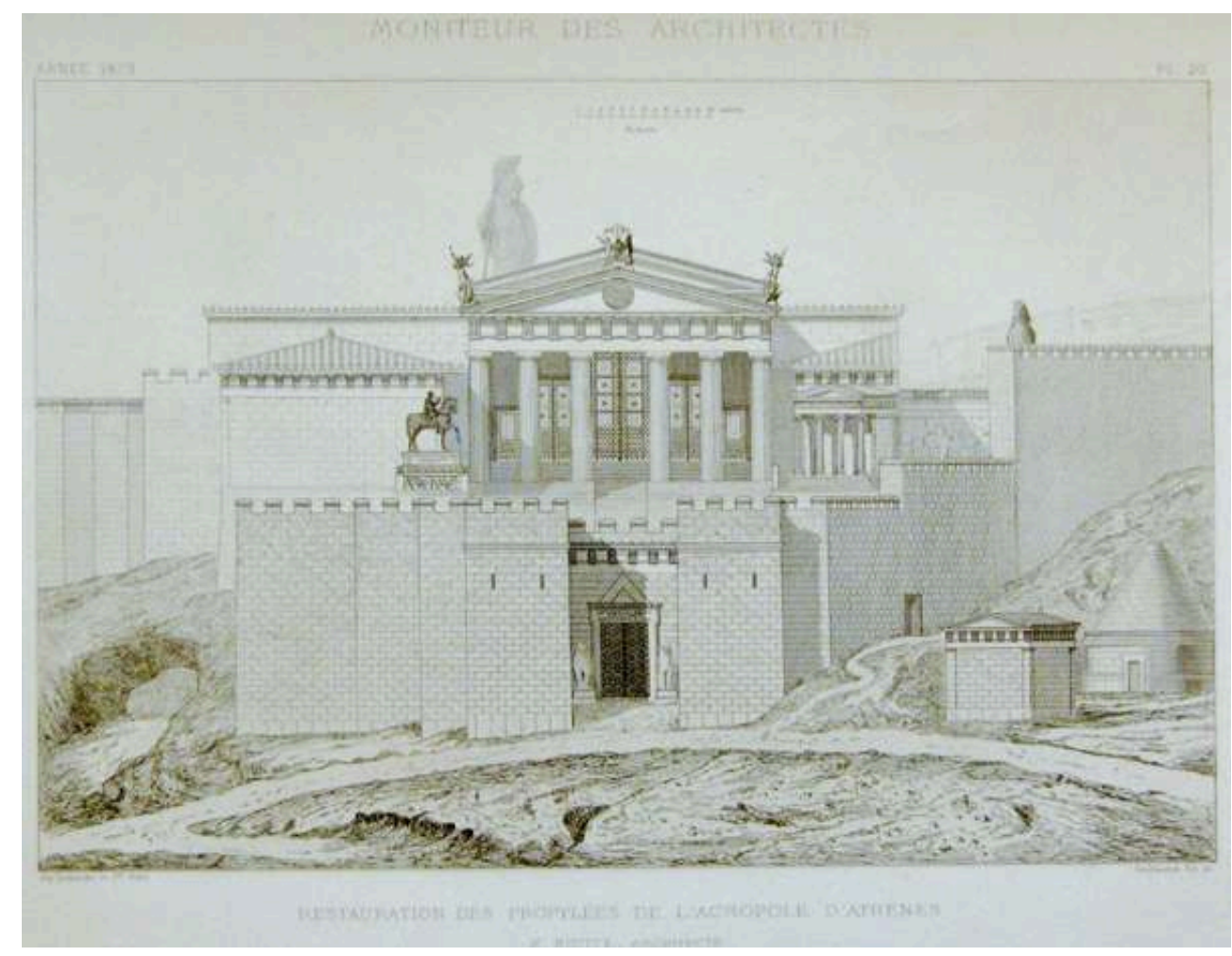

Gravure sur acier

Paris, Bibliothèque du musée d'Orsay, Fol X A-13 (1873).

Ces dessins sont publiés neuf ans après leur exécution, sans qu'aucune actualité, ni article paru dans la revue, ne justifient leur présence. En plus de son envoi réglementaire de quatrième année consacré aux Propylées, salué par la critique, Louis Boitte a livré une importante série de dessins dédiée au temple d'Athéna Niké. Récompensés par une première médaille au Salon de 1872, ils connurent une large diffusion et furent assimilés sinon confondus avec l'envoi, alors qu'il s'agissait en réalité d'une extension ${ }^{22}$. Les dessins de Rome, témoins de l'habileté de leurs auteurs, sont reconnus pour leur valeur intrinsèque à la fois esthétique et pédagogique, et audelà des considérations archéologiques. Émerge alors la volonté de les compiler afin de leur assurer une plus large diffusion. En 1877, Firmin-Didot publia le premier volume d'une luxueuse collection ${ }^{23}$ intitulée Restaurations des monuments antiques par les architectes pensionnaires de l'Académie de France à Rome depuis 1788 jusqu'à nos jours, dont seuls sept volumes parurent. Le sixième volume, consacré au temple de Jupiter panhellénien à Égine, par Garnier, est publié en 1884. Sont reproduits treize dessins (l'envoi en compte quatorze) dont six en chromolithographie. À la fin du siècle, des initiatives privées s'inscrivent dans la même lignée, offrant ainsi au public contemporain l'occasion de découvrir des dessins réalisés des décennies plus tôt. Citons aussi Les Envois de Rome : restaurations des monuments anciens reproduites d'après les dessins originaux de MM. les architectes pensionnaires de l'Académie de France à Rome, publié en phototypie par Pourchet vers 1899 (fig. 8). 
8. Jacques Martin Tétaz (Paris 1818 - Rueil-Malmaison 1865), L'Érechthéion, façade principale, pl. 23, dans [Édouard Pourchet], Les Envois de Rome. Restaurations des monuments anciens reproduites d'après les dessins originaux de MM. les architectes pensionnaires de l'Académie de France à Rome, [Paris], [Imp. Aron], [vers 1899].

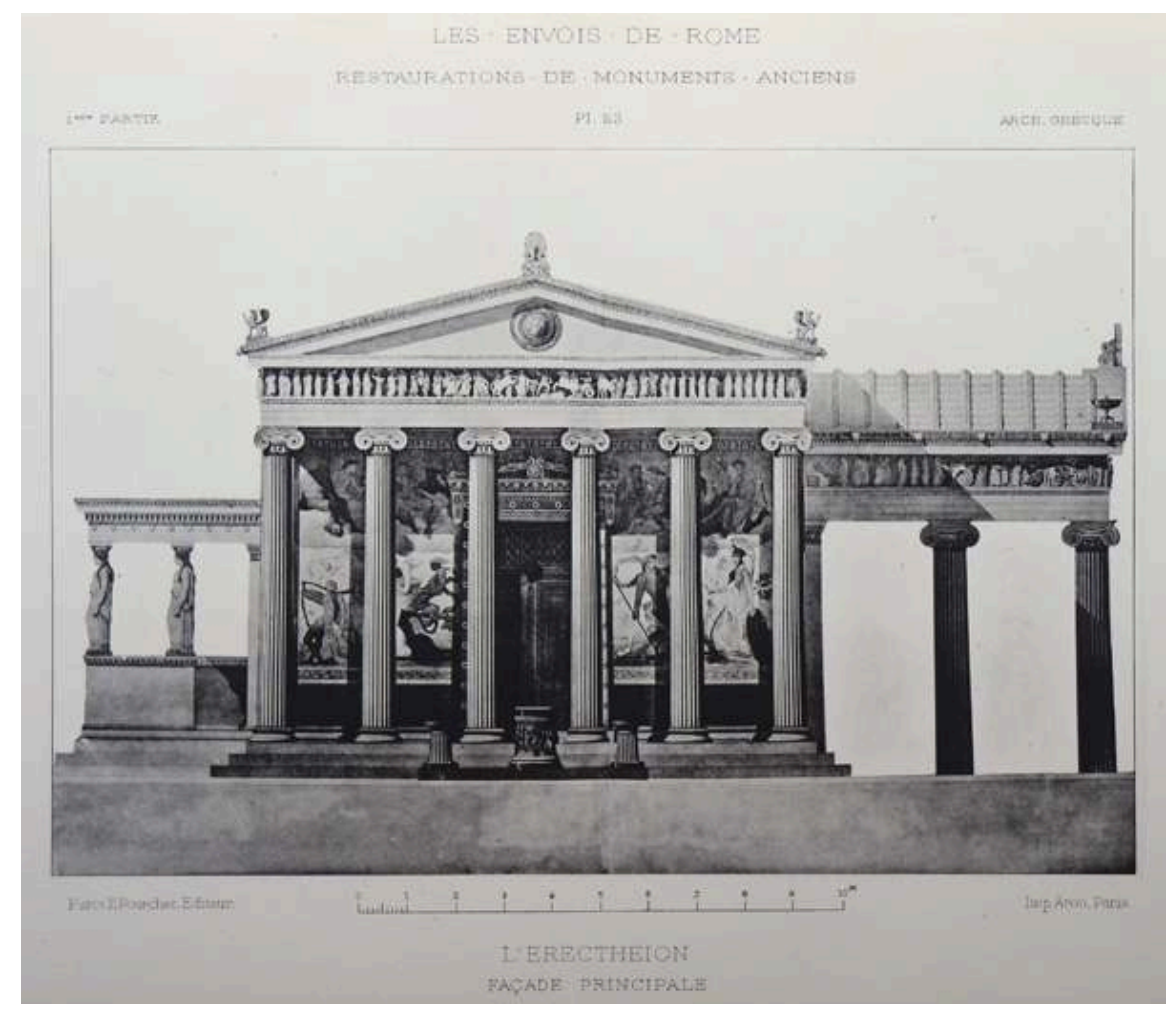

Phototypie

Paris, Bibliothèque de l'INHA, collections Jacques Doucet, Fol VA 227.

Plus tardives sont les séries lancées par Hector d'Espouy, lui-même ancien pensionnaire : «L'Académie des Beaux-Arts avait jadis tenté, en quelques fascicules seuls parus, la publication intégrale des Envois de Rome [...]. Le présent ouvrage répond aux mêmes préoccupations et s'honore du même patronage ${ }^{24} »$ (fig. 50 et 51 ). Grands succès éditoriaux, ces volumes deviendront une référence à partir de laquelle les dessins seront souvent reproduits via la photographie. 
9. Louis Boitte (1830 - 1906), [Coupe longitudinale des Propylées de l'Acropole d'Athènes], [1864].

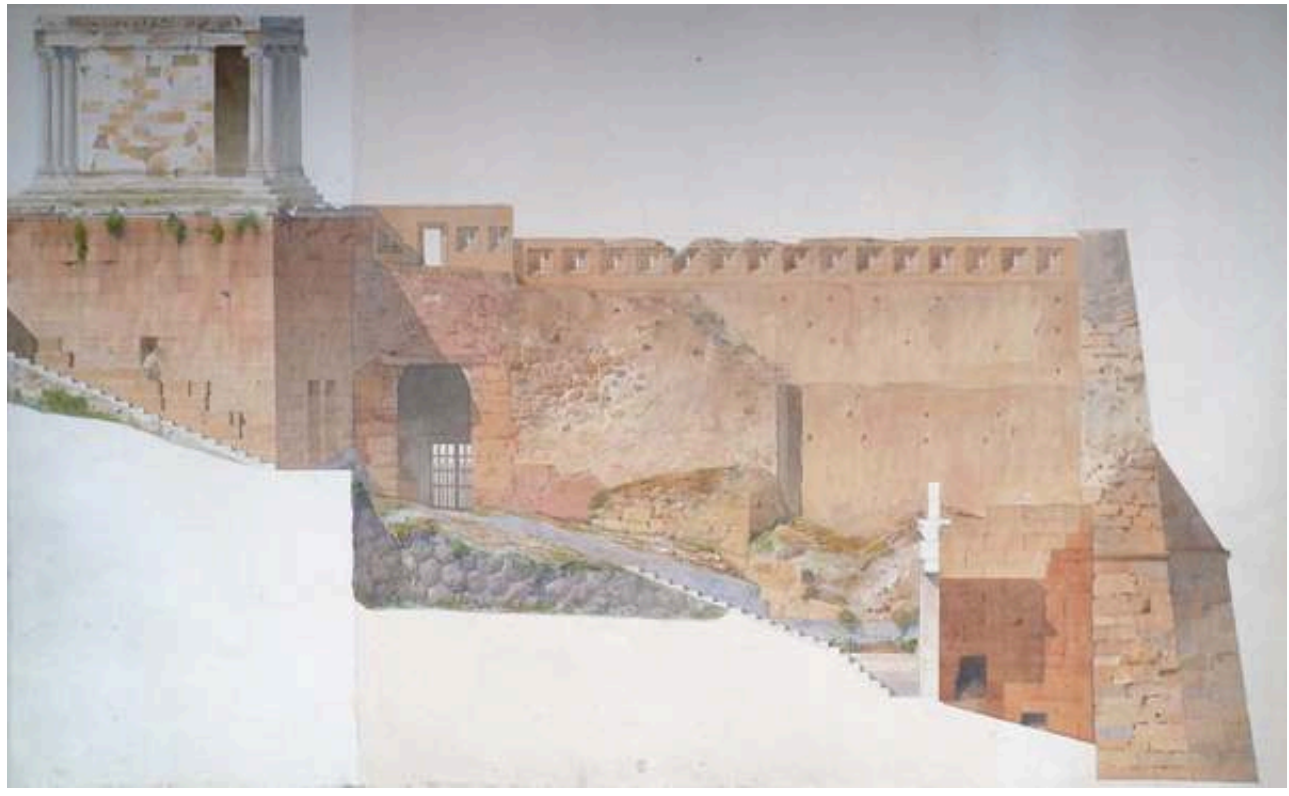

Dessin original aquarellé sur papier

H. 49,5, L. 84,2.

Paris, Bibliothèque de l'INHA - collections Jacques Doucet, PI Est 7 (35). 
10. Louis Boitte (1830 - 1906), Propylées, coupe longitudinale restaurée et état actuel, pl. 25, dans Hector d'Espouy, Monuments antiques, relevés et restaurés par les architectes pensionnaires de l'Académie de France à Rome. Notices archéologiques par Georges Seure, Paris, Ch. Massin, [s. d.] [1910-1912].

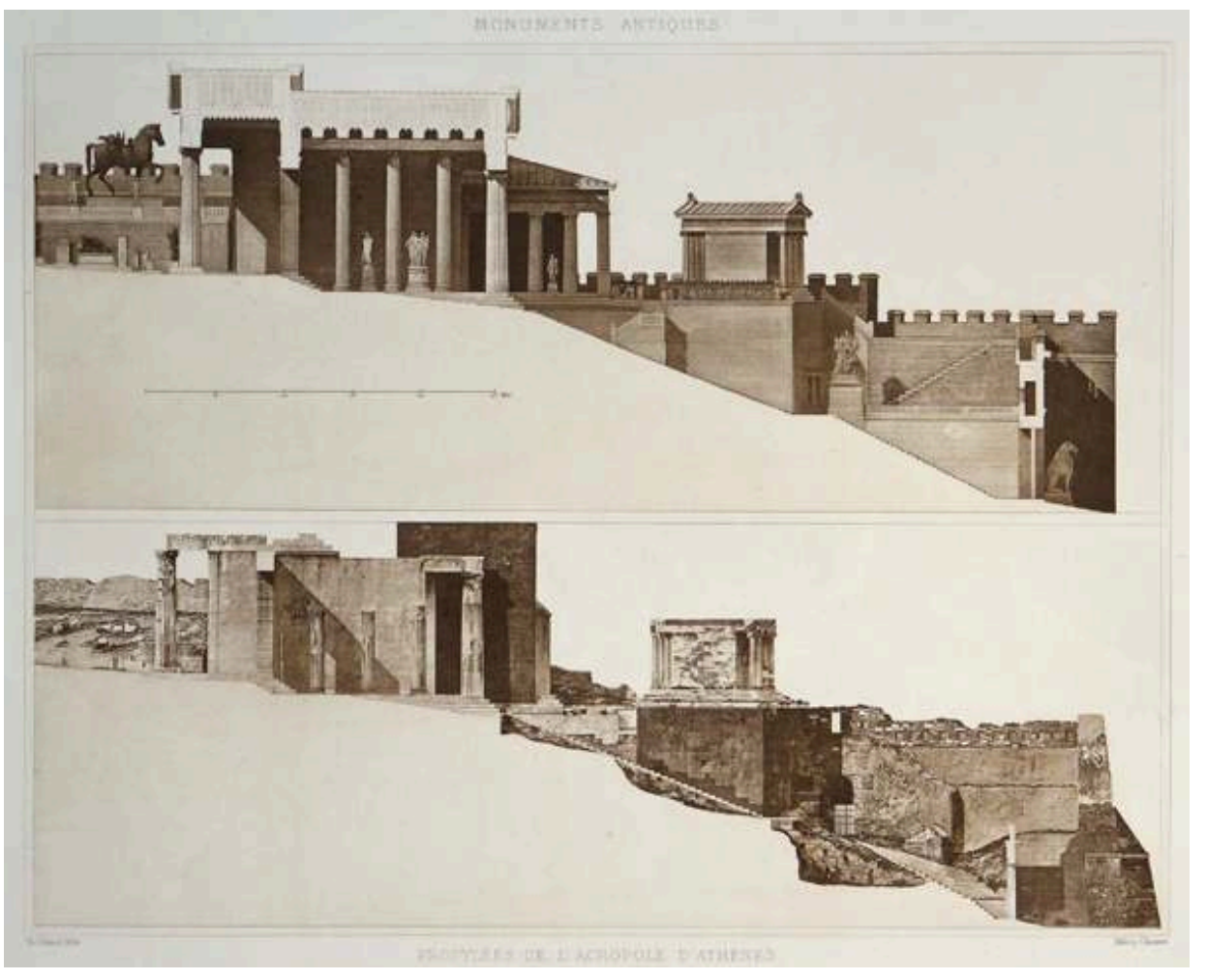

Héliogravure

H. 63,4, L. 45

L'héliogravure utilisée par Hector d'Espouy s'impose dans les publications architecturales dans les années 1880 comme la meilleure manière de reproduire les dessins et les photographies. Le tirage s'opère d'abord comme pour une gravure en taille douce jusqu'en 1895 où l'Allemand Karl Klic invente I'héliogravure sur cylindre de cuivre. Il s'agit d'un procédé monochrome, mais qui permet un excellent rendu des contrastes, ce qui assura son succès, pour la reproduction de la photographie, jusqu'à la fin du xxe siècle.

Paris, collection particulière.

La fin du XIX ${ }^{e}$ siècle voit se multiplier les écrits des anciens pensionnaires architectes. Il s'agit le plus souvent de monographies, réalisées avec ou sans le concours d'un archéologue de l'École française d'Athènes, dans lesquelles les auteurs ont l'occasion de faire reproduire leurs dessins à l'identique ou bien de les reprendre et de les réinterpréter. Les relevés et restaurations réalisés lors de leur pensionnat servent de support et de prétexte à l'archéologue. Citons ainsi la collaboration de Victor Laloux et Paul Monceaux, auteurs de Restauration d'Olympie en 1889, Alphonse Defrasse et Henri Lechat en 1895, Emmanuel Pontremoli qui s'associe à Maxime Collignon en $1900^{25}$. À cette série s'ajoutent d'autres ouvrages réalisés en collaboration entre un architecte Prix de Rome et un archéologue. S'il s'agit davantage de publications de fouilles que de synthèses monographiques, elles permettent aux architectes de présenter les dessins réalisés lors de leur pensionnat.

21 Exercices académiques, les envois de Rome sont autant de témoins des réflexions et polémiques dont la plus marquante du siècle fut sans doute celle de la couleur. Tandis que les archéologues le consacrent comme illustration, le dessin est pour l'architecte une mise en forme, une construction graphique et intellectuelle élaborée à partir de données matérielles tangibles. Les revues spécialisées et les études archéologiques ont 
offert une large tribune à ces dessins, tout en les accommodant à un propos qui dépasse leur objectif et en leur faisant parfois subir des déformations. Au contraire, les recueils dans lesquels les dessins sont reproduits fidèlement, avec un rendu très soigné, en noir et blanc ou en couleur, sont davantage des objets de collection. Leur publication s'est soldée par un relatif échec, du fait de leur coût et de la faiblesse de leur tirage. Le XIX siècle avançant, c'est la reproduction par la photographie, en feuilles ou en volumes reliés, qui a assuré leur fortune aux envois de Rome. À ce titre, les volumes édités par Hector d'Espouy ont permis une large diffusion auprès des architectes et des amateurs, en France comme à l'étranger.

\section{NOTES}

1. Georges Seure, « Préface » dans Hector D’Espouy, Monuments antiques, relevés et restaurés par les architectes pensionnaires de l'Académie de France à Rome, Paris, Massin, [1910], vol. 1, p. 1.

2. Durée limitée à trois ans jusqu'en 1793, augmentée à cinq ans en 1846 et ramenée à quatre ans en 1863. Pour une étude complète des envois, voir Pierre Pinon et François Xavier Amprimoz, Les Envois de Rome, architecture et archéologie, Rome/Paris, École française de Rome, 1988. Voir également les catalogues d'exposition : Paris, Rome, Athènes, le voyage en Grèce des architectes français aux XIX et $X^{e}$ siècles, Paris, ENSBA, 1982 ; Roma antiqua, envois des architectes français, 1788-1924, Paris/Rome, ENSBA / École française de Rome, 1986 ; Italia Antiqua, envois de Rome des architectes français en Italie et dans le monde méditerranéen aux XIXe et XXe siècles, Paris, ENSBA, 2002.

3. La Bibliothèque de l'INHA, collections Jacques Doucet conserve un fonds Louis Boitte composé de 141 dessins dont 12 sont des dessins préparatoires ou originaux envoyés par l'architecte au cours de son pensionnat à l'Académie de France à Rome.

4. Jean-Pierre Adam, «Les envois de Rome : modèles académiques, documents archéologiques ou œuvres d'art? » in Italia antiqua [...], op. cit, p. XVII.

5. Albert Louvet, L'Art d'architecture et la profession d'architecte, Paris, Librairie de la Construction moderne, [1910], t. 1, p. 204.

6. "Guide du jeune architecte en Grèce. Conseils à un jeune camarade ", Revue générale de l'architecture, vol. XVII, 1859, col. 136.

7. Albert Louvet, L'Art d'architecture et la profession d'architecte, Paris, Librairie de la Construction moderne, [1910], t. 1, p. 209.

8. Citons Émile Jacques Gilbert (Agrigente), Théodore Labrouste (Pompéi), Henri Labrouste (Paestum) et Léon Vaudoyer (Bénévent).

9. Publié à Paris chez P. Renouard, 1826 et suivantes. Ouvrage complété et réédité en 1870 chez E. Donnaud.

10. Publié à Paris chez Firmin-Didot en 1851. Reprise d'un mémoire lu devant les membres de l'Institut de France en 1830 et publié « De l'architecture polychrome chez les Grecs, ou restitution complète du temple d'Empédocle dans l'acropole de Sélinonte", Annales de l'Institut de correspondance archéologique, 1820, p. 263-284.

11. Titeux et Chaudet (1846), Desbuissons (1848) et Boitte (1864) consacrent leur envoi de quatrième année aux Propylées. 
12. Abel Blouet, Expédition scientifique de Morée, ordonnée par le gouvernement français : architecture, sculptures, inscriptions et vues du Péloponnèse, des Cyclades et de l'Attique, Paris, Firmin-Didot, 1831-1838, 3 vol.

13. Marie-Christine Helmmann, «Les Architectes de l'École française d'Athènes ", Bulletin de correspondance hellénique, vol. 120, livraison 1, 1996, p. 191-222.

14. Marie-Christine Helmmann et Philippe Fraisse, «Architecture grecque et envois de Rome : historique et tendance » dans Paris-Rome-Athènes, p. 34.

15. Charles Ernest Beulé, «La Polychromie », Revue générale de l'architecture, vol. XVI, 1858, col. 196.

16. Charles Garnier, À travers les arts, Paris, Librairie de L. Hachette, 1869, p. 20.

17. Charles Ernest Beulé, L'Acropole d'Athènes, Paris, Firmin-Didot, 1853-1854, 2 vol. cité par Marie-Christine Hellmann, «Les Architectes de l'École française d'Athènes », op. cit., p. 192.

18. Mémoire explicatif et justificatif de la restauration de l'Érechthéion d'Athènes, présenté à l'Institut en 1850, publié in Revue archéologique, 1851, p. 1-12 et 81-96.

19. Comme tous les Envois de $4^{\mathrm{e}}$ année, ceux-ci sont conservés dans les collections de l'École nationale supérieure des beaux-arts (Plan restauré: Env. 38-02 et Coupe longitudinale restaurée : Env. 38-04).

20. Charles Ernest Beulé, « La Polychromie », op. cit., col. 203.

21. Le Moniteur des architectes, 1872, vol. VI, pl. 72 et 1873, vol. VII, pl. 5 : Plan de la restauration, pl. 20 : Restauration, élévation et pl. 21 : Restauration des propylées de l'acropole d'Athènes, coupe longitudinale.

22. L'Architecture au Salon: Art antique, Moyen Âge et Renaissance, Paris, A. Lévy, 1872 (6 pl. num. I-II et 1 à 5). Voir également, [Édouard Pourchet, Les Envois de Rome. Restaurations des monuments anciens reproduites d'après les dessins originaux de MM. les architectes pensionnaires de l'Académie de France à Rome, [Paris], [Imp. Aron], [après 1889] pl. 18, 19 ; Hector d'Espouy, Fragments de monuments antiques, Paris, Ch. Schmid, [1905-1925] vol. 1 : pl. 5.

23. Ordonnée par un arrêté du ministre de l'Instruction publique en date du 17 juin 1872.

24. Voir supra, note 1.

25. Victor Laloux et Paul Monceaux, Restauration d'Olympie, l'histoire, les monuments, le culte et les fêtes, Paris, maison Quantin, 1889 ; Alphone Defrasse et Henri Lechat, Épidaure, Restauration et description des principaux monuments du sanctuaire d'Asclépios, Paris, Ancienne maison Quantin, 1895 ; Emmanuel Pontremoli et Maxime Collignon, Restauration, Paris, Société française d'éditions d'art, 1900 et Jean Hulot et Gustave Fougères, Sélinonte, la Ville, l'Acropole et les Temples, Paris, Massin, 1910. Sur cette question voir Manuel Royo, «Livres d'architectes ou d'archéologie ? La «vulgarisation » des Envois à travers quelques grandes monographies archéologiques françaises à la fin du $\mathrm{XIX}^{\mathrm{e}}$ et au début du $\mathrm{xx}^{\mathrm{e}}$ siècle » dans Jean-Philippe Garric, Émilie d'Orgeix et Estelle Thibault (dir.), Le Livre et l'Architecte, Wavre, Mardaga, 2011. 